MECHANISM UNDERLYING PTBP1-MEDIATED ALTERNATIVE PRE-MRNA SPLICING IN REGULATING TISSUE-SPECIFIC GENE EXPRESSION

MUHAMMAD FURSHAM BIN HAMID SCHOOL OF BIOLOGICAL SCIENCES 2016 


\section{Mechanism underlying Ptbp1-mediated alternative pre-mRNA splicing in regulating tissue-specific gene expression}

\section{Muhammad Fursham bin Hamid}

School of Biological Sciences

A thesis submitted to the Nanyang Technological University in partial fulfilment of the requirement for the degree of Doctor of

Philosophy 


\section{Acknowledgements}

I would like to extend my sincerest gratitude to my supervisor, Nanyang Assistant Professor Eugene Makeyev for his guidance, leadership, patience and motivation without which this project would not have been possible.

I am grateful to the current and past members of the Makeyev lab, including Piyush Kandelia, Yap Lin Choo Karen, Stefan Mockenhaupt, Dai Weijun, Svetlana Mukhina and Manish Muhuri for their valuable discussions and sharing of technical expertise.

I would also like to thank my beloved family and close friends for their support, encouragement and understanding 


\section{Table of Contents}

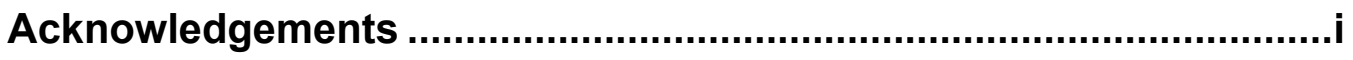

Table of Contents ...........................................................................

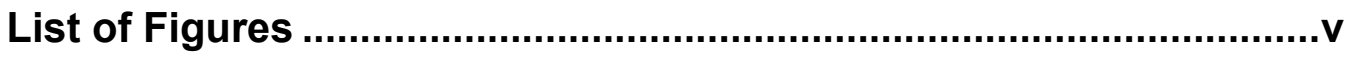

List of Tables .....................................................................................ii

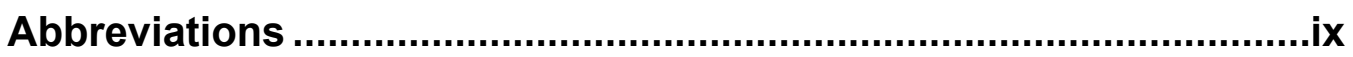

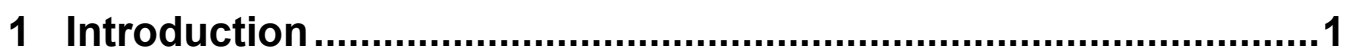

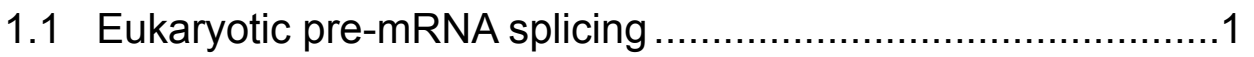

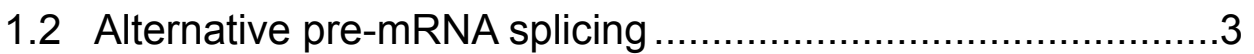

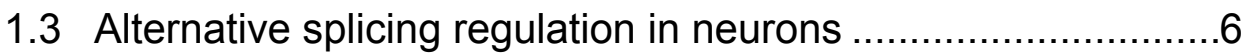

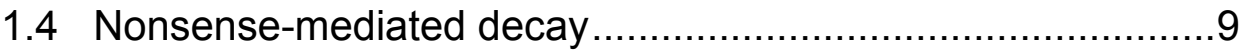

1.5 Alternative splicing coupled to nonsense-mediated decay (AS-

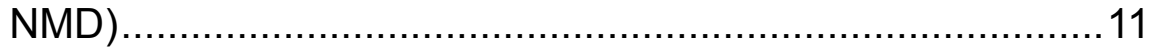

1.6 Polypyrimidine-tract binding protein $1 \ldots \ldots \ldots \ldots \ldots \ldots \ldots \ldots \ldots \ldots \ldots \ldots \ldots \ldots \ldots \ldots \ldots \ldots . . .12$

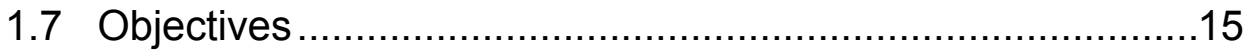

2 Materials and Methods …............................................................

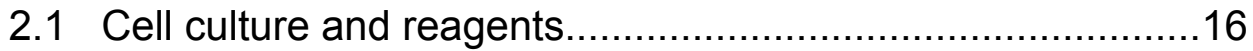

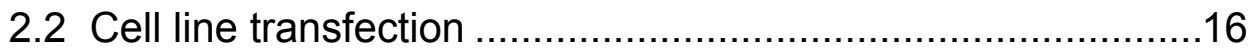

2.3 Molecular cloning.............................................................

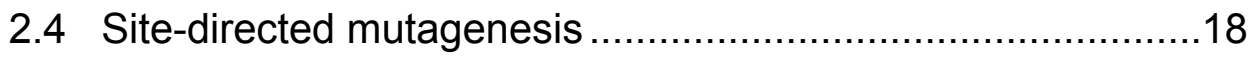

2.5 Plasmid DNA transformation, extraction and analysis. .........18

2.6 Total RNA extraction ……………..................................19

2.7 Reverse transcription polymerase chain reaction (RT-PCR).20

2.8 Reverse transcription Real-time PCR (RT-qPCR) ................21

2.9 Cloning of PCR products for sequencing …………............22

2.10 Biotinylated RNA pull-down assay ...................................22

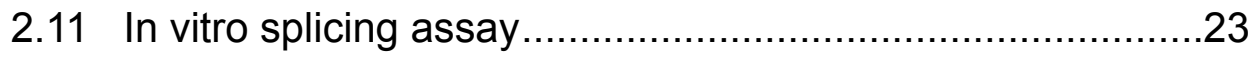

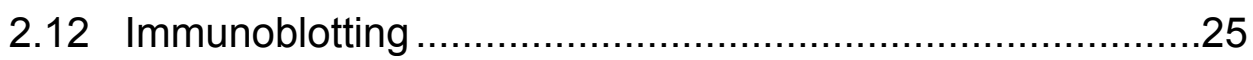


2.13 Immunofluorescence

2.14 Statistical analyses and bioinformatics ..............................26

2.15 CRISPR/Cas9-mediated exon deletion ……………...........27

3 Results

3.1 Ptbp1 may promote expression of several important genes by suppressing their AS-NMD-mediated down-regulation 29

3.2 Ptbp1 regulates Hps1 mRNA expression by orchestrating the choice between alternative 5 ' splice sites

3.3 Ptbp1-mediated regulation of Hps1 expression is evident at the protein level.

3.4 Hps1 expression positively correlates with Ptbp1 levels in vivo

3.5 Polypyrimidine-rich sequences are necessary for Ptbp1regulated choice between the u5'ss and the d5'ss

3.6 Overexpression of Ptbp1 and, to a lesser extent, Ptbp2 promotes usage of Hps1 u5'ss

3.7 Ptbp1 directly binds to Py1 and Py2

3.8 Ptbp1 directly regulates the choice between the u5'ss and the d5'ss.

3.9 Ptbp1 activates the u5'ss.

3.10 Inherent difference between the u5'ss and the d5'ss strengths is important for the regulation.

3.11 Ptbp1 down-regulation alters the lysosomal compartment in a Hps1-dependent manner

3.12 Ptbp1 regulates a number of other alternative 5'ss and 3'ss events

3.13 Ptbp1 activates inclusion of a subset of cassette exons .....55

3.14 Inclusion of Dtx2e6 positively correlates with Ptbp1 expression.

3.15 Polypyrimidine sequences downstream of Dtx2e6 are necessary for its efficient inclusion

3.16 Interaction between Ptbp1 and U1 snRNA stem-loop 4 of is required for optimal Dtx2e6 inclusion. 
3.17 Ptbp1 promotes binding of U1 snRNP to Ptbp1-activated 5' splice sites

3.18 Knockout of Dtx2 exon 6 affects the expression of a subset of genes involved in the Notch pathway

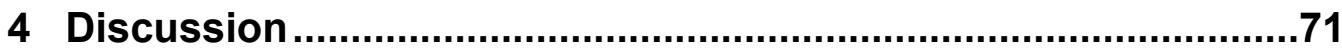

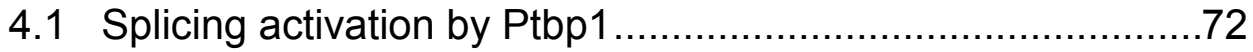

4.2 Regulation of alternative splice site usage by Ptbp 1 .............75

4.3 Pervasive post-transcriptional regulation of gene expression

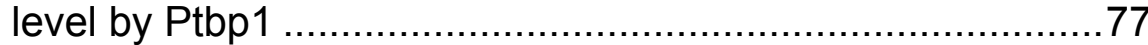

4.4 Functional significance of Dtx2 splicing regulation ................79

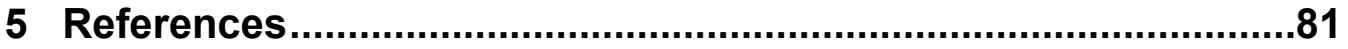

6 Author's publications ….................................................................96

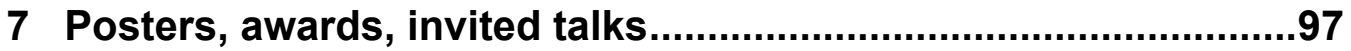

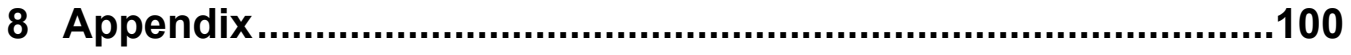




\section{List of Figures}

Figure 1.1 Cis-elements and trans-factors required for efficient premRNA splicing

Figure 1.2 Topologies and regulation of pre-mRNA alternative splicing

Figure 1.3 Functional mechanism of the nonsense-mediated decay pathway

Figure 1.4 AS-NMD strategies.

12

Figure 1.5 Ptbp1-mediated regulation of target gene expression through AS-NMD 14

Figure 3.1 Ptbp1 regulates the alternate 5'ss choice on Hps1 mRNA

Figure 3.2 Ptbp1-mediated regulation of Hps1 splicing affects Hps1 mRNA expression

Figure 3.3 Ptbp1 regulates Hps1 expression at the protein level 35

Figure 3.4 Hps1 co-expresses with Ptbp1 in vivo.

Figure 3.5 Ptbp1 binds to pyrimidine-rich sequences between u5'ss and d5'ss to regulate Hps1 5'ss usage.

Figure 3.6 Ptbp1 and, to a certain extent Ptbp2, overexpression stimulates u5'ss usage

Figure 3.7 Ptbp1 directly binds to the polypyrimidine-rich sequences on Hps1

Figure 3.8 Ptbp1 directly regulates Hps1 alternative 5'ss usage 43

Figure 3.9 Ptbp2 contributes to a lesser extant to 5'ss usage on Hps1 
Figure 3.10 Ptbp1 activates the usage of Hps1 u5'ss

Figure 3.11 Ptbp1 directly activates the usage of Hps1 u5'ss .....

Figure 3.12 Hps1 regulation depends on u5'ss being weaker than d5'ss (I)

Figure 3.13 Hps1 regulation depends on u5'ss being weaker than d5'ss (II) 49

Figure 3.14 Ptbp1 knockdown of CAD cells results in changes in lysosomal characteristics

Figure 3.15 Ptbp1 regulates a class of 5'ss and 3'ss events (I) .. 53

Figure 3.16 Ptbp1 regulates a class of 5'ss and 3'ss events (II) . 54

Figure 3.17 Hps1-like regulation of 5'ss usage may recur in other genes

Figure 3.18 Ptbp1 activates splicing of Deltex2 exon 6 in cultured cells and in vivo

Figure 3.19 Polypyrimidine-rich stretches downstream of Dtx2e6 is necessary for its inclusion. 60

Figure 3.20 Ptbp1-U1 stem loop 4 (U1-SL4) interaction is crucial for Dtx2e6 splicing regulation 63

Figure 3.21 Ptbp1 promotes U1 snRNP binding to the weak 5'ss (I) 66

Figure 3.22 Ptbp1 promotes U1 snRNP binding to the weak 5'ss (II)

Figure 3.23 Knockout of Dtx2e6 affects expression of some Notch target genes (I) 69

Figure 3.24 Knockout of Dtx2e6 affects expression of some Notch target genes (II) 
Figure 4.1 Recurring model of Ptbp1-mediated splicing activation 71

Figure 4.2 Secondary RNA structure of Ptbp1-regulated 5'ss..... 75 


\section{List of Tables}

Table 1 List of genes found to be regulated via Ptbp1-mediated AS-

NMD

Table 2 List of genes containing Ptbp1-activated cassette exons 52

Table 3 List of positively-regulated Notch targets ......

62 


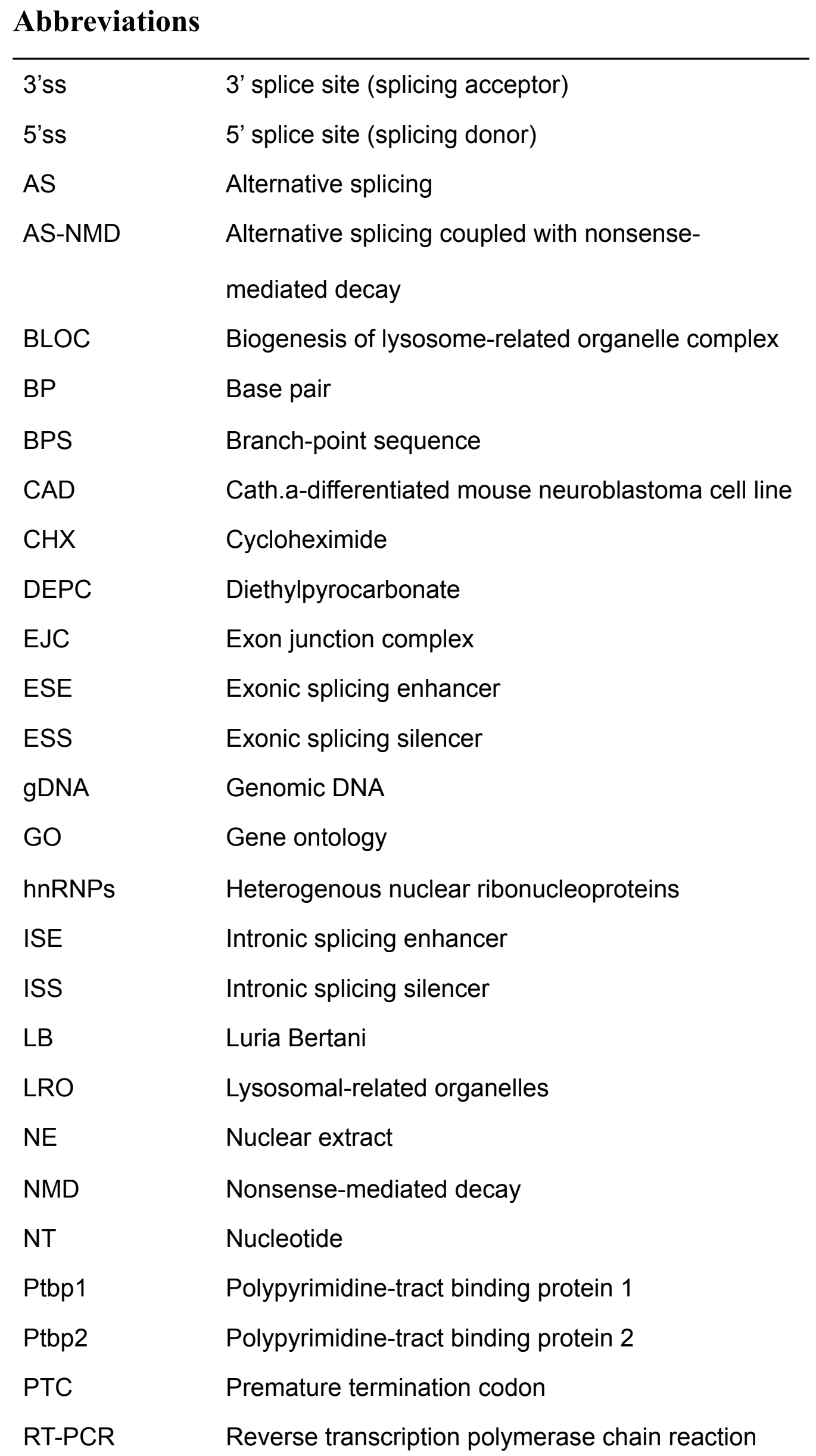




$\begin{array}{ll}\text { RT-qPCR } & \text { Reverse transcription quantitative polymerase chain } \\ & \text { reaction } \\ \text { siControl } & \text { Non-targeting siRNA } \\ \text { siPtbp1 } & \text { Ptbp1-specific siRNA } \\ \text { siPtbp2 } & \text { Ptbp2-specific siRNA } \\ \text { SL4 } & \text { U1 stem loop 4 } \\ \text { snRNP } & \text { Small nuclear ribonucleoprotein } \\ \text { SR } & \text { Serine-Arginine-rich } \\ \text { U2AF } & \text { U2 snRNA auxiliary factor } \\ \text { Upf1 } & \text { Upframe-shift factor 1 }\end{array}$




\section{Abstract}

Alternative pre-mRNA splicing (AS) provides an efficient means for diversifying the proteome and regulating gene expression levels in the higher eukaryotes. The gene regulation function often involves coupling between AS and nonsense-mediated decay (NMD), a cytoplasmic surveillance mechanism destabilizing mRNAs with premature termination codons. AS is controlled by interplay between cis-regulatory elements and trans-acting factors modulating the usage of alternative pre-mRNA segments. Polypyrimidine tract-binding protein 1 (Ptbp1/PTB/ hnRNP-I), a global repressor of neuron-specific alternative splicing program in non-neuronal cells, has been previously shown to repress several neuronal genes by inhibiting the inclusion of open reading frame-maintaining exons and subjecting the exon-skipped transcripts to NMD. Down-regulation of Ptbp1 levels in developing neurons alleviates this effect and gives rise to translation-competent transcripts. Here we identified several new Ptbp1-dependent AS-NMD targets that, unlike the earlier described examples, require Ptbp1 for their optimal expression. One such target, the Hermansky-Pudlak Syndrome 1 (Hps1) gene, is regulated by a unique Ptbp1-mediated choice between two competing alternative 5' splice sites (5'ss). Dampening Ptbp1 levels promotes the usage of the downstream 5'ss and gives rise to an NMD-susceptible Hps1 mRNA isoform in neurons. We show that Ptbp1 functions in this circuitry by activating the upstream 5'ss rather than repressing the downstream 5'ss. This was surprising since Ptbp1 typically functions as a splicing repressor. To understand molecular mechanisms underlying Ptbp1-mediated splicing activation, we examined both Hps1 and another 
gene, Deltex2, containing a Ptbp1-dependent cassette exon. In both systems, Ptbp1 promotes the recruitment of a core spliceosomal component, U1 snRNP, to a weak 5'ss by interacting with a specific structural element in the U1 snRNA. 


\section{Introduction}

\subsection{Eukaryotic pre-mRNA splicing}

Pre-mRNA splicing is a mechanistically conserved post-transcriptional process that removes non-coding intronic sequences from primary mRNA transcripts (pre-mRNAs) and generates mature mRNAs by joining exonic segments (Faustino and Cooper, 2003). This reaction is catalyzed by a large and dynamic molecular complex called the spliceosome and comprising up to five distinct small nuclear ribonucleoproteins (snRNP; U1, U2, U4, U5, U6) (Black, 2003). In addition to removing intervening introns from RNA messengers, splicing greatly influences the translation, surveillance and localization of the mature mRNAs (Lareau et al., 2007a; Lareau et al., 2004; Palacios, 2002). Thus, tight regulation of the splicing pathway is crucial for proper gene expression in eukaryotic cells.

Efficient splicing depends on the presence of cis-acting elements that are recognized by their cognate trans-acting factors (Fig. 1.1). The boundaries of each intron are delineated by the $5^{\prime}$ donor and the $3^{\prime}$ acceptor splice sites (5'ss and 3'ss) often containing the 'CAG/ GURAGU' and 'CAG/GU' motifs, respectively (De Conti et al., 2013; Li et al., 2007; Zhang et al., 2005). Of these, the 5'ss is found at the upstream boundary and is recognized by the U1 snRNP through RNARNA base-pairing. The 3'ss demarcating the downstream boundary interacts with several trans-factors including U2 snRNA auxiliary factor (U2AF). The 3'ss is typically preceded by a polypyrimidine-rich sequence interacting with U2AF (Black, 2003; Chen and Manley, 2009) 


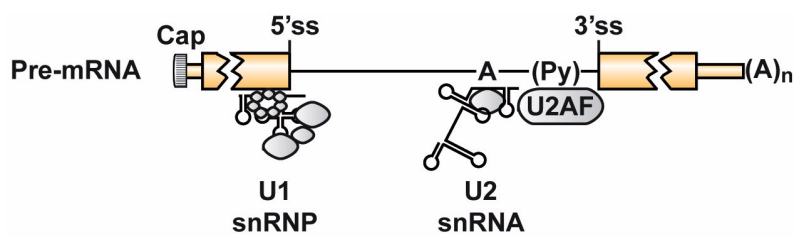

Figure 1.1 Cis-elements and trans-factors required for efficient pre-mRNA splicing. Intronic segment of a pre-mRNA (thin lines) is demarcated by the 5'ss and 3 'ss and contains constitutive splicing elements such as the branch point site and pyrimidine-rich tract. These sequences are recognized and bound by different components of the core spliceosome complex to mediate splicing

and a branch-point sequence (BPS; typically 'yUnAy' in human mRNAs) recruiting U2 snRNP and a splicing regulator SF1 (Gao et al., 2008).

Molecular mechanisms of pre-mRNA splicing have been well studied (Black, 2003). This two-step trans-esterification reaction begins with recruitment of U1 snRNP to the 5'ss as well as binding of the U2AF protein complex to the 3'ss. Together, these components form the socalled E-complex (Kent and MacMillan, 2002). Subsequently, the Acomplex is formed through binding of U2 snRNP to the BPS. Recruitment of U4/U5/U6 tri-snRNP to the spliceosome forms the B complex. This follows a complicated modular rearrangement that results in the release of $\mathrm{U} 1$ and $\mathrm{U} 4 \mathrm{snRNPs}$, and the recruitment of the nineteen complex (NTC) and NTC-related proteins, resulting in the assembly of the activated $\mathrm{B}^{\text {act }}$ complex. The first transesterification step, which involves the nucleophillic attack on the first nucleotide of the 5'ss by the adenine nucleotide, generates a free 5' exon and an intron-3'exon lariat within a so-called $\mathrm{B}^{*}$ complex. The ligation of the exons is carried out by the $\mathrm{C}$ complex via the second transesterification reaction between the $3^{\prime} \mathrm{OH}$ of the 5' exon and the last nucleotide of the $3^{\prime}$ splice site. The release of the exons occur during the formation of the $P$ complex, but the release of the intron-lariat occur only after the 
formation of the intron-lariat spliceosomal complex (ILS) (Chen and Manley, 2009; Fourmann et al., 2013; Matera and Wang, 2014; Yoshimoto et al., 2009).

Notably, recent cryo-EM studies, combined with earlier structural work, have provided unprecedented molecular insights into the spliceosome dynamics (Galej et al., 2016; Nguyen et al., 2016; Wan et al., 2016; Yan et al., 2015; Yan et al., 2016). In particular, the Yigong lab have reconstructed the Bact, C and ILS complexes, and provided a working model on the structural remodelling that occur at the RNA level during pre-mRNA splicing (Wan et al., 2016; Yan et al., 2015; Yan et al., 2016).

\subsection{Alternative pre-mRNA splicing}

While many exons in the eukaryotic genome are constitutively included into mature mRNAs, others can be spliced in a context-dependent manner. This process, called alternative pre-mRNA splicing (AS), affects exons and introns associated with suboptimal core cis-elements (5'ss, BPS, polypyrimidine tract, 3'ss). Outcome of AS can be controlled by trans-regulators interacting with specialized splicing enhancer and silencer sequences (Coelho and Smith, 2014; Irimia et al., 2009; Lee and Rio, 2015; Wagner and Berglund, 2014). Several topologies of AS have been described (Wang et al., 2008; Yeo et al., 2004) (Fig. 1.2A). These include alternative splicing of cassette exons, changing the border of exons by utilizing alternative 5'ss and 3'ss, splicing of exons in a mutually exclusive fashion, switching between various promoter and poly (A) signals and also intron retention (Black, 2003). Transcripts 
undergoing AS produce two or more mRNA isoforms that may give rise to functionally distinct proteins or/and have differential stability and cellular localization. Some $95 \%$ of all multi-exon human genes produce alternatively spliced transcripts and many of these are expressed in a unique manner (Chen and Manley, 2009; Pan et al., 2008). This argues for the importance of alternative splicing in diversification of the human gene expression program.

As already mentioned, utilization of alternative exons and introns can be controlled by several factors (Fig. 1.2B). For example, alternative premRNA features tend to bear suboptimal core splicing motifs, which may favor regulation by diminishing their interaction with the corresponding spliceosomal components (Hertel, 2008; Roca et al., 2013). On the other hand, core sequences that closely resemble consensus sequences are expected to increase the efficiency of spliceosome assembly and promote constitutive splicing. Binding of trans-regulator proteins to their cognate recognition sequences is another common mechanism influencing splicing decisions (Busch and Hertel, 2012). The serine/arginine-rich (SR) family RNA-binding proteins have been identified as activators of splicing, whereas the heterogeneous nuclear ribonucleoproteins (hnRNPs) are typically thought of as splicing repressors (Geuens et al., 2016; Martinez-Contreras et al., 2007; Sahebi et al., 2016; Zhou and Fu, 2013). These proteins recognize cis-elements located in both exonic and intronic regions, functionally classified into splicing enhancer (ESE and ISE) and silencer (ESS and ISS) categories (Matlin et al., 2005). Activation of splicing by SR proteins is generally achieved by their interaction with splicing enhancers, which promotes 
A

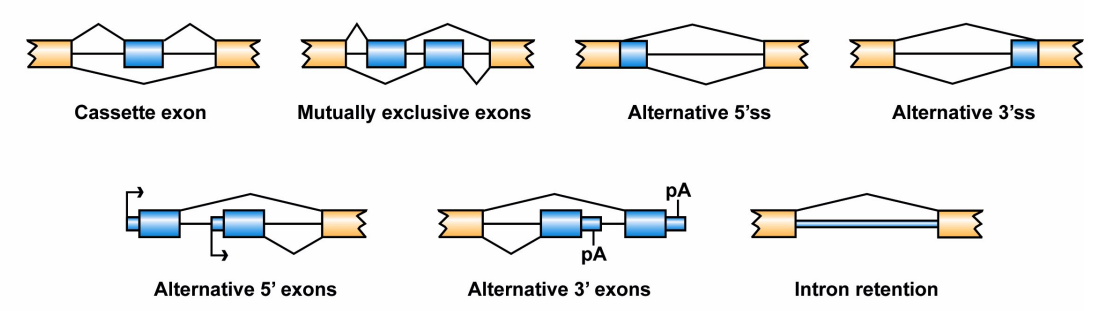

B

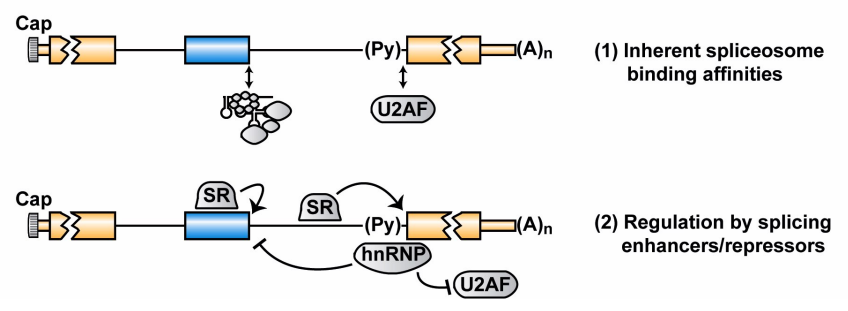

Figure 1.2 Topologies and regulation of pre-mRNA alternative splicing. (A) Regulated exonic and intronic segments (blue boxes) can be alternatively spliced through various strategies and (B) this decision relies on interplay between ciselements and corresponding trans-acting factors.

the recruitment of the spliceosome components to the corresponding part of the transcript. Conversely, the hnRNP proteins often repress splicing by interacting with the corresponding silencer elements and (1) occluding snRNPs recruitment to its splice sites, (2) interfering with the function of splicing activators or (3) looping out the regulated exons (Jean-Philippe et al., 2013; Roca et al., 2013).

Recent studies have begun refining this classical view of SR and hnRNP functions by showing that activities of these proteins may depend on their precise binding position in the regulated transcript (Erkelenz et al., 2013; Martinez-Contreras et al., 2006; Motta-Mena et al., 2010; Oh et al., 2013). Several in vivo and in vitro experiments suggest that interaction of SR proteins with exonic sequences typically stimulate exon inclusion, while their binding to intronic sequences downstream of the regulated exon promotes skipping. An opposite trend is observed for 
hnRNP proteins: their binding to exonic or intronic elements upstream of the regulated 5'ss represses the regulated exon, while binding to downstream intronic elements may lead to splicing activation. Transcriptome-wide binding patterns of several splicing regulators have been mapped using high-throughput sequencing technologies (CLIPSEQ, HITS-CLIP) and the results of these studies corroborate the position-dependent model of splicing regulation (Licatalosi et al., 2008; Rossbach et al., 2014; Yeo et al., 2009).

\subsection{Alternative splicing regulation in neurons}

A spatiotemporal change in cellular alternative splicing circuitry is commonly observed during tissue differentiation. The nervous system expresses a highly conserved set of uniquely spliced RNAs that is believed to contribute to neuronal complexity and function ( $\mathrm{Li}$ et al., 2007; Vuong et al., 2016). One recent example of such brain-specific regulation involves the expression of a neuronal splice form of the Ninein gene (Zhang et al., 2016). Alternative splicing of two of its exon led to the expression of a protein isoform that delocalizes from the centrosome loci and potentially triggering microtubule reorganization during neurogenesis. Interestingly, this splicing shift of Ninein mRNA was found to be sufficient to differentiate precursor neurons to its mature form. This, and many other previous examples have provided valuable insights into the molecular changes that occur during neuronal development. 
Shifts in neuronal alternative splicing program is, in part, attributed to the up-regulation of a subset of neuronal specific splicing regulators. Several well-studied factors include the family of NOVA, RBFOX and PTBP proteins, as well as nSR100. NOVA proteins (NOVA1 and NOVA2), initially described as antigens targeted by an autoimmune response in patients with paraneoplastic opsoclonus myoclonus ataxia (POMA), are the first neuron specific splicing regulators (Buckanovich et al., 1993; Yang et al., 1998). Knockout of either of these proteins in mice models result in multiple physiological defects of the nervous system, and their combined deletion lead to mice paralysis and death after birth (Huang et al., 2005; Jensen et al., 2000; Ruggiu et al., 2009). NOVA recognizes 'YCAY' motif on target mRNAs and carry out regulatory functions in a position-dependent manner (Ule et al., 2003; Ule et al., 2006). Notably, NOVA proteins promote correct splicing of mRNAs involved in synaptic functions (Ule et al., 2005). nSR100 is another example of a brain- and vertebrate-specific splicing regulator (Calarco et al., 2009; Nakano et al., 2012). Mice lacking the expression of this protein display impaired features of the brain which include neurite outgrowth, cortical layering and axon guidance (Quesnel-Vallieres et al., 2015). Research done by the Blencowe lab showed that nSR100 regulates splicing of so-called microexons found on a subset of neural genes (Irimia et al., 2014). Inclusion of these regulated exons is required for proper protein-protein interaction. An in vivo study have shown that the nSR100-mediated inclusion of a 6-nt exon of the Unc13b gene is sufficient to rescue the nSR100 knockout phenotype, clearly suggesting 
the importance of this splicing regulator during neurogenesis (QuesnelVallieres et al., 2015).

Owing to the importance of alternative splicing in the brain, it comes to no surprise that mis-splicing of brain-specific mRNAs is one of the major causes of a number of neurodegenerative diseases including amyotrophic lateral sclerosis (ALS) and frontotemporal lobar degeneration (FTLD) (Ahmad et al., 2016; Anthony and Gallo, 2010; Mills and Janitz, 2012). ALS is characterized by the progressive loss of motor neurons in the spinal cord. Patients who suffer from this disease display signs of muscle weakness that hinders them from performing voluntary actions such as moving, speaking and swallowing (Morgan and Orrell, 2016). On the other hand, FTLD patients suffer from neurodegeneration of the frontotemporal cortex that affect cognitive abilities which include speech and language (Burrell et al., 2016; Mackenzie and Neumann, 2016). Several splicing-related pathogenesis of these diseases have been documented. Firstly, mutations on the microtubule-associated protein tau (MAPT) gene in FTLD patients was found to increase the inclusion of its exon 10 that essentially alter the affinity of the protein for microtubules (Bodea et al., 2016; Hutton et al., 1998). This results in protein aggregation in the form of neurofibrillary tangles, thus affecting the axonal function of MAPT. Secondly, mislocalization of the nuclear DNA/RNA-binding protein TDP-43, a result of dominant mutations that produces hyperphoshphorylated and ubiquitinylated protein isoform, was found to cause formation of neuronal aggregates in both ALS and FTLD patients (Guerrero et al., 2016; Ratti and Buratti, 2016). Being a regulator of RNA metabolism, 
TDP-43 has been shown to be important in mediating alternative splicing of its target genes in the brain. Interestingly, a recent RNAsequencing analysis of TDP-43-depleted mouse adult brain revealed major changes in the brain splicing program and alterations in the expression of many neurodegenerative disease-associated transcripts (Polymenidou et al., 2011). This study have provided a useful perspective on the functional link between TDP-43 mislocalization and the ALS/FTLD phenotype. Another commonly mutated gene in both ALS and FTLD patients is the fused in sarcoma (FUS) gene, also known as translocated in sarcoma (TLS) (Guerrero et al., 2016). Similarly to TDP-43, mutations found on FUS/TLS affect the nuclear localization of the protein and this led to the formation of aggregates. FUS/TLS is also an important regulator of various RNA processes including splicing (Guerrero et al., 2016; Orozco and Edbauer, 2013). Recent studies have shown that FUS/TLS splice targets are commonly involved in important neuronal functions such as axonogenesis, axon guidance, neuron projection and vesicle transport (Ishigaki et al., 2012; Nakaya et al., 2013). Interestingly, loss of FUS/TLS in primary cortical neuron transduced with FUS shRNA was found to upregulate the inclusion of exon 10 of the MAPT gene, suggesting a common underlying mechanism of this neurodegenerative disease (Ishigaki et al., 2012).

\subsection{Nonsense-mediated decay}

Errors occurring during cellular processes such as DNA replication, transcription or pre-mRNA splicing may affect the sequence of the mature transcript and thus alter the protein products. A point mutation or 
a frame-shift may introduce a premature termination codon (PTC) into the mRNA coding sequence and result in the translation of a truncated protein. To circumvent the expression of such aberrant transcripts, eukaryotic cells developed a highly conserved quality control mechanism, termed nonsense-mediated decay (NMD), which destabilizes PTC-containing RNAs (Kurosaki and Maquat, 2016; Ni et al., 2007). Interestingly, approximately $20 \%$ of all alternatively spliced protein-encoding transcripts contain a PTC (Lareau et al., 2004). Moreover, production of PTC-containing mRNAs accounts for $30 \%$ of all known disease-related mutations (Muhlemann et al., 2008).

The recognition of NMD targets typically occurs in the cytoplasm during the "pioneer" round of translation. A recurring molecular feature found in these mRNAs is the presence of a PTC $>50-55$ nucleotides (nt) upstream of an exon-exon junction. To distinguish between bona fide stop codons and PTCs, NMD relies on a mechanism that recognizes an exon-exon junction complex (EJC) positioned downstream of a terminating ribosome (Fig. 1.3) (Hamid and Makeyev, 2014; Neu-Yilik and Kulozik, 2008). This multimeric complex made up of at least four highly conserved proteins (Barentz, elF4AIII, Magoh, Y14) gets deposited 20-24 nt upstream of exon-exon junctions following a splicing reaction (Maquat, 2004; Muhlemann, 2008). During the initial round of translation, EJCs are dislodged from the mRNAs by the translational machinery (Chang et al., 2007). Most mammalian transcripts naturally encode stop codons in the last exon or at the end of the penultimate exon, thus ensuring a rapid and complete removal of EJC marks in translation-competent mRNA. Conversely, NMD-sensitive transcripts 
retain one or more EJCs downstream of the PTCs, which allow the interaction of the halted ribosomes with the nearest EJC via the upframe-shift proteins (Upf1, Upf2, Upf3). This is followed by the activation of Upf1 helicase protein by Smg1-mediated phosphorylation, which recruits endoribonuclease (Smg6) and related proteins (Smg5 and Smg7) promoting degradation of the PTC-containing mRNA (Fig. 1.3) (McGlincy and Smith, 2008; Muhlemann, 2008; Yamashita, 2013). Notably, mRNA translation is a key process for PTC recognition, as evident from the inactivation of the NMD pathway by translational inhibitors such as cycloheximide (CHX) (Ishigaki et al., 2001; Lareau et al., 2007b).

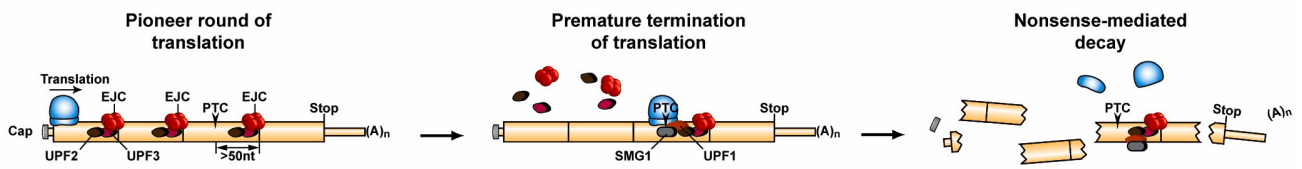

Figure 1.3 Functional mechanism of the nonsense-mediated decay pathway. Destabilization of NMD-susceptible transcripts is triggered upon the premature termination of the pioneer round of translation and commonly involves the interaction between Upf1 and the EJC complex. (modified from Hamid and Makeyev 2014)

\subsection{Alternative splicing coupled to nonsense-mediated decay (AS-} NMD)

In addition to its error surveillance function protecting the cell from aberrant transcripts, NMD is known to participate in normal gene regulation through functional coupling to AS. This post-transcriptional mechanism referred to as AS-NMD, has been shown to control many important processes including homeostasis of RNA binding proteins and proteome dynamics in cells undergoing differentiation or responding to stress (Hamid and Makeyev, 2014; Yap and Makeyev, 2013; Zheng, 2016). 
Several AS-NMD strategies have been described (Fig. 1.4) (Hamid and Makeyev, 2014; Yap and Makeyev, 2013). Essentially, AS-NMD target genes can generate a productively spliced protein-encoding isoform and an NMD-susceptible PTC-containing isoform. The balance between the two outcomes is controlled at the level of AS. Two common strategies of AS-NMD rely on the alternate inclusion of an ORF-maintaining exon and a poison exon. Inclusion of an ORF-maintaining exon ensures translation of the full-length protein while inclusion of a poison exon triggers the NMD pathway. Collectively, these strategies regulate the expression of various cellular proteins including RNA-binding proteins, spliceosome components, splicing regulators, and a wide range of developmental marker proteins (Colak et al., 2013; Eom et al., 2013; Lareau et al., 2007a; McGlincy and Smith, 2008; Wong et al., 2013).

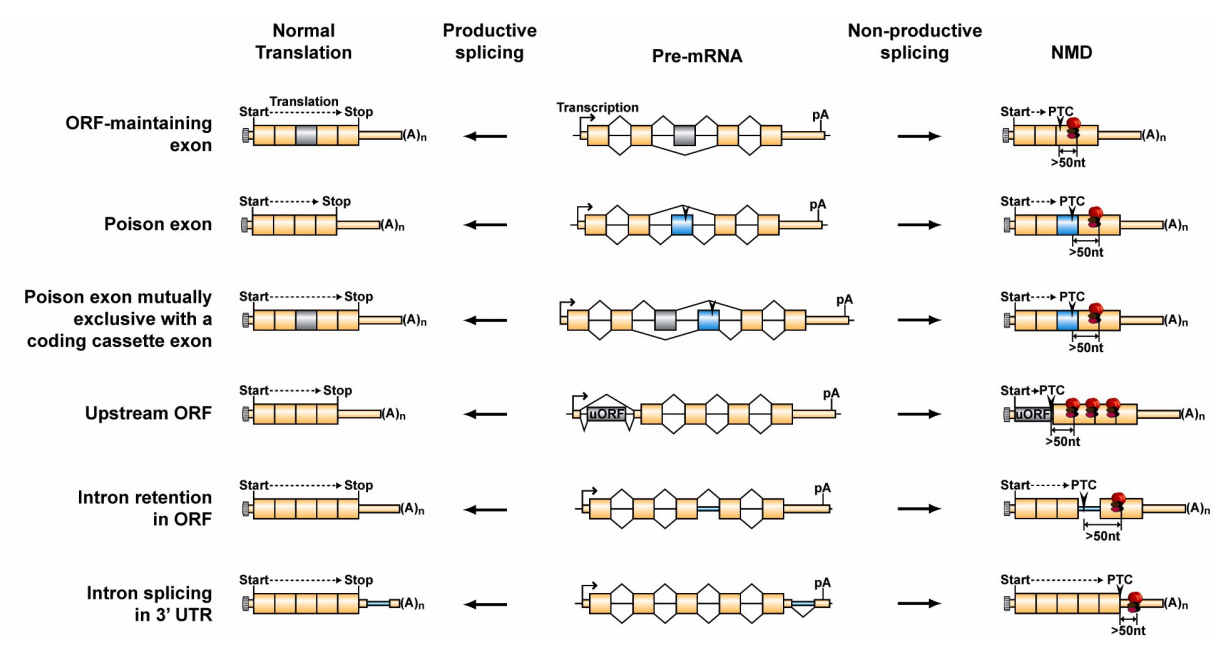

Figure 1.4 AS-NMD strategies. Differential splicing of alternative coding segments (in blue or gray) may produce translation-competent or NMD-sensitive transcripts. (modified from Hamid and Makeyev 2014)

\subsection{Polypyrimidine-tract binding protein 1}

A member of the hnRNP family, Polypyrimidine-tract binding protein (Ptbp1/PTB/hnRNP I), is a global regulator of AS known to control several genes through AS-NMD (Boutz et al., 2007; Li et al., 2007). 
Ptbp1 interacts with target mRNAs at regions containing polypyrimidinerich sequences and conventionally, functions as a repressor of alternative splicing (Amir-Ahmady et al., 2005; Chan and Black, 1997; Wollerton et al., 2004). Interestingly, Ptbp1 regulates its own expression by repressing the inclusion of its exon 11 to generate an NMDsusceptible transcript (Wollerton et al., 2004). Other notable examples of Ptbp1-mediated splicing regulation include the skipping of the mutually exclusive exon 3 of the tropomyosin gene through the recruitment of a co-repressor Raver1 and the inhibition of exon 10 splicing of the MAPT/ Tau gene (Gromak et al., 2003; Wang et al., 2004). Apart from regulating splicing outcome, Ptbp1 also binds to 3'UTR and internal ribosome entry site (IRES) to regulate mRNA processing and stimulate IRES-mediated translation (Castelo-Branco et al., 2004; Kafasla et al., 2011; Millevoi et al., 2009).

The mechanisms of Ptbp1-induced splicing repression have been investigated in considerable detail. Relevant examples include competition with U2AF for binding onto polypyrimidine tracts (Spellman and Smith, 2006), looping out alternative exons to prevent their recognition by the spliceosome (Chou et al., 2000) and interaction with U1 snRNP to block the intron definition complex (Sharma et al., 2011). Similar to many other splicing regulators, Ptbp1 has been shown to work in a position-dependent manner (Erkelenz et al., 2013; Llorian et al., 2010; Xue et al., 2009). High-throughput studies on Ptbp1-RNA interactions showed that Ptbp1 binding to pyrimidine-rich elements located downstream of the 5'ss of a regulated exon may favor its activation, whereas other binding patterns lead to repression (Llorian et 
al., 2010; Xue et al., 2009). Although this finding has been confirmed by several recombinant and/or in vitro studies, the molecular mechanism underlying Ptbp1-mediated activation remains unclear (Erkelenz et al., 2013).

Ptbp1 is expressed at relatively high levels in most cell types, with the notable exception for neurons. In the immune system, Ptbp1 was recently found to be required for CD4 T cell activation by stabilising the PLCY1/ERK1/2 and the NF-KB pathways (La Porta et al., 2016). In neurons, the dampening of Ptbp1 levels is triggered, at least in part, by microRNA miR-124, which results in a global change in the AS pattern (Makeyev et al., 2007). In addition to a large number of purely AS events, this leads to increased expression of at least three AS-NMD targets: the brain-enriched Ptbp1 paralog Ptbp2/nPTB/brPTP and postsynaptic proteins Gabbr1 and PSD-95/Dlg4 (Fig. 1.5A) (Makeyev et al., 2007; Yap et al., 2012; Zheng et al., 2012). All three genes contain Ptbp1-dependent ORF-maintaining alternative exons, which are skipped in non-neuronal cells and neuronal precursors expressing large amounts of Ptbp1 leading to a frame-shift and NMD. Conversely, in Ptbp1depleted neurons, these alternative exons are included to generate relatively stable and translationally active mRNAs.

A

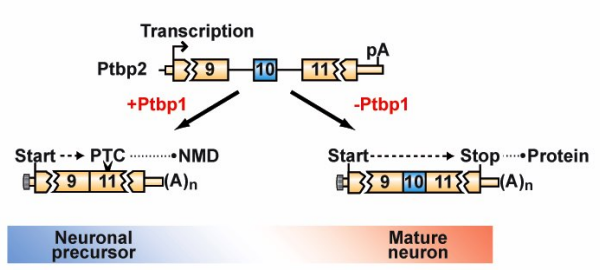

B

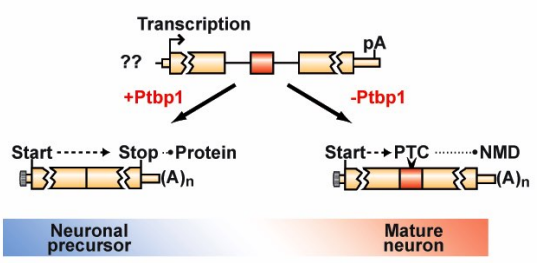

Figure 1.5 Ptbp1-mediated regulation of target gene expression through ASNMD. (A) Ptbp1 represses expression of neuronal genes (Ptbp2, Gabbr1, PSD95) through the ORF-maintaining strategy. (B) Hypothetic model of Ptbp1-mediated stimulation of gene expression of poison-exon containing transcripts. 


\subsection{Objectives}

Thus far, most studies on Ptbp1-mediated AS-NMD regulation focused on brain-specific transcripts bearing an ORF-maintaining exon and whether this protein can participate in the poison-exon AS-NMD regulation has remained an open question (Fig. 1.5B). Thus, the first aim of my Ph.D. project has been to uncover novel AS-NMD targets of Ptbp1 including those regulated through the poison-exon strategy. Indeed our analyses uncovered several such genes. We showed that one of these genes, $H p s 1$, is regulated by a unique switch in alternative 5'ss usage in a Ptbp1-dependent manner. Further research on this regulation revealed that Ptbp1 functions in this circuitry as a splicing activator, rather than a conventional repressor. This suggested the second aim of the project, which was elucidation of the mechanism that underlies Ptbp1-mediated splicing activation. To address this, we turned to a different model gene, Dtx2, which harbor a Ptbp1-activated alternative exon. Our data suggested that Ptbp1 promotes the recruitment of U1 snRNP onto the weak 5'ss of Dtx2 exon 6 to activate its splicing. Knockout of Dtx2 alternative exon using the CRISPR/Cas9 system affected the expression of several Notch target genes, which are important for maintaining 'stemness' of neuronal precursors. Collectively, the results gathered from this project have provided a deeper understanding on the function of Ptbp1 as a regulator of AS-NMD, a splicing activator as well as a regulator of neurogenesis. 


\section{Materials and Methods}

\subsection{Cell culture and reagents}

CAD cells (Cath.a-derived mouse neuroblastoma) ( $\mathrm{Li}, 2007)$ were cultured in Dulbecco's Modified Eagle Medium/High Glucose (DMEM; GIBCO, USA), supplemented with $11 \%$ Fetal Clone Serum III (FCSIII; HyClone, USA), 1mM sodium pyruvate (GIBCO, USA), 1× penicllinstreptomycin $(100 \mathrm{IU} / \mathrm{ml}$ penicillin and $100 \mu \mathrm{g} / \mathrm{ml}$ streptomycin; Invitrogen), at $37^{\circ} \mathrm{C}$ in $5 \% \mathrm{CO}_{2}$. N2a cells (Neuro-2a) were cultured in DMEM/High Glucose supplemented with 10\% Fetal Bovine Serum (FBS; HyClone, USA), 1mM sodium pyruvate and $1 \times$ penicllinstreptomycin, at $37^{\circ} \mathrm{C}$ in $5 \% \mathrm{CO}_{2}$.

\subsection{Cell line transfection}

One day prior to transfection, $4 \times 10^{5}$ cells were seeded per a 6-well culture plate in a complete culture medium. For siRNA-mediated knockdown experiments, cells were transfected with Ptbp1- and/or Ptbp2-specific or control siRNAs (Thermo Scientific/Dharmacon, USA) using Lipofectamine RNAiMAX (Invitrogen, USA). 36 hours posttransfection, cells were transfected with another round of siRNAs or $1 \mu \mathrm{g}$ of plasmid mix using Lipofectamine 2000 (Invitrogen, USA) and incubated for another 36 hours followed by RNA harvest. In siRNAunrelated experiments, cells were incubated with $1 \mu \mathrm{g}$ of plasmid mix diluted in Lipofectamine 2000 for 48 hours prior to the harvest. In certain experiments where the effects of NMD were studied, cells were treated 
with $100 \mu \mathrm{g} / \mathrm{ml}$ of CHX dissolved in DMSO or with DMSO (control) for 8 hours prior to the harvest.

\subsection{Molecular cloning}

DNA fragment of interests were produced using (1) PCR amplification either from wild-type mouse embryonic genomic DNA (gDNA) or from BAC clones, or (2) in vitro annealing of complementary short oligonucleotide fragments. Sequences of primers used in this study are listed in Appendix 1 . In general, PCR reactions were carried out in $50 \mu \mathrm{l}$ reaction volume in the presence of $500 \mathrm{ng}$ of template, $0.4 \mu \mathrm{M}$ primer mixture, $0.2 \mathrm{mM}$ dNTPs mix (NEB, UK), and $0.01 \mathrm{U} / \mu \mathrm{l} \mathrm{KAPA} \mathrm{HiFi} \mathrm{DNA}$ Polymerase (KAPA Biosystems, South Africa). Reactions were carried out with an initial denaturation step at $95^{\circ} \mathrm{C}$ for $3 \mathrm{~min}$, followed by 30 cycles of denaturation at $98^{\circ} \mathrm{C}$ for $20 \mathrm{~s}$, annealing at $58^{\circ} \mathrm{C}$ for $30 \mathrm{~s}$, and extension at $72^{\circ} \mathrm{C}$ for $1 \mathrm{~min}$ per kilobase pair of the PCR product, and a final extension step at $72^{\circ} \mathrm{C}$ for $5 \mathrm{~min}$. Amplicons were purified using Nucleospin® Gel and PCR Clean-up (Macherey-Nagel, Germany) according to manufacturer's protocol. One microgram of plasmid backbone and the purified PCR products were digested with $0.5 \mathrm{U} / \mu \mathrm{l}$ of the appropriate restriction enzymes (NEB, UK) at $37^{\circ} \mathrm{C}$ overnight. Fragments were separated by $1 \%$ agarose gel electrophoresis (Vivantis, USA) and desired bands were excised and purified as described above. Ligation reactions were carried out in a $10-\mu l$ reaction volume containing 1:3 molar ratio of vector to insert, in the presence of $1 \times$ T4 DNA ligase 
buffer and $0.1 \mathrm{U} / \mu \mathrm{l}$ T4 DNA ligase (NEB, UK). Plasmid constructs generated in this study are listed in Appendix 2.

\subsection{Site-directed mutagenesis}

Site-directed mutagenesis was carried out using a modified Quikchange protocol (Stratagene) where KAPA HiFi DNA polymerase was used instead of Pfu Turbo. Reactions were done in a $25 \mu \mathrm{l}$ volume, in the presence of $50 \mathrm{ng}$ of plasmid, $0.4 \mu \mathrm{M}$ primer mix, $0.3 \mathrm{mM}$ dNTPs mix and $0.02 \mathrm{U} / \mu \mathrm{l} \mathrm{KAPA} \mathrm{HiFi} \mathrm{Polymerase.} \mathrm{Cycling} \mathrm{conditions} \mathrm{for} \mathrm{the} \mathrm{reaction}$ were as follows: initial denaturation at $95^{\circ} \mathrm{C}$ for $3 \mathrm{~min}$, followed by 20 cycles of denaturation at $98^{\circ} \mathrm{C}$ for $20 \mathrm{~s}$, annealing at $55^{\circ} \mathrm{C}$ for $1 \mathrm{~min}$, and extension at $68^{\circ} \mathrm{C}$ at a rate of 1 min per plasmid length, and lastly a final extension step at $68^{\circ} \mathrm{C}$ for $5 \mathrm{~min}$. Amplicons were purified using Nucleospin ${ }^{\circledR}$ Gel and PCR Clean-up according to manufacturer's protocol and eluted in $22.5 \mu \mathrm{l} \mathrm{NE}$ buffer. DNA was then treated with 0.8 $\mathrm{U} / \mu \mathrm{l}$ of $\mathrm{Dpnl}(\mathrm{NEB}, \mathrm{UK})$ at $37^{\circ} \mathrm{C}$ overnight. A list of modified plasmid constructs generated is listed in Appendix 2.

\subsection{Plasmid DNA transformation, extraction and analysis.}

$1.5 \mu \mathrm{l}$ of the plasmid were incubated with $25 \mu \mathrm{l}$ of E. coli TOP10 competent cells (Invitrogen, USA) for $30 \mathrm{~min}$ on ice. Cells were subjected to heat-shock treatment at $42^{\circ} \mathrm{C}$ for $90 \mathrm{~s}$ and returned onto ice for another $2 \mathrm{~min}$. Transformed cells were then incubated in the presence of $1 \mathrm{ml}$ Luria-Bertani (LB) broth (Beckton Dickinson (BD), 
USA) for 1 hour at $37^{\circ} \mathrm{C}$. Recovered cells were briefly spun at $9000 \mathrm{rpm}$ for a minute, resuspended in $100 \mu$ of fresh LB broth and plated onto LB agar plates containing an appropriate antibiotic. Plates were incubated at $37^{\circ} \mathrm{C}$ overnight.

Antibiotic-resistant colonies were picked and propagated in $4 \mathrm{ml}$ LB broth containing antibiotics. Cultures were grown in a $37^{\circ} \mathrm{C}$ shaking incubator for 24 hours followed by extraction of the plasmid DNA using PureLink $^{\text {TM }}$ Quick Plasmid Miniprep Kit (Invitrogen, USA) according to the manufacturer's protocol. Desired plasmid constructs were screened by digesting the extracted plasmid DNAs with $0.5 \mathrm{U} / \mu \mathrm{l}$ of appropriate restriction enzymes and constructs showing correct sized fragments were sequenced by AIT Biotech using a suitable sequencing primer.

\subsection{Total RNA extraction}

For the extraction of total RNA from cultured cell lines, $0.5 \mathrm{ml}$ of TRIzol Reagent (Invitrogen, USA) was added to each well of a 6-well plate and incubated for 10 minutes on a rocker at room temperature. For the extraction of total RNA from tissues, up to $1 \mathrm{ml}$ of TRIzol Reagent was added and tissues were homogenized using a Dounce homogenizer (Sigma). Cell lysates were transferred to $1.5 \mathrm{ml}$ eppendorf tubes and supplemented with $100 \mu \mathrm{l}$ of chloroform. The mixtures were vortexed for $30 \mathrm{~s}$ and centrifuged in a pre-chilled microcentrifuge for $10 \mathrm{~min}$ at the maximum speed. The top aqueous layer was collected and mixed with $250 \mu \mathrm{l}$ acid-phenol chloroform (1:1) to further purify the RNA. Mixture was spun at the maximum speed for $10 \mathrm{~min}$, the aqueous layer was 
collected and mixed with $250 \mu \mathrm{l}$ of isopropanol. Solution was incubated at $-20^{\circ} \mathrm{C}$ for 15 min to precipitate the RNA, followed by centrifugation for $15 \mathrm{~min}$ at the maximum speed. RNA pellet was washed with $70 \%$ ethanol, air-dried and rehydrated in $84 \mu$ l Diethylpyrocarbonate (DEPC)treated water. Solubilised RNA was incubated with $0.01 \mathrm{U} / \mu \mathrm{L}$ R1 RNase-Free DNase (Promega, USA) for $1 \mathrm{~h}$ at $37^{\circ} \mathrm{C}$ to digest traces of genomic DNA. $150 \mu$ l of DEPC-treated water was added to the reaction mixture and RNA was extracted by adding $250 \mu$ lacid-phenol:chloroform (1:1). The RNA-containing aqueous layer was transferred into a fresh eppendorf tube and mixed with $25 \mu \mathrm{l}$ of $3 \mathrm{M}$ Sodium Acetate and $750 \mu \mathrm{l}$ of $100 \%$ ethanol. RNA was left to precipitate at $-80^{\circ} \mathrm{C}$ for $1 \mathrm{~h}$ and spun down in a pre-chilled microcentrifuge for $30 \mathrm{~min}$ at the maximum speed. RNA pellets were washed with $70 \%$ ethanol, air-dried and resuspended in $25 \mu$ l DEPC-treated water. RNA yield was quantified $\left(A_{260}\right)$ using Nanodrop-1000 spectrophotometer.

\subsection{Reverse transcription polymerase chain reaction (RT-PCR)}

To synthesize first-strand cDNA, $2.5 \mu \mathrm{g}$ of total RNA was incubated with $1 \mu \mathrm{M} \mathrm{N} 10$ random oligo (Sigma Aldrich, USA) for $10 \mathrm{~min}$ at $70^{\circ} \mathrm{C}$ and snap-chilled on ice for $5 \mathrm{~min}$. Reaction mixtures were then supplemented with $10 \mathrm{mM}$ DTT, $0.4 \mathrm{mM}$ dNTPs, $1 \mathrm{U} / \mu \mathrm{l}$ RNAsin (Promega, USA) and $10 \mathrm{U} / \mu \mathrm{l}$ SuperScript $\AA$ III Reverse Transcriptase (Invitrogen, USA) to a final volume of $10 \mu \mathrm{l}$. RT reactions were further incubated at $50^{\circ} \mathrm{C}$ for 1 hour followed by incubation at $70^{\circ} \mathrm{C}$ for $15 \mathrm{~min}$. Freshly synthesized cDNAs were diluted with $90 \mu$ I DEPC-treated water. 
To study alternative splicing, RT-PCR reactions were carried out using corresponding primers that anneal to exonic sequences flanking regulated exons (Appendix 1). RT-PCR reactions were usually done in a $20 \mu \mathrm{l}$ volume in the presence of $5 \mu \mathrm{l} \mathrm{cDNA}$ template, $0.5 \mu \mathrm{M}$ primer mix, $0.5 \mathrm{mM}$ dNTPs, $0.05 \mathrm{U} / \mu \mathrm{l}$ KAPA Taq DNA polymerase (KAPA Biosystems, South Africa) and an appropriate reaction buffer. PCR cycling conditions were as follows: initial denaturation at $95^{\circ} \mathrm{C}$ for $3 \mathrm{~min}$, followed by 35 cycles of denaturation at $98^{\circ} \mathrm{C}$ for $20 \mathrm{~s}$, annealing at $58^{\circ} \mathrm{C}$ $-60^{\circ} \mathrm{C}$ for $30 \mathrm{~s}$, and extension at $72^{\circ} \mathrm{C}$ for $30 \mathrm{~s}$, and a final extension step at $72^{\circ} \mathrm{C}$ for $5 \mathrm{~min}$. PCR amplicons were resolved on $2 \%$ or $3 \%$ Agarose (Vivantis, USA) gel to discriminate alternatively spliced transcripts.

\subsection{Reverse transcription Real-time PCR (RT-qPCR)}

RT-qPCR reactions were performed using a StepOnePlus ${ }^{T M}$ Real-Time PCR System (Applied Biosystems). Reactions were typically done in a $20-\mu$ volume and contained $5 \mu \mathrm{l}$ of a cDNA template, $150 \mathrm{nM}$ of each primer and $1 \times$ qPCR reaction mix Fast SYBR $®$ Green Master Mix (Applied Biosystems). Cycling program was as follows: initial denaturation at $95^{\circ} \mathrm{C}$ for $1 \mathrm{~min}, 45$ cycles of $5 \mathrm{~s}$ denaturation and $45 \mathrm{~s}$ annealing/extension at $60^{\circ} \mathrm{C}$, and lastly a melting curve analysis.

Reactions were carried out in triplicates and the relative mRNA expression levels were quantified using the $\Delta \Delta C T$ method with Gapdh being the housekeeping gene. 


\subsection{Cloning of PCR products for sequencing}

RT-PCR products of interest were excised from the agarose gel and purified using NucleoSpin $\circledast$ Gel and PCR Clean-up (Macherey-Nagel, Germany) according to the manufacturer's instruction. $15 \mathrm{ng}$ of purified products were cloned into $0.5 \mu \mathrm{l}$ of $\mathrm{pCR}^{\mathrm{TM}} 4$ - TOPO TA vector (Invitrogen, USA) in a 3- $\mu$ l reaction, and incubated at room temperature for a period of $25 \mathrm{~min}$. Cloned products were transformed using the protocol described above.

\subsection{Biotinylated RNA pull-down assay}

Biotinylated RNA probes/baits were synthesised using in vitro transcription of plasmid-containing desired sequences driven by a T7 promoter. Essentially, one microgram of linearized plasmid was incubated with biotin-UTP labeling NTP mixture (Roche) and $1 \mathrm{U} / \mu \mathrm{l}$ of $\mathrm{T} 7$ polymerase for $2 \mathrm{~h}$ at $37^{\circ} \mathrm{C}$. Plasmid template contaminants were digested with RQ1 DNase at $37^{\circ} \mathrm{C}$ for 15 min using $1 \mathrm{U}$ of the enzyme per $\mu \mathrm{g}$ of the input DNA template. Biotinylated RNA were purified using acid-phenol:chloroform (1:1) mixture, precipitated with ethanol and rehydrated in DEPC-treated water.

To study RNA/RNA-binding protein interactions, two micrograms of a biotinylated RNA probe was mixed with 50\% HeLa S3 nuclear extract (vol/vol; $100 \mu \mathrm{g}$ in total; dialyzed in Buffer D containing 20 mM HEPES, pH 7.9, $100 \mathrm{mM} \mathrm{KCl}, 20 \%$ Glycerol, $0.5 \mathrm{mM}$ DTT and $0.2 \mathrm{mM}$ EDTA), 80 ng yeast tRNA, $2.5 \mu \mathrm{g}$ heparin and $40 \mathrm{U}$ rRNAsin (Promega) for $30 \mathrm{~min}$ at room temperature. RNA-protein complexes were incubated with $20 \mu \mathrm{l}$ 
of pre-washed Streptavidin Sepharose beads (Sigma) for $1 \mathrm{~h}$ at $4^{\circ} \mathrm{C}$ and washed thrice with Buffer $D$. To release RNA-binding proteins, the beads were boiled in $30 \mu \mathrm{l} 1 \times$ SDS sample buffer $(0.0624 \mathrm{M}$ Tris $\mathrm{HCl} \mathrm{pH} \mathrm{6.8,}$ $2 \%$ SDS, $5 \% \beta$-mercaptoethanol, $10 \%$ glycerol and $0.01 \%$ bromophenol blue) for $10 \mathrm{~min}$ and the eluted proteins were analyzed by immunoblotting.

To study interaction between biotinylated RNAs with U1 snRNPs, two micrograms of the probe was incubated in $400 \mu \mathrm{l}$ of binding buffer (20 mM HEPES-KOH, pH 7.5, $100 \mathrm{mM} \mathrm{KCl,} 10 \mathrm{mM} \mathrm{MgCl} 2,0.01 \%$ Nonidet P-40 and $1 \mathrm{mM}$ DTT) and $500 \mu \mathrm{g}$ HeLa S3 nuclear extract for $1 \mathrm{~h}$ at room temperature. Complexes were incubated with $30 \mu \mathrm{l}$ of Streptavidin Sepharose beads pre-washed in washing buffer $(20 \mathrm{mM}$ HEPES-KOH, pH 7.5, $200 \mathrm{mM} \mathrm{KCl}, 10 \mathrm{mM} \mathrm{MgCl} 2,0.01 \%$ Nonidet P-40 and $1 \mathrm{mM}$ DTT) and pre-blocked with $0.2 \mathrm{mg} / \mathrm{ml} \mathrm{BSA}$ for $1 \mathrm{~h}$ at $4^{\circ} \mathrm{C}$. Beads were washed with buffer $D$ thrice and the bound U1 snRNPs were eluted by boiling the beads for $1 \mathrm{~min}$ in $30 \mu \mathrm{l}$ of $1 \mathrm{X}$ SDS sample buffer and analyzed by immunoblotting. To isolate the RNA fraction of the pull-down assay, reactions were incubated with $250 \mu \mathrm{l}$ of denaturation buffer (20 $\mathrm{mM}$ Tris- $\mathrm{HCl}, 4 \mathrm{M}$ Urea, $0.5 \%$ SDS, $10 \mathrm{mM}$ EDTA, $0.3 \mathrm{M} \mathrm{NaCl}$ ) at $37^{\circ} \mathrm{C}$ for 10 minutes followed by acidic-phenol/chloroform extraction and RNA precipitation.

\subsection{In vitro splicing assay}

RNA splicing substrates were prepared using the in vitro transcription protocol as described above, however, the biotin-UTP labeling NTP 
mixture was replaced by a T7 polymerase buffer and individual NTPs (0.5 mM each). Splicing reactions were carried out in $20 \mu \mathrm{l}$ reaction volumes consisting of $30 \%$ (vol/vol; $60 \mu \mathrm{g})$ HeLa S3 nuclear extract dialyzed in Buffer D, $2 \mu \mathrm{l}$ of $10 \times$ splicing reaction buffer $(120 \mathrm{mM}$ HEPES, pH7.9, $32 \mathrm{mM} \mathrm{MgCl}$, $725 \mathrm{mM} \mathrm{KCl),} 1 \mathrm{mM}$ ATP (NEB), $20 \mathrm{mM}$ phosphocreatine (Sigma), $2.5 \%$ poly(vinyl alcohol) (Sigma, MW 30-70K), $1 \mathrm{mM}$ DTT, $0.5 \mathrm{U} / \mathrm{\mu l}$ rRNAsin (Promega) and $200 \mathrm{ng}$ of splicing RNA substrate. Splicing reactions were carried out at $30^{\circ} \mathrm{C}$ for $60 \mathrm{~min}$, followed by the addition of $200 \mu \mathrm{l}$ Proteinase K buffer (10 mM Tris- $\mathrm{HCl}$, $\mathrm{pH}$ 7.4, 1\% SDS, $150 \mathrm{mM} \mathrm{NaCl}, 10 \mathrm{mM}$ EDTA) and $0.25 \mathrm{mg} / \mathrm{ml}$ proteinase $\mathrm{K}$ (Fermentas) for $15 \mathrm{~min}$ at $37^{\circ} \mathrm{C}$. RNA products were purified using phenol-chloroform (1:1), precipitated with ethanol and dissolved in DEPC-treated water (Invitrogen). Changes in alternative splicing was analysed by RT-PCR using exon-specific primer pairs (Appendix 1).

For experiments that required immunodepletion of PTBP1 from the splicing reaction, $50 \mu \mathrm{l}$ nuclear extract was incubated with $40 \mu \mathrm{g}$ of mouse monoclonal anti-PTBP1 antibody (Invitrogen, clone 1) bound onto $40 \mu \mathrm{l}$ of protein $\mathrm{G}$ sepharose beads (GE Healthcare) for $4 \mathrm{~h}$ at $4^{\circ} \mathrm{C}$ with continuous rotation. Nuclear extract-containing supernatant was recovered by centrifugation at 3,000 rpm for 2 min and subsequently used for splicing reactions. 


\subsection{Immunoblotting}

Cultured cells were pre-washed with PBS and subsequently incubated with NP-40 lysis buffer (20 mM Tri-HCl, pH7.5, 150 mM NaCl, 5 mM EDTA, 10\% glycerol, 1\% Nonidet P-40, 1 mM PMSF, 1× Complete EDTA free protease inhibitor cocktail (Roche)) for 10 min on ice. Lysates were spun at max speed for $5 \mathrm{~min}$, and protein-containing supernatant was transferred into a fresh eppendorf tube. Protein concentration was quantified using a BCA Protein Assay Kit (Thermo Scientific) as recommended. $10-20 \mu \mathrm{g}$ of protein were separated on a $4-20 \%$ gradient SDS-PAGE gel (BioRad) for $1 \mathrm{~h}$ at $120 \mathrm{~V}$. Samples were then transferred to nitrocellulose membranes for $90 \mathrm{~min}$ at $300 \mathrm{~mA}$ in the cold room. Membranes were stained with Ponceau S stain and de-stained with $5 \%$ acetic acid to visualize transferred protein bands. This was followed by blocking the membrane with $5 \%$ non-fat milk in $1 \times$ TBST $(0.1 \mathrm{M} \mathrm{NaCl}, 0.01 \mathrm{M} \mathrm{TrisHCl}, 0.1 \%$ Tween20) for $2 \mathrm{~h}$. After washing the membrane thrice with $1 \times$ TBST, desired proteins were detected by incubating the membrane at $4^{\circ} \mathrm{C}$ overnight with the following primary antibodies: mouse monoclonal anti-Ptbp1 (1:1000, Invitrogen), mouse monoclonal anti-Ptbp2 (1:20,000, a gift from external source), mouse monoclonal anti- GFP (1:2000, Invitrogen), mouse polyclonal antiU1-70k (1:1000, a gift from Tom Maniatis), mouse monoclonal antiGAPDH (1:10,000, Ambion), rabbit monoclonal anti-Lamp1 (1:1000, Abcam). Membranes were washed thrice with $1 \times$ TBST before incubating them with the appropriate secondary antibody diluted 1:5000 in $5 \%$ milk in TBST. Protein bands were detected using enhanced 
chemiluminescence (Merck Millipore, Germany) exposed on Kodak Xray film.

\subsection{Immunofluorescence}

Cells grown on poly-D-lysine/Laminin coated coverslips (BD, USA) were washed twice with PBS followed by a fixation with $4 \%$ paraformaldehyde (Ted Pella Inc, USA) for 15 min. Fixed cells were further washed with PBS thrice for 5 min each. Cells were then permeabilized with $1 \%$ Triton-X for 5 min and blocked with 3\% BSA (Sigma) in PBS for $1 \mathrm{~h}$. Cells were then incubated with the following primary antibodies overnight at room temperature: rabbit anti-Lamp1 (1:300, Abcam). Secondary antibodies were incubated with PBS-washed cells together with $5 \mu \mathrm{g} / \mathrm{ml}$ of DAPI at room temperature for $1 \mathrm{~h}$. Coverslips were washed thrice before mounting onto a microscope slide using ProLong ${ }^{\circledR}$ Gold antifade reagent (Invitrogen, USA). Slides were imaged using Zeiss LSM710 Confocal microscope.

\subsection{Statistical analyses and bioinformatics}

All quantitative data were expressed as mean \pm standard deviation.

Student T-test and ANOVA analyses were carried out using Microsoft Excel's data analysis feature. Pearson's correlation test and Kolmogorov-Smirnov test was carried using R statistical software (http:// CRAN.R-project.org/doc/FAQ/R-FAQ.html). To identify alternative 5' and 3' splicing events, fastq RNA-seq files for CAD cells treated with 
siControl, siPtbp1 or siPtbp1/2 (NCBI Gene Expression Omnibus accession number GSE37933) were analyzed using TopHat aligner (Trapnell et al., 2009) and mm9 mouse genome assembly. The aligned junction read files were then processed using in-house Perl scripts designed to identify all possible pairs for A5C (u5'ss-c3'ss and d5'ssc3'ss) and A3C (c5'ss- u3'ss and c5'ss-d3'ss) junctions across experimental samples. Junction reads corresponding to cassette exons were depleted by requesting that u5'ss in alternative 5' events and d3'ss in alternative 3'ss events pairs map to a known exon present in the UCSC gene, RefSeq gene or mRNA libraries (http://genome.ucsc.edu/). Alternative 5'ss events and alternative 3'ss events pairs undergoing significant changes were identified by Fisher's exact test using $R$.

\subsection{CRISPR/Cas9-mediated exon deletion}

To delete the Dtx2 exon 6 sequences using the CRISPR/Cas9 gene editing system, we prepared several constructs; (1) two plasmids coexpressing Cas9n (nickase) and two different gRNA sequences (pEM1487 and pEM1488; Appendix 2) and (2) a donor construct that expresses a neomycin-resistant gene flanked by homology arms corresponding to Dtx2 sequences (pEM1486; Fig. 3.23A). Constructs were transfected into Neuro-2a cell line at a ratio of $8: 1: 1$ (Donor:gRNA1:gRNA2; $500 \mathrm{ng}$ in total) on a 24-well plate. 24 hours post-transfection, cells were re-plated onto $10 \mathrm{~cm}$ culture dishes and mutants were selected using G418 (100 $\mu \mathrm{g} / \mathrm{ml})$. Single colonies were scraped and propagated in a 24-well or 12-well plate. Clones with Dtx2 
exon 6 deletion were tested by RT-PCR to check for changes in their splicing pattern. 


\section{Results}

\subsection{Ptbp1 may promote expression of several important genes by suppressing their AS-NMD-mediated down-regulation}

We began this project by analyzing gene expression changes in CAD neuroblastoma cells responding to siRNA-mediated knockdown of Ptbp1 in the presence or absence of $\mathrm{CHX}$ using an appropriate microarray platform (Agilent). To identify genes regulated by Ptbp1 via a poisonexon strategy, we shortlisted candidates that were downregulated upon Ptbp1 knockdown in a manner that could be rescued by $\mathrm{CHX}$. Essentially, we selected genes that showed significant down-regulation in Ptbp1 knockdown cells in the absence but not in the presence of $\mathrm{CHX}$. To confirm the presence of a regulated PTC-containing or frameshifting exons, we manually screened available cDNA/EST sequences (UCSC Genome browser; http:// genome.ucsc.edu). In addition, we identified intronic regions showing unusually high interspecies conservation, which may indicate the presence of non-annotated poison exons. To validate our bioinformatic predictions, we carried out RT-PCR assay using specific primers flanking putative poison exons. In total, we identified 18 poison exon-containing genes whose expression was regulated by Ptbp1 (Table 1).

Gene ontology (GO) analysis showed that $33 \%$ (6 out of 18) of these candidate mRNAs are involved in cytoskeletal organization, which suggests that Ptbp1 may play an active role in cellular actin remodelling. While $89 \%$ (16 out of 18 ) of the identified mRNAs contain a cassettetype poison exon, two transcripts were found to be regulated by 
Table 1. List of genes found to be regulated via Ptbp1-mediated AS-NMD

\begin{tabular}{|c|c|c|c|}
\hline $\mathbf{S} / \mathbf{N}$ & Gene Identifier & Alternative splicing topology & GO Keyword \\
\hline 1 & Ctnnal1 & Cassette exon & Cellular Adhesion \\
\hline 2 & lqgap1 & Cassette exon & Cellular Adhesion \\
\hline 3 & Fhod1 & Cassette exon & Actin Cytoskeleton Organization \\
\hline 4 & Lima1 & Cassette exon & Actin Cytoskeleton Organization \\
\hline 5 & Fmn/3 & Cassette exon & Actin Cytoskeleton Organization \\
\hline 6 & Daam2 & Cassette exon & Actin Cytoskeleton Organization \\
\hline 7 & Myo19 & Cassette exon & Unconventional Myosin \\
\hline 8 & Bak1 & Cassette exon & Pro-apoptotic \\
\hline 9 & Mripk1 & Cassette exon & Necroptotic \\
\hline 10 & Reck & Cassette exon & ECM Organization \\
\hline 11 & Itga8 & Cassette exon & ECM Organization \\
\hline 12 & Magi3 & Cassette exon & JUN Kinase Pathway \\
\hline 13 & Lrrcc1 & Alt 3'SS & Mitosis \\
\hline 14 & $R b / 1$ & Cassette exon & Cell Cycle \\
\hline 15 & Col4a1 & Cassette exon & Angiogenesis \\
\hline 16 & Snap23 & Cassette exon & Exocytosis \\
\hline 17 & Hps1 & Alt 5'SS & Melanosome Biogenesis \\
\hline 18 & Malt1 & Cassette exon & NF-kB Pathway \\
\hline
\end{tabular}

alternating splice site choice. This mode of regulation by Ptbp1 is rather unusual and is not well studied. To further understand the underlying molecular mechanism of this unique regulation by Ptbp1, we focused on Hps1, a gene frequently mutated in patients with Hermansky Pudlak Syndrome, and attempted to understand biological significance of its down-regulation in developing neurons.

\subsection{Ptbp1 regulates Hps1 mRNA expression by orchestrating the choice between alternative 5 ' splice sites}

Hps1 (Hermansky Pudlak Syndrome 1) has been previously identified to mediate the formation of early melanosomes as part of the biogenesis of 
lysosome-related organelle complex (BLOC) (Martina et al., 2003; Nazarian et al., 2003; Oh et al., 2000). Mutations in the human HPS1 gene have been linked to an autosomal recessive disorder that displayed characteristics of reduced pigmentation and prolonged bleeding (Dell'Angelica et al., 2000). Detailed analyses of Hps1 mRNA and EST sequences revealed the presence of two competing 5' splice sites (5'ss) near exon 18 (Fig. 3.1A). Usage of the upstream 5'ss (u5'ss) has been annotated as the RefSeq and known to generate a full-length, protein-encoding Hps1 transcript while a shift towards the downstream 5'ss (d5'ss) usage is predicted to generate an extended exon 18 sequence (18L) that harbors an in-frame PTC $96 \mathrm{nt}$ upstream of the exon-exon junction (Fig. 3.1A). To determine whether Ptbp1 regulates the choice of these 5'ss, we transfected CAD cells with siRNAs targeting Ptbp1 alone (siPtbp1), or Ptbp1 together with Ptbp2 (siPtbp1/2) in the presence of $\mathrm{CHX}$ or a control solution (DMSO). Our RT-PCR assay using primers binding to flanking exonic sequences was sensitive enough to detect the Hps1 constitutive isoform in siControl-treated CAD cells (Fig. 3.1B). Interestingly, upon Ptbp1 and Ptbp1/2 knockdown, we observed the emergence of a $130 \mathrm{nt}$ longer PCR product in addition to the constitutive form (Fig. 3.1B). Sequencing analysis of this amplicon confirmed that the downstream 5'ss (d5'ss) was utilized and resulted in an extended exon 18L configuration. To quantify the relative d5'ss usage, we normalized the density of the d5'ss band as a percentage of the total band densities for the particular lane (d5'ss-pecific "percentage spliced in" statistic, or $\Psi(\mathrm{d} 5$ 'ss)). We observed a 28 -fold increase in the usage of the d5'ss in siPtbp1-treated cells, and a further 10-fold 
A

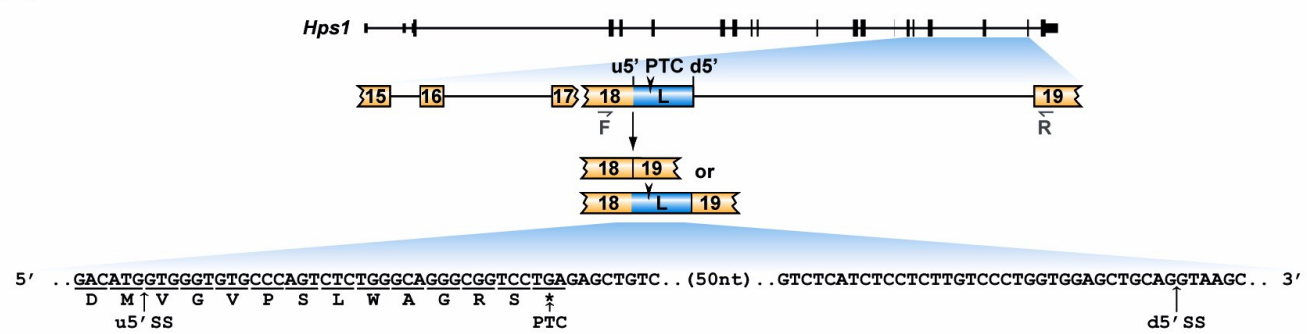

B

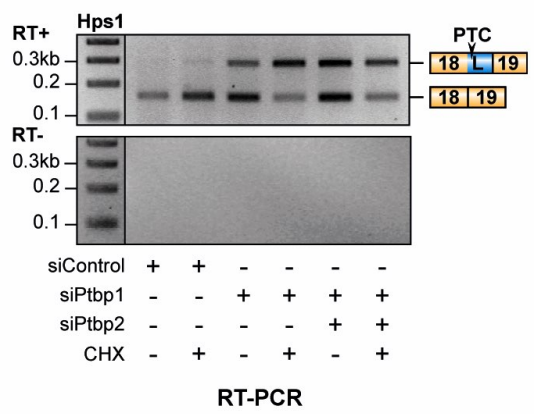

D

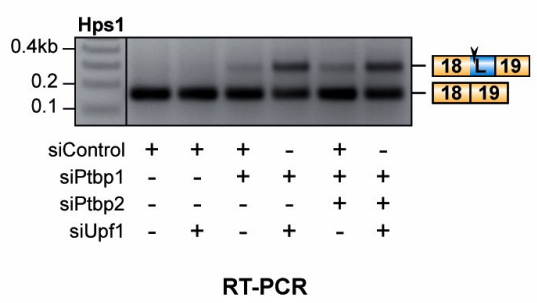

C

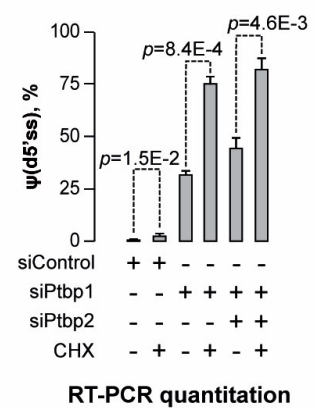

E

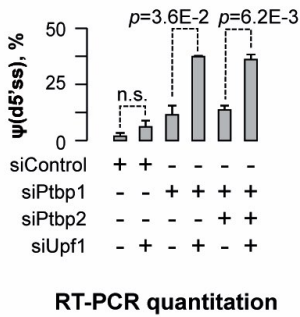

Figure 3.1 Ptbp1 regulates the alternate 5'ss choice on Hps1 mRNA. (A) Hps1 gene structure with a close-up of the exon 15-exon 19 segment. The arrowhead indicates premature termination codon (PTC) in the longer (L) isoform of exon 18 and the half-arrows underneath correspond to PCR primers used in this study. PTCcontaining sequence between the alternate u5'ss and d5'ss is shown at the bottom. (B) CAD cells transfected with siControl, siPtbp 1 or siPtbp $1 / 2$ were treated with cycloheximide ( $\mathrm{CHX}$ ) or DMSO (control) and the Hps1 splicing pattern was analyzed by RT-PCR with F1/R1 primers. Note that knock-down of Ptbp1 alone or together with Ptbp2 promote utilization of d5'ss and that the corresponding PTC-containing splice product is further stabilized by $\mathrm{CHX}$ treatment. (C) Relative utilization of the d5'ss quantified from (B). (D) A repeat of experiment (B) where $\mathrm{CHX}$ was replaced with siUpf1, also a potent inhibitor of NMD. (E) Relative utilization of the d5'ss quantified from (D). Data are averaged from at least three independent experiments \pm SD.

increase in siPtbp1/2-treated cells (Fig. 3.1B,C). In addition, the relative amount of d5'ss-spliced transcripts doubled in these samples upon treatment with $\mathrm{CHX}$ (Fig. 3.1B,C) $\left(p=8.4 \times 10^{-4}\right.$ and $p=4.63 \times 10^{-3}$ for siPtbp1- and siPtbp1/2-treated samples respectively). This indicated that the Hps1 18L transcripts might be regulated by NMD. To further demonstrate that the $18 \mathrm{~L}$-containing isoform is susceptible to NMD, we 
repeated the experiment by replacing $\mathrm{CHX}$ with an siRNA that targets Upf1, an indispensable component of the NMD pathway (Applequist et al., 1997). RT-PCR analysis confirmed the up-regulation of d5'ss-spliced isoform upon Upf1 knockdown, as seen from the significant increase in $\Psi$ (d5'ss) values in both siPtbp1- and siPtbp1/2-treated samples (fold increase $=3.27$ and 3.67 respectively; Fig. 3.1D,E). Overall, these results suggested that Ptbp1 regulates the choice of u5'ss and d5'ss of Hps1 exon 18, and that the d5'ss-spliced isoform is an NMD target.

To confirm that the Ptbp1-regulated splicing switch contributes to regulation of the Hps1 expression levels, we analyzed the above siRNAand CHX-treated CAD cells by RT-qPCR (Fig. 3.1A). As expected, Hps1 mRNA expression was down-regulated in siPtbp1- (1.75-fold; $\left.p=1.7 \times 10^{-3}\right)$ and siPtbp1/2-treated samples $\left(1.95\right.$-fold; $\left.p=2.5 \times 10^{-2}\right)$ (Fig. 3.2A). This dampening of Hps1 expression levels indicate that the Ptbp1-mediated switch in 5'ss usage modulates its cellular steady-state

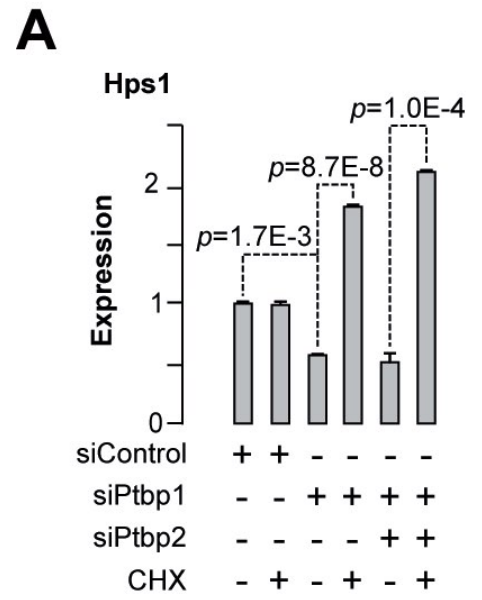

RT-qPCR
B

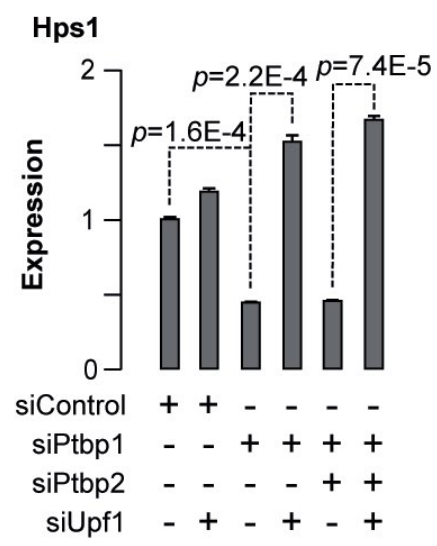

RT-qPCR

Figure 3.2 Ptbp1-mediated regulation of Hps1 splicing affects Hps1 mRNA expression. Quantification of Hps1 mRNA steady state levels in CAD cells pretreated with siPtbp1, siPtbp1+2 or siControl, together with $\mathrm{CHX}(\mathrm{A})$ or siUpf1 (B). Note that the switch to the d5'ss-utilized transcript in Ptbp1-knockdown samples results in a general down-regulation of Hps1 levels and that abolishing the NMD pathway rescues this effect. Data are averaged from at least three independent experiments $\pm S D$. 
levels. Moreover, treatment with $\mathrm{CHX}$ or siUpf1 led to a significant upregulation of Hps1 mRNA levels (3.22-fold, $p=8.7 \times 10^{-8}$ and 4.25 -fold, $1.0 \times 10^{-4}$ for siPtbp1- and siPtbp1/2-treated samples respectively; Fig. 3.2B). Taken together, these results validate Hps1 mRNA as a bona fide AS-NMD target regulated by Ptbp1 through differential utilization of alternative 5'ss's.

\subsection{Ptbp1-mediated regulation of Hps1 expression is evident at the protein level}

We then wondered whether the newly identified post-transcriptional mechanism regulated Hps1 expression at the protein level. Due to the lack of specific antibodies recognizing endogenous Hps1 protein, we decided to generate a CMV promoter-driven plasmid that expresses an EGFP ORF fused in-frame with the Ptbp1-dependent 3'-terminal segment of the Hps1 gene (Fig. 3.3A). To test whether this construct could recapitulate the endogenous AS-NMD regulation, we transfected siRNA-treated CAD cells with it. We firstly carried out an RT-PCR assay to check whether the fusion mRNA was alternatively spliced (Fig. 3.3A). Primer pair used for this reaction was designed to specifically amplify the EGFP-Hps1 fusion transcripts but not endogenous Hps1 mRNAs (see samples transfected with an EGFP control plasmid; Fig. 3.3A). Importantly, our RT-PCR analyses showed that, similar to the endogenous Hps1, the recombinant transcripts responded to Ptbp1 or Ptbp1/2 knockdown by increased utilization of the d5'ss (Fig. 3.3A). The expression levels of EGFP-Hps1 mRNA in these samples were concomitantly down-regulated, as validated by RT-qPCR quantification 
(Fig. 3.3B). This data confirmed that the EGFP-Hps1 expression vector is a suitable model for downstream studies.

Immunoblotting analysis of the EGFP-Hps1-transfected CAD cells using an EGFP-specific antibody showed a $50 \mathrm{kDa}$ fusion protein band that was absent in mock-transfected sample (Fig. 3.3C). More importantly,

A

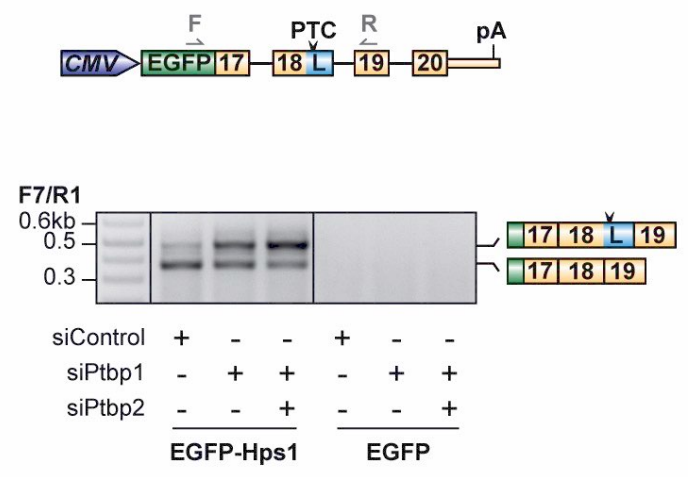

RT-PCR
B

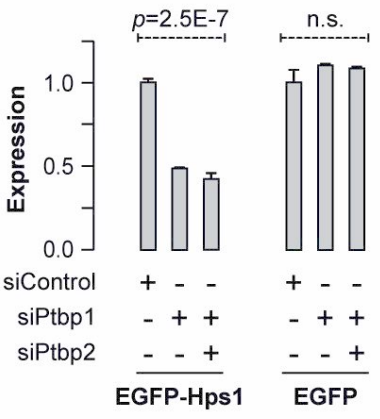

RT-qPCR
C

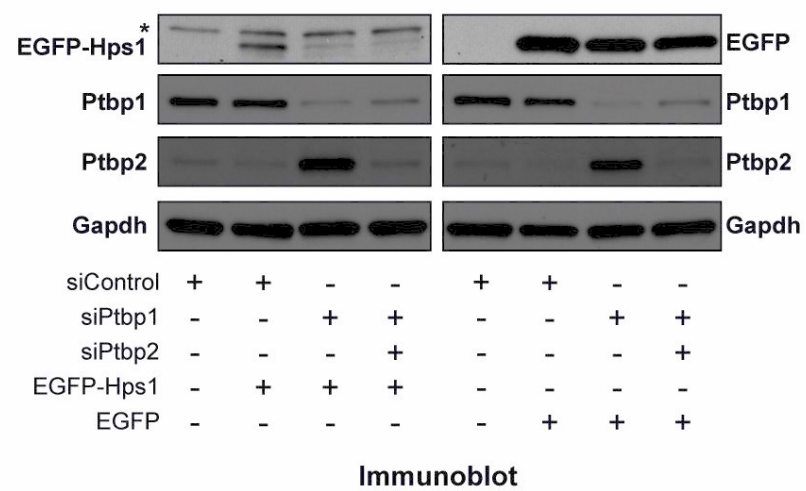

D

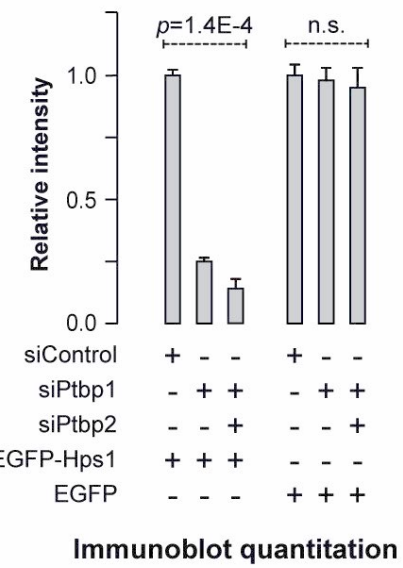

Figure 3.3 Ptbp1 regulates Hps1 expression at the protein level (A) Top, exon 17-20 segment of Hps1 was fused to an EGFP sequence driven by CMV promoter. Below, RT-PCR analysis on the alternative splicing of the EGFP-Hps1 fusion transcript showed two isoforms that differ in the 5'ss usage on Hps1 exon 18. (B) RTqPCR quantification of the fusion mRNA expression in (B) using primer pairs specific for the EGFP sequence. Note the Hps1 sequence-dependent down-regulation of the mRNA upon Ptbp1 or Ptbp1/2 knockdown. (C) Immunoblot analysis of EGFPcontaining proteins in CAD samples prepared as in (B). Ptbp1- and Ptbp2-specific antibodies were used to validate corresponding knockdown efficiencies, whereas Gapdh-specific antibody was used as a lane loading control. (D) Quantitation of the results in (C). Data are averaged from at least three independent experiments \pm SD. 
the expression of this EGFP-Hps1 protein product decreased upon knockdown of Ptbp1 or Ptbp1/2 by $\sim 4$ and $\sim 4.3$ fold, respectively (ANOVA $p=1.4 \times 10^{-4}$ ) (Fig. 3.3C,D). On the other hand, CAD cells expressing EGFP-only control constructs showed no change in the EGFP protein expression across all siRNA-treated samples (Fig. 3.3C,D). These results suggested that regulation of Hps 1 expression by AS-NMD is evident at both the RNA and protein level.

\subsection{Hps1 expression positively correlates with Ptbp1 levels in vivo}

Ptbp1 is expressed at relatively high levels in most mouse tissues but is noticeably down-regulated in the brain and heart, as validated by our RT-qPCR assay (Fig. 3.4A). We hypothesized that if Hps1 is indeed a target of Ptbp1-mediated AS-NMD regulation, its steady-state mRNA expression profile should positively correlate to that of Ptbp1. To test this, we measured the levels of endogenous Hps1 mRNA expression in a set of mouse tissues and compared it to Ptbp1 transcript levels (Fig. 3.4B-E). Our data showed that Hps1 expression was relatively high in most tissues except for adult brain and embryonic heart (Fig. 3.4B), where Ptbp1 was also found to be down-regulated. Importantly, we detected a striking positive correlation between Ptbp1 and Hps1 expression levels across all samples used in our analyses (Pearson's correlation coefficient $\rho=0.951, p=3.2 \times 10^{-16}$; Fig. 3.4B and Fig. 3.4D). RT-PCR analysis on Hps1 exon 18 splicing pattern in these tissues revealed the presence of the $d 5$ 'ss-spliced isoform exclusively in tissues expressing little Ptbp1 (Fig. 3.4C). This was consistent with our previous 
findings that a switch in Hps1 alternative splicing results in downregulation of Hps1 expression levels.

Ptbp2, the neuronal paralog of Ptbp1, is known to regulate alternative splicing of an overlapping set of genes (Keppetipola et al., 2012; Li et al., 2014; Licatalosi et al., 2012). In line with this functional similarity between the two Ptb proteins, our RT-PCR analysis of siRNA-treated CAD cells showed a slight increase in d5'ss-spliced transcript when levels of both Ptbp1 and Ptbp2 were dampened. Interestingly, however,

A

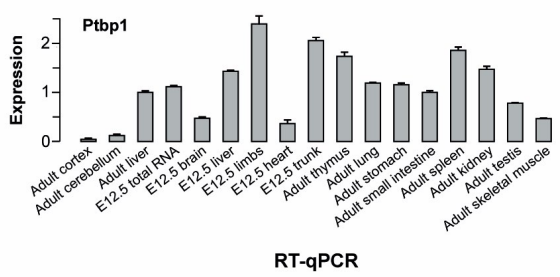

B

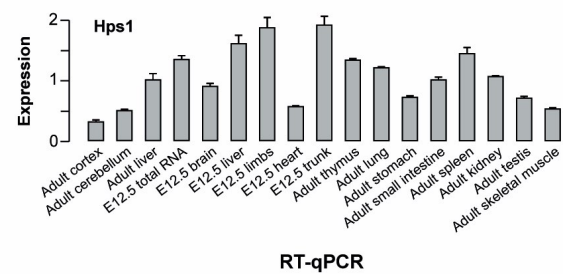

C

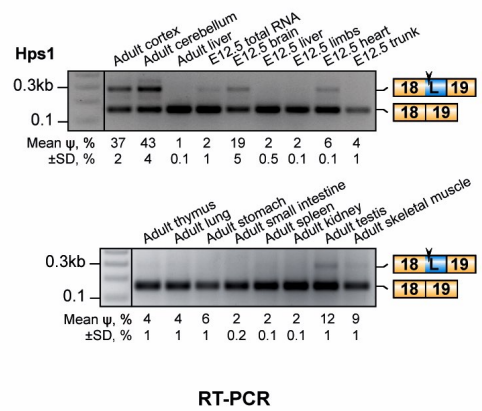

$\mathbf{F}$

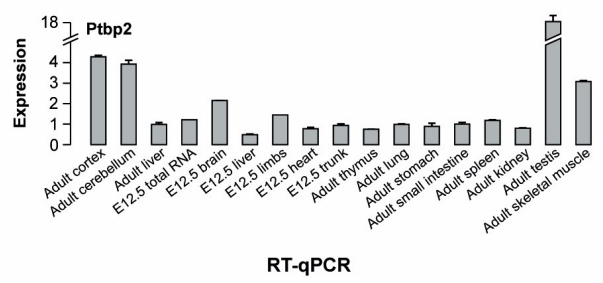

D

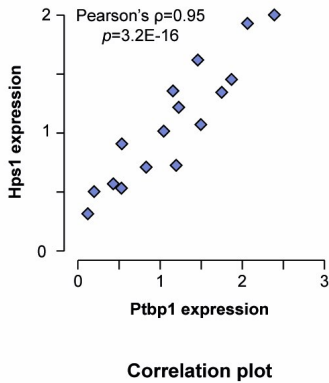

$\mathbf{E}$

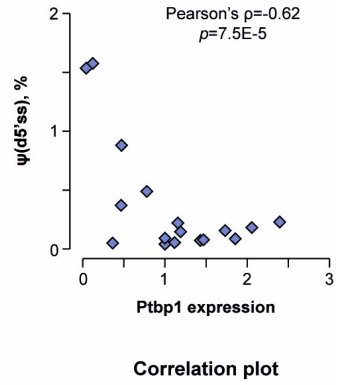

G

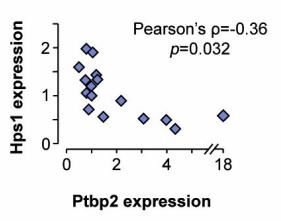

Correlation plot

Figure 3.4 Hps1 co-expresses with Ptbp1 in vivo (A) RT-qPCR analysis of Ptbp1 expression in embryonic (E12.5) and adult mouse tissues. Expression level in adult mouse liver is set to 1. (B) RT-qPCR quantitation of Hps1 mRNA expression levels in the same set of mouse tissues as in (A) averaged from three independent experiments $\pm S D$. (C) RT-PCR analysis of the Hps1 exon18-exon19 tissue-specific splicing patterns. Relative abundances of the d5'ss-spliced products [ $\Psi$ (d5'ss)] averaged from two independent experiments $\pm S D$ are indicated at the bottom. (D-E) Scatter plots showing significant positive correlation between Ptbp1 and Hps1 mRNA expressions and negative correlation between Ptbp1 expression and Hps1 $\Psi$ (d5'ss) values. (F) RT-qPCR quantification of Ptbp2 expression in the same sample set as (A). (G) Scatter plot showing a negative correlation between Ptbp2 and Hps1 mRNA expressions. 
steady-state expression of Ptbp2 was relatively low in most tissues (Fig. 3.4F), except for brain and muscle samples where Ptbp1 expression was low. In general, the expression level of Ptbp2 showed a week negative correlation with that of Hps1 (Fig. 3.4G; Pearson's $\rho=-0.36$, $p=3.2 \times 10-2$ ), suggesting that $\mathrm{Ptbp} 2$ does not play a major role in shaping Hps1 expression in vivo. Taken together, we conclude that Ptbp1 but not Ptbp2 regulate Hps1 abundance across mouse tissues.

\subsection{Polypyrimidine-rich sequences are necessary for Ptbp1- regulated choice between the u5'ss and the d5'ss}

To further understand the mechanism underlying the choice between alternative 5'ss's in exon 18, we constructed a minigene plasmid containing a segment of the Hps 1 gene from exon 18 to exon 19 under control of a doxycycline-inducible promoter [TRE-mini-1819; Fig. 3.5A]. This construct was transfected into CAD cells pre-treated with Ptbp1, Ptbp1/2 or control siRNAs, and splicing regulation was analyzed by RTPCR with minigene-specific primers. Satisfyingly, the minigene-derived transcripts were alternatively spliced producing both the u5'ss- and the d5'ss-specific isoforms, and the abundance of the latter isoform noticeably increased upon Ptbp1 or Ptbp1/2 knockdown (Fig. 3.5B). This indicated that the sequence between Hps1 exon 18 and exon 19 contained cis-elements responsible for Ptbp1-regulated alternative splicing. 
Ptbp1 is known to interact preferentially with polypyrimidine-rich motifs containing UCUC, UCUU, or UUCU tetranucleotide cores (Oberstrass et al., 2005). We examined sequences around Hps1 exon 18 and identified two polypyrimidine-rich tracts (Py1 and Py2) located between the two competing 5'ss's and comprising clustered tetranucleotide cores (Fig. 3.5A). To test whether these sequences were necessary for Ptbp1 regulation, we independently mutated them in the TRE-mini-1819 construct and analyzed splicing regulation of the mutant transcripts in siRNA-treated CAD cells. Our RT-PCR data suggested that mutation of either of these motifs was sufficient to completely abolish Ptbp1 regulation, as evident from the quantitative switch towards the d5'ss (Fig. 3.5B,C). Mutation of Py2 led to a somewhat more pronounced d5'ss bias, suggesting that this Py element played a more important role in the regulation (Fig. 3.5B,C). Overall, we concluded that polypyrimidine-rich sequences between the u5'ss and d5'ss were necessary for the Ptbp1 regulation.

A

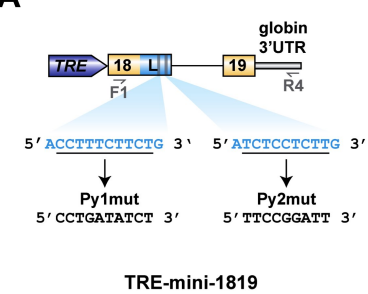

B

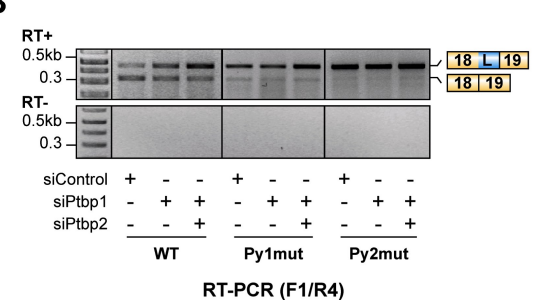

C

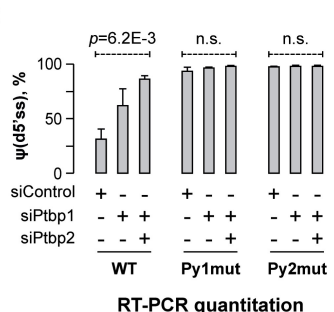

Figure 3.5 Ptbp1 binds to pyrimidine-rich sequences between u5'ss and d5'ss to regulate Hps1 5'ss usage. (A) Minigene construct encoding Hps1 exon 18-intron 18-exon 19 segment. Putative Ptbp1 binding motifs, Py1 and Py2, and their mutated versions are depicted below. (B) CAD cells treated with indicated siRNAs were transfected with either the wild-type (WT) TRE-mini-1819 construct or its Py1-mut or Py2-mut derivatives and analyzed by RT-PCR using F1/R4 primers. (C) Quantitation of the relative abundances of the d5'ss-spliced form $[\Psi(\mathrm{d} 5$ 'ss)] in (B) averaged from three independent experiments $\pm S D$. 


\subsection{Overexpression of Ptbp1 and, to a lesser extent, Ptbp2 promotes usage of Hps1 u5'ss}

As shown above, knockdown of Ptbp1 as well as both Ptbp1 and Ptbp2 in CAD cells biases Hps1 exon 18 splicing towards the d5'ss. To test whether the two Ptb proteins were sufficient for the regulation, we overexpressed equal amounts of FLAG-tagged versions of Ptbp1 and Ptbp2 in CAD cells and transfected the same cultures with either the WT Hps1 minigene or its Py-mutant derivatives (Fig. 3.6A). RT-PCR analyses on the splicing pattern of the WT minigene transcripts revealed a significant decrease in the abundance of the d5'ss-spliced transcript in Ptbp1-overexpressing samples (4.9-fold, $p=3.5 \times 10^{-3}$; Fig. 3.6B,C). Usage of the d5'ss also declined in samples overexpressing Ptbp2 but to a lesser extent compared to Ptbp1 overexpression (3.4-fold, $p=3.9 \times 10^{-2}$; Fig. 3.6B,C). This reduction in the utilization of the d5'ss of

A

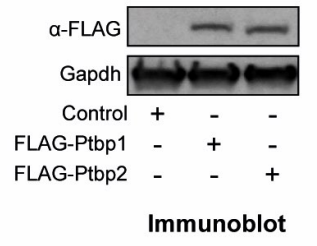

B

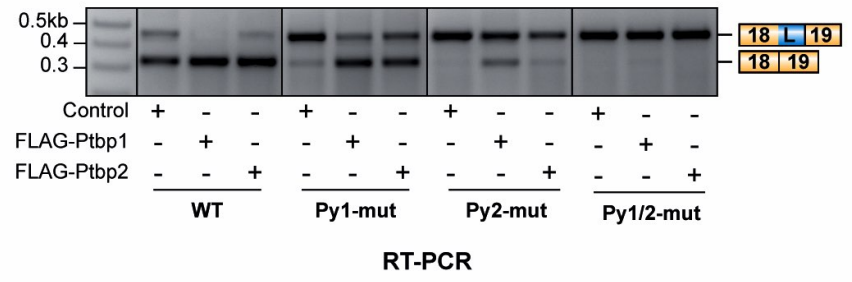

C

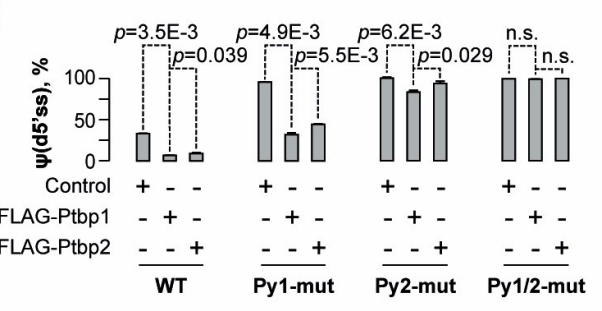

RT-PCR quantitation

Figure 3.6 Ptbp1 and, to a certain extent Ptbp2, overexpression stimulates u5'ss usage $(A)$ Immunoblot depicting the comparative amounts of FLAG-tagged Ptbp1 and Ptbp2 overexpressed in CAD cells. (B) Analysis of splicing pattern of minigene transcripts expressed from various forms of TRE-mini-1819 constructs cotransfected into samples in (A). Note the increase in the u5'ss-splice form abundance upon Ptbp1 overexpression. (C) Quantitation of the relative abundances of the d5'ssspliced form $[\Psi(\mathrm{d} 5$ 'ss $)]$ in $(B)$ averaged from three independent experiments $\pm S D$. 
Hps1 mRNA was also observed in cells transfected with Py-mutant versions of Hps1 minigene, although it was noticeably less drastic. Finally, overexpression of either of the two paralogs together with Hps1 minigene devoid of both Py stretches showed no change in splicing pattern as compared to control-treated samples. Taken together, these results suggested that Ptbp1 is sufficient to promote the usage of the u5'ss of Hps1 transcripts in a manner depending on the Py sequences and that Ptbp2 can contribute to this regulation to a lesser extent.

\subsection{Ptbp1 directly binds to Py1 and Py2}

To test whether Ptbp1 directly interacted with the polypyrimidine-rich sequences between the u5'ss and the d5'ss, we carried out a pull down assay using $\sim 100 \mathrm{nt}$ biotinylated RNA probes containing either the WT Hps1 sequence or its Py mutants. Probes were incubated with HeLa nuclear extract and the RNA-protein complexes were captured using streptavidin beads (Fig. 3.7A). Immunoblot assay, using antibodies specific to Ptbp1, showed that Ptbp1 readily interacted with WT Hps1

probe but bound Py1- and Py2-mutated probes less efficiently (Fig. 3.7B,C). The effect of Py2 mutation on Ptbp1 binding was especially pronounced, which was consistent with a stronger effect of this mutation on splicing regulation in our previous experiment (Fig. 3.5B). Thus, Ptbp1 directly binds to the polypyrimidine-rich sequences between the two alternative 5'ss of Hps1 exon 18. 
A

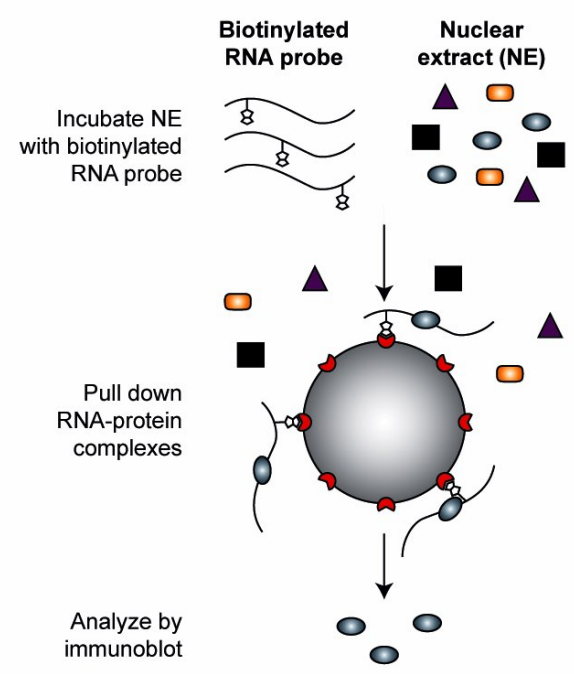

B

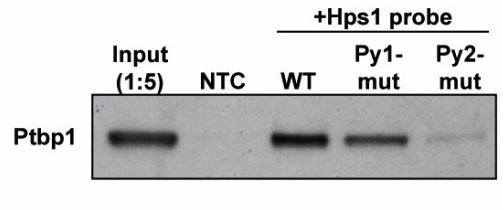

C

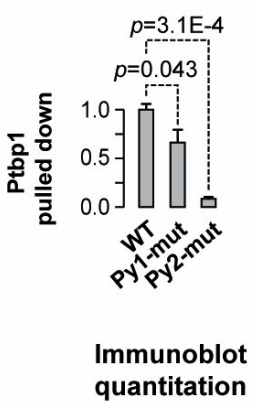

Figure 3.7 Ptbp1 directly binds to the polypyrimidine-rich sequences on Hps 1 (A) Ptbp1-RNA binding assay. Ptbp1(shown in gray ovals)-containing HeLa nuclear extract is incubated with biotin-labelled RNA and the Ptbp1-RNA complex is purified using streptavidin. (B) Immunoblot analysis showing readily detectable Ptbp1 interaction with the wild-type mini-1819 RNA, reduced interaction with the Py1-mut mini-1819 RNA and severely diminished interaction with the Py2-mut mini-1819 RNA. NTC is a no-template control. (C) Quantitation of the relative amount of Ptbp1 pulleddown from experiment in (B) averaged from two independent experiments.

\subsection{Ptbp1 directly regulates the choice between the u5'ss and the d5'ss}

To test whether Ptbp1 binding to polypyrimidine-rich motifs on Hps1 mRNA could directly regulate the 5'ss usage, we carried out an in vitro splicing assay using an in vitro transcribed Hps1 RNA substrate containing WT sequence corresponding to exon 18 , exon 19 and the intervening intronic sequence. This RNA substrate was incubated with HeLa nuclear extract under splicing conditions and the outcome of the reaction was analyzed by RT-PCR. Following a $60-$ min incubation, both Hps1 splice isoforms were detected (Fig. 3.8A,B). To test whether Ptbp1 is a direct regulator of AS in this system, we repeated the splicing assay using nuclear extract immunodepleted from the Ptbp1 protein and observed a distinct shift towards the d5'ss utilization (2.2-fold increase in $\Psi$ (d5'ss), $\left.p=5.2 \times 10^{-3}\right)$. We observed no change in the splicing efficiency 
of a control AdV RNA substrate, suggesting that the change in Hps1

splicing was not a result of changes in other splicing components.

We wondered whether Ptbp1 was sufficient for the change in Hps1 exon

18 splicing. To this end, we repeated the splicing assay using Ptbp1immunodepleted nuclear extract and supplemented the reaction with increasing amounts of recombinant PTBP1 (Fig. 3.8C,D). Satisfyingly, our RT-PCR analysis showed a gradual decrease in the relative amount of the d5'ss-spliced isoform as a function of PTBP1 concentration (Fig.

A

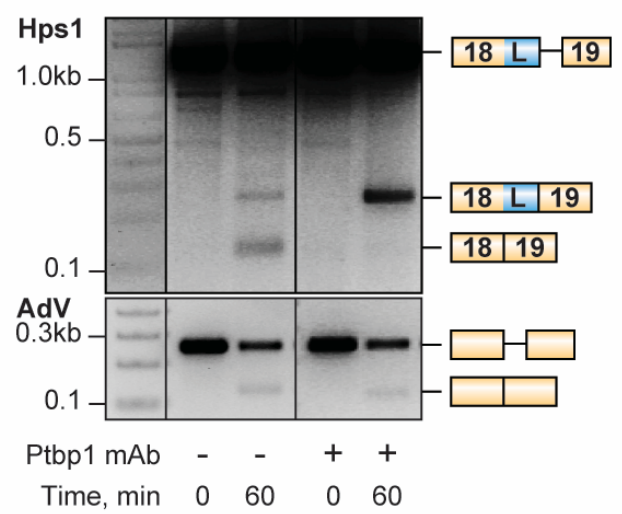

In vitro splicing/

RT-PCR

C

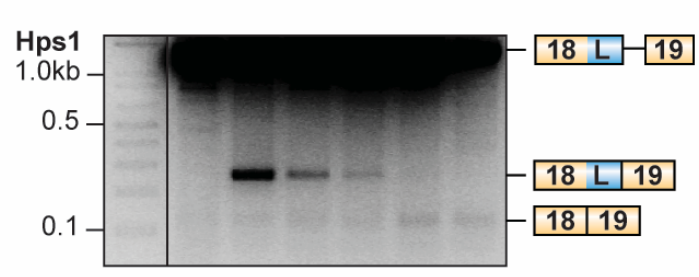

Ptbp1, $\mu$ g $\quad 0 \quad 0 \quad 0.250 .5 \quad 1.0 \quad 2.0$

Time, $\min \quad 0 \quad 60 \quad 60 \quad 60 \quad 60 \quad 60$

In vitro splicing/

RT-PCR
B

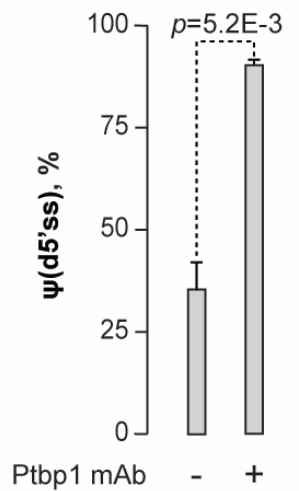

In vitro splicing/ RT-PCR quantitation

D

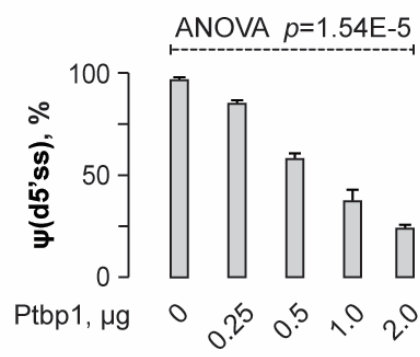

In vitro splicing/ RT-PCR quantitation

Figure 3.8 Ptbp1 directly regulates Hps1 alternative 5'ss usage (A) Splicing of the Hps1 or AdV RNA substrates was assayed in vitro using control-treated or Ptbp1immunodepleted NEs and the reaction products were analyzed using RT-PCR at the 0 - and 60-minute time points. (B) Quantitation of the results from (A) showing relative abundance of the $\mathrm{d} 5$ 'ss-spliced form $[\Psi(\mathrm{d} 5$ 'ss)] averaged from two independent experiments $\pm S D$. (C) Ptbp1-immunodepleted splicing reactions were supplemented with indicated amounts of purified recombinant Ptbp1 protein and the reaction products were analyzed as in (A). (D) Relative abundance of the d5'ss-spliced form $[\Psi(\mathrm{d} 5$ 'ss $)]$ in $(\mathrm{C})$ averaged from two independent experiments \pm SD. 
3.8C). Taken together, our results suggested that Ptbp1 directly regulates the choice between the two alternative 5'ss's in the Hps1 exon 18.

Our previous data indicated that contribution of Ptbp2 to Hps1 exon 18 splicing was relatively minor. To validate this conclusion, we repeated our in vitro splicing experiments using Ptbp1-immunodepleted nuclear extract and supplemented the reactions with increasing amounts of recombinant Ptbp2 (Fig. 3.9A-C). Using RT-PCR we detected a similar shift in the splicing of Hps1 RNA substrate only when Ptbp2 amounts exceed $1 \mu \mathrm{g}$ (Fig. 3.9B,C). In general, the shift towards u5'ss usage was significantly less pronounced in Ptbp2-supplemented reactions compared to reactions containing equal amounts of Ptbp1 (Fig. 3.9C). This supported our conclusion that Ptbp2 is a less efficient regulator of Hps1 alternative 5'ss usage.

A

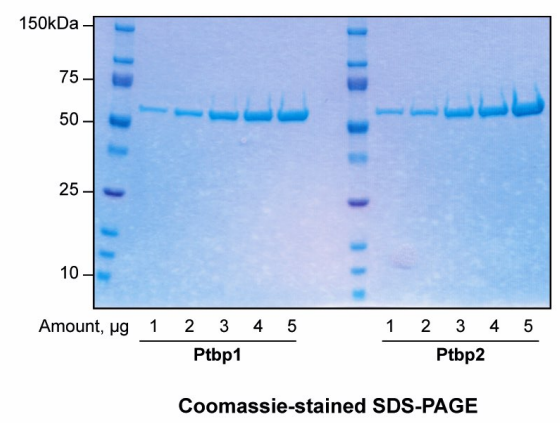

B

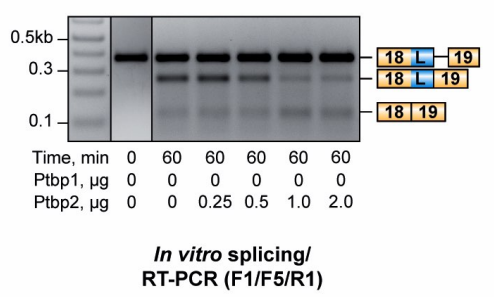

C

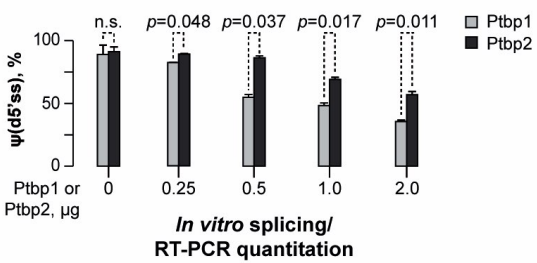

Figure 3.9 Ptbp2 contributes to a lesser extent to 5'ss usage on Hps1 (A) Coomassie staining on the absolute amounts of recombinant Ptbp1 and Ptbp2 proteins used in the experiment. (B) Ptbp1-immunodepleted splicing reactions were supplemented with indicated amounts of purified recombinant Ptbp2 protein and the reaction products were analyzed by RT-PCR. (D) Relative abundance of the d5'ssspliced form $[\Psi(d 5 ' s s)]$ in (B) averaged from two independent experiments $\pm S D$. 


\subsection{Ptbp1 activates the u5'ss}

Our data so far showed that an increase in Ptbp1 concentration biases the Hps1 exon 18 splicing towards the u5'ss while Ptbp1 knockdown promotes the d5'ss usage. Ptbp1 also binds to the Py sequences between the two competing splice sites. Since Ptbp1 has been previously shown to function in a position-dependent manner, it is equally plausible that Ptbp1 inhibits the d5'ss or activates the u5'ss in this context. To select between these two possibilities, we mutated the u5'ss and d5'ss sequences in the TRE-mini-1719 minigene (u5'ss-mut and d5'ss-mut respectively) and transfected these constructs into CAD cells pre-treated with siRNA against Ptbp1, Ptbp1/2 or control (Fig. 3.10A). We argued that the mutant minigene constructs can help us evaluate the effect of Ptbp1 on each 5'ss independently. The splicing reactions were analyzed using a multiplex RT-PCR assay containing a primer pair against the alternatively spliced part and another primer pair amplifying the 3'UTR region of the minigene and functioning as a 'normalizer' for the purpose of quantitation (Fig. 3.10A). Mutation of either of the two splice sites was sufficient to block its usage, as judged by complete disappearance of the corresponding RT-PCR band. Importantly, Ptbp1 knockdown showed no change in the splicing efficiency of the u5'ss-mut transcripts, but significant decreased the splicing efficiency of the d5'ss-mut transcripts (Fig. 3.10B,C). We also quantified the abundance of the u5'ss-spliced and d5'ss-spliced isoform in each sample using RT-qPCR with exon-specific primers (Fig. 3.10DF). This showed that in cells transfected with the d5'ss-mut construct, the relative amounts of u5'ss-spliced transcripts decreased upon Ptbp1 
A

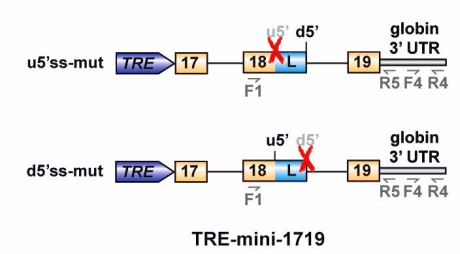

B

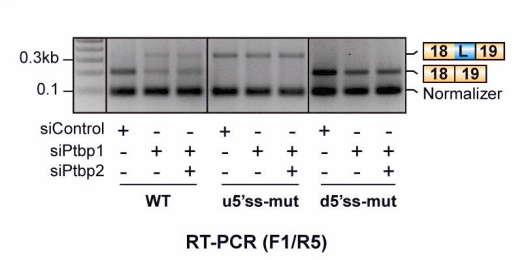

C

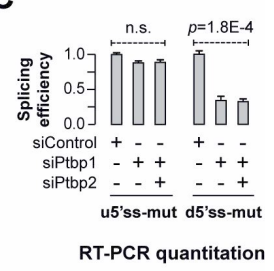

D

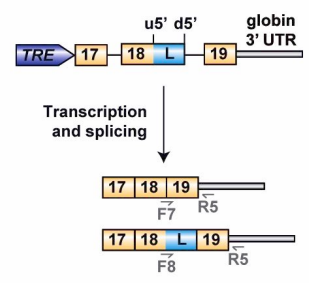

$\mathbf{E}$

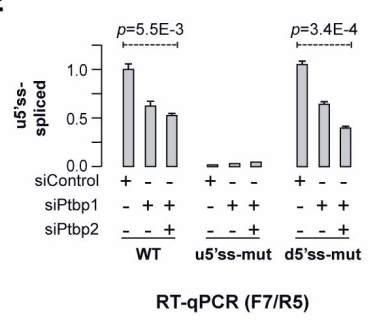

$\mathbf{F}$

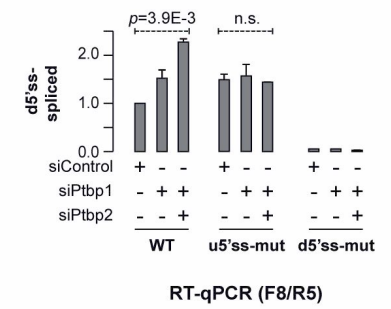

Figure 3.10 Ptbp1 activates the usage of Hps1 u5'ss (A) TRE-mini-1719 minigene constructs used in this experiment. Red crosses indicate mutational inactivation of the corresponding splice sites. (B) CAD cells treated with indicated siRNAs were transfected with either WT or mutated (u5'ss-mut or d5'ss-mut) TRE-mini-1719 constructs and analyzed by multiplex RT-PCR combining two primer pairs, F1/R5 and F4/R4, to detect the ratio between spliced and total minigene-specific transcript levels. (C) Relative splicing efficiencies of TRE-mini- 1719(u5'ss-mut) the TREmini-1719(d5'ss-mut) samples in (B) calculated as a ratio between spliced and total transcript abundance. Data are averaged from three independent experiments \pm SD. (D) Schematic diagram of the in vitro splicing assay and the junction specific primers used for relative quantification of the transcripts. (E-F) RT-qPCR quantitation on the amount of u5'ss-spliced (E) and d5'ss-spliced (F) products from experiment in (D).

knockdown (Fig. 3.10E) while no significant change in the amounts of d5'ss-spliced transcripts was observed in u5'ss-mut-transfected cells (Fig. 3.10E,F). The fact that only the intact u5'ss construct remained responsive to Ptbp1 expression suggested that Ptbp1 functions in this context as an activator of the u5'ss rather than a repressor of d5'ss.

To further validate this model, we carried out an in vitro splicing reaction using the d5'ss-mut Hps1 RNA as a substrate (Fig. 3.11A). Products of the reaction was analyzed using a multiplex PCR reaction that detects the unspliced RNA (F5/R1) or the spliced species (F1/R1). As expected, the u5'ss form was the only splice product detectable in this reaction mixture after 60 min of incubation with HeLa nuclear extract (Fig. 
3.11B,C). Similar to the situation in vivo, the amount of the spliced product decreased 9.5 -folds ( $p=1.1 \times 10^{-6}$; Fig. 3.11B) upon depletion of Ptbp1 protein from the nuclear extract. Importantly, we observed a modest but significant rescue of the Hps1 d5'ss-mut splicing efficiency when increasing amounts of recombinant Ptbp1 were added to the Ptbp1-immunodepleted mixtures (Fig. 3.11D,E). To further confirm our conclusions, we quantified the relative amounts of unspliced and spliced products in each reaction using RT-qPCR (Fig. 3.11F-J). Using two independent primer pairs to detect the unspliced RNA (F1/R6 and F9/ R1), we showed that the amounts of the unspliced substrate increased in Ptbp1-immunodepleted reactions (Fig. 3.11G). On the other hand, the amounts of the spliced product decreased in Ptbp1-depleted reactions and increased when the Ptbp1 levels were restored by the addition of

A

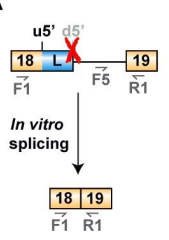

$\mathbf{F}$

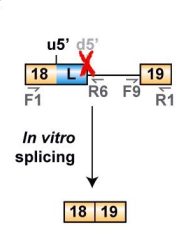

B

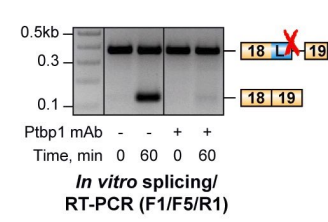

G

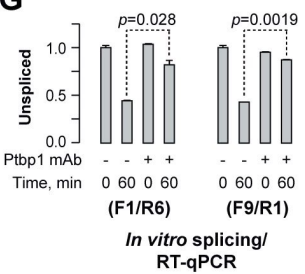

C

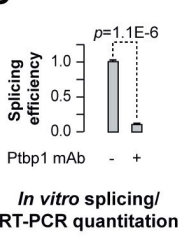

H

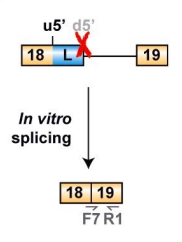

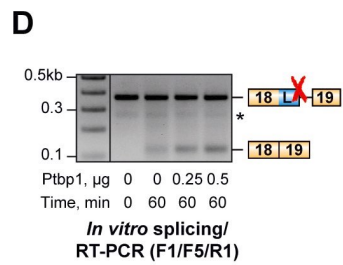

E

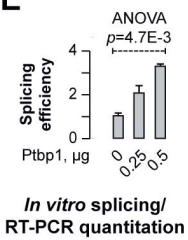

I

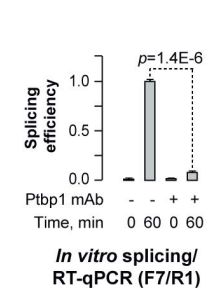

$\mathbf{J}$

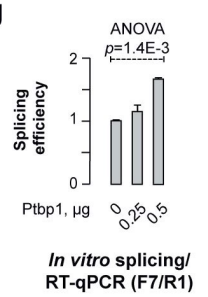

Figure 3.11 Ptbp1 directly activates the usage of Hps1 u5'ss (A-E) Splicing of mini-1819(d5'ss-mut) RNA was assayed in the presence of control-treated or Ptbp1immunodepleted NE and the reaction products were analyzed by multiplex RT-PCR. (C) Quantitation of the results from (B), represented as average splicing efficiency from two independent experiments, $\pm S D$. (C) Ptbp1-immunodepleted reactions were rescued with increasing concentration of recombinant $P$ tbp1 protein and analyzed by RT-PCR. (E) Quantitation of the results from (D), represented as splicing efficiency averaged from two independent experiments, $\pm S D$. $(F, G)$ Relative amounts of unspliced product from in vitro reaction were quantified using RT-qPCR using two primer pair sets. $(H)$ Relative amounts of spliced product from in vitro splicing assay quantified using primer pair F7/R1.(I) RT-qPCR quantitation of amount of spliced product from experiment in (B). (J) RT-qPCR quantitation of amount of spliced product from experiment in (D). Data are representative as an average of two independent experiments, \pm SD. 
recombinant Ptbp1 (Fig. 3.11H-J). Taken together, our in vivo and in vitro data strongly suggest that Ptbp1 functions as a splicing activator stimulating the usage of the Hps1 exon 18 u5'ss.

\subsection{Inherent difference between the u5'ss and the d5'ss strengths is important for the regulation}

We further inspected the u5'ss and the d5'ss sequences and noticed that the d5'ss bears a closer resemblance to the consensus 5'ss sequence and therefore might interact with U1 snRNP more efficiently than the u5'ss. Indeed, the predicted splicing strength of u5'ss was lower than that of d5'ss (score $S_{u 5}$ 'ss $=76.1, S_{d 5}$ ss $=94.1$; Analyzer Splice Tool server http://ibis.tau.ac.il/ssat/ SpliceSiteFrame.htm). This might suggest that Ptbp1 functions in this system as an activator of a weak 5'ss, evocative of the earlier published mechanism regulated by the splicing activator Tia-1 (Forch et al., 2000; Forch and Valcarcel, 2001). To test

A

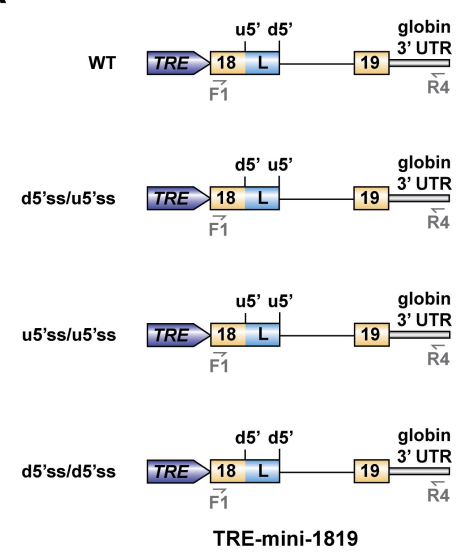

B

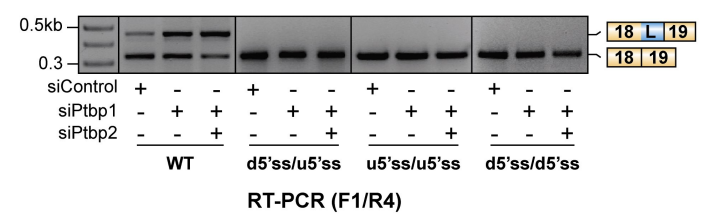

C

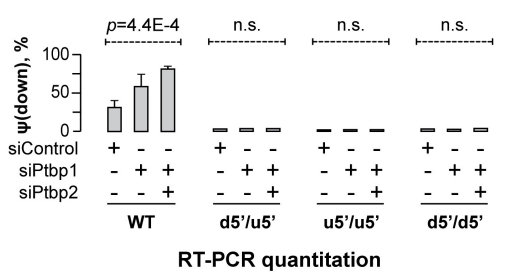

Figure 3.12 Hps1 regulation depends on u5'ss being weaker than d5'ss (I). (A) TRE-mini-1819 minigenes containing either a wild-type (top) or a permuted arrangement of the two 5'ss. (B) CAD cells pre-treated with indicated siRNAs were transfected with the TRE-mini-1819 constructs introduced in (A) and analyzed by RTPCR using minigene-specific primers F1/R4. Note that the upstream 5 ' splice position is constitutively used in all permuted minigene samples. (C) Utilization of the topologically downstream 5 ' splice site $[\Psi($ down)] in $(B)$ averaged from three independent experiments $\pm \mathrm{SD}$. 
whether this difference in the 5'ss strengths contributed to the regulation, we generated mutant TRE-mini-1819 constructs where the u5'ss and the d5'ss sequences were swapped (d5'ss/u5'ss), or constructs where both splice sites had the u5'ss (u5'ss/u5'ss) or the d5'ss (d5'ss/d5'ss) sequences (Fig. 3.12A). Plasmids were transfected into siPtbp1-, siPtbp1/2- or siControl-treated CAD cells and RT-PCR was carried out to determine the minigene-specific splicing patterns (Fig. 3.12B,C). Interestingly, our results showed that all the mutant transcripts failed to undergo alternative splicing in response to Ptbp1 changes, as obvious from the complete disappearance of the d5'ss-spliced isoform (Fig. 3.12B). This data might suggest that, in order for Ptbp1 to regulate the splice site usage, the u5'ss sequence on Hps1 has to be relatively weaker than the d5'ss. If this criterion is not met, the splicing machinery will favor the u5'ss regardless of the Ptbp1 concentration.

A

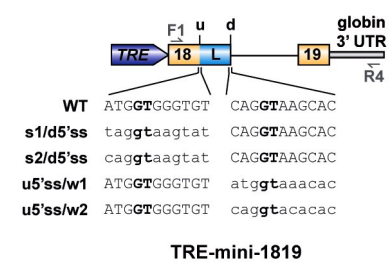

B

\begin{tabular}{cc}
\multicolumn{2}{c}{ Predicted 5'ss strengths } \\
\hline 5'ss & $\begin{array}{c}\text { Predicted } \\
\text { strength }\end{array}$ \\
\hline Hps1 WT u5'ss & 76.12 \\
Hps1 WT d5'ss & 94.14 \\
s1 & 95.54 \\
s2 & 100.0 \\
w1 & 73.51 \\
w2 & 71.53 \\
\hline
\end{tabular}

C

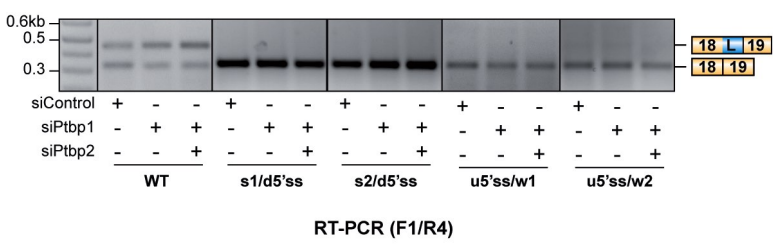

D

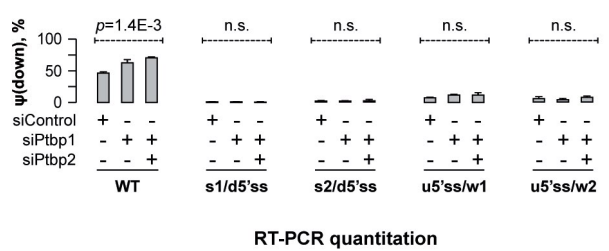

Figure 3.13 Hps1 regulation depends on u5'ss being weaker than d5'ss (II). (A) u5'ss and d5'ss strengths on TRE-mini-1819 minigenes were strengthen ( $\mathrm{s} 1$ and $\mathrm{s} 2$ ) or weaken ( $w 1$ and $w 2$ ) respectively. (B) Predicted binding strengths of the wild-type or mutant splice sites to U1 snRNA. A value of 100 represent highest predicted binding affinity. (C) RT-PCR analysis on the minigene splicing pattern in CAD cells pre-treated with siPtbp1, siPtbp1+2 or siControl. Note the complete de-regulation of Ptbp1 splicing regulation in all mutant transcripts. (D) Quantitation of results in (C) measuring the utilization of downstream 5' splice site $[\Psi($ down $)]$ in (C) averaged from three independent experiments $\pm S D$. 
To further test this model, we generated more constructs where we improved the strength of u5'ss sequence or weaken the d5'ss strength and repeated the experiment (Fig. 3.13A-D). Similar to the above results, changing the difference in strengths between the u5'ss and d5'ss deregulated Ptbp1-mediated alternative splicing (Fig. 3.13C,D). Taken together, these experiments argued that the regulation of the 5'ss choice in Hps1 exon 18 relies on the inherent difference between the u5'ss and the d5'ss strengths.

\subsection{Ptbp1 down-regulation alters the lysosomal compartment in a Hps1-dependent manner}

Hps1 protein is known to participate in the biogenesis of lysosomerelated organelles (Martina et al., 2003). To understand the functional significance of the natural decline in the Ptbp1 and the Hps1 levels in developing neurons, we examined the effect of Ptbp1 down-regulation on the CAD cell lysosomes. Our immunoblot analyses of siPtbp1-, siPtbp $1 / 2$ and siControl-treated cells showed no change in the expression of the lysosomal marker Lamp1 across these samples (Fig. 3.14C). We then carried out immunofluorescence staining of siRNAtreated CAD cells with antibodies against Lamp1 to identify possible changes in the Lamp1-positive compartment (Fig. 3.14A,B). Interestingly, the average apparent densities of lysosomes increased from 6 particles $/ 10 \mu \mathrm{m}^{2}$ in siControl cells to 8.9 particles $/ 10 \mu \mathrm{m}^{2}$ $\left(p=8.3 \times 10^{-11}\right)$ and 8.3 particles $/ 10 \mu m^{2}\left(p=1.42 \times 10^{-6}\right)$ in siPtbp1 and siPtbp $1 / 2$ cells, respectively (Fig. 3.14A,E). The median size of each lysosomal particle increased from $0.076 \mu \mathrm{m}^{2}$ in siControl cells to 0.096 $\mu \mathrm{m}^{2}$ and $0.097 \mu \mathrm{m}^{2}$ in the siPtbp1- and Ptbp1/2-knockdown cells 
A

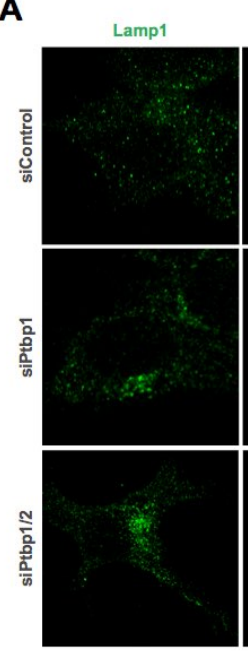

C

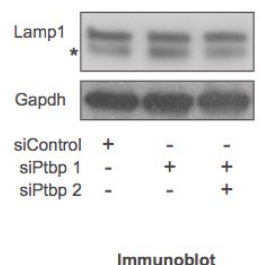

$\mathbf{F}$

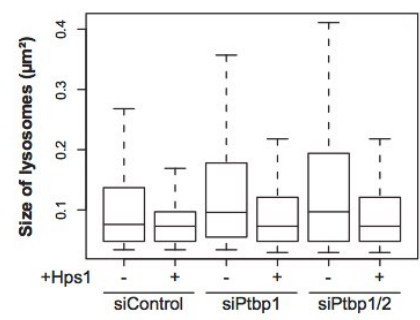

B

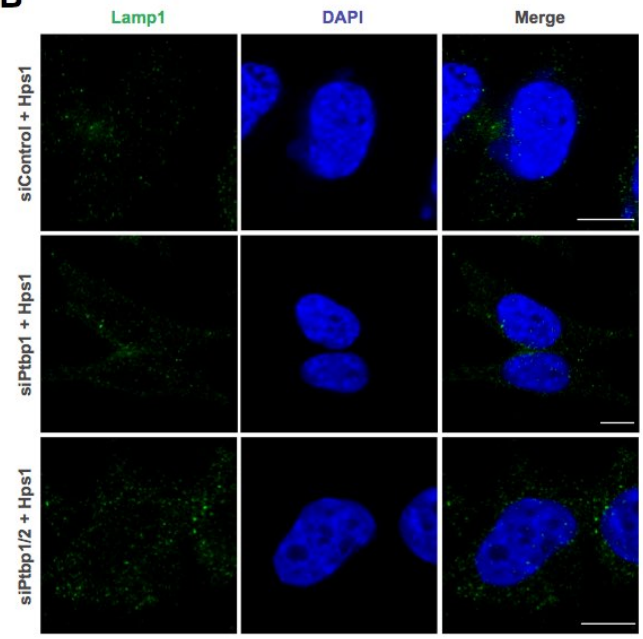

E
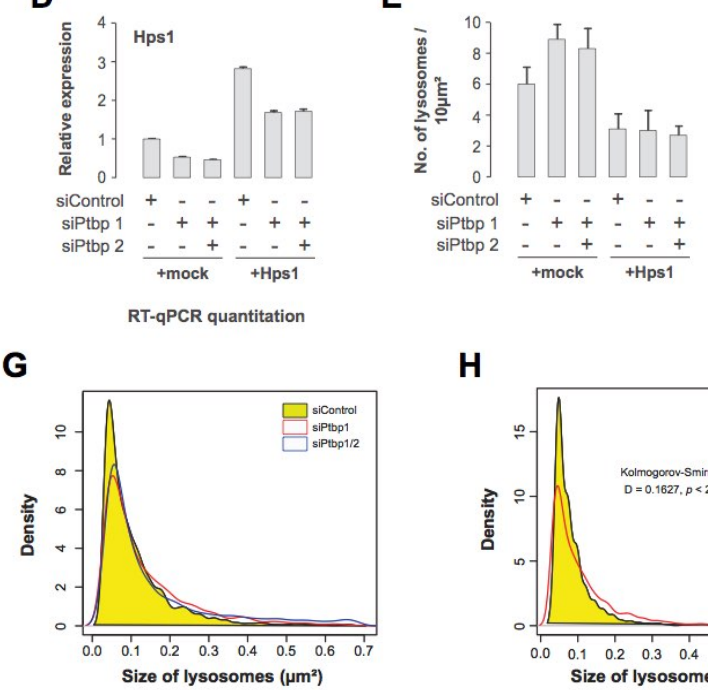

H

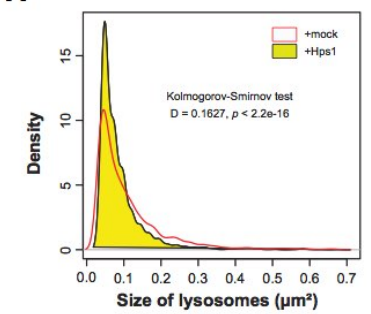

Figure 3.14 Ptbp1 knockdown of CAD cells results in changes in lysosomal characteristics. $(A, B)$ Indirect Immunofluorescence staining of CAD cells, imaged

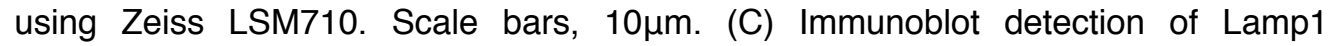
expression in CAD cells. Asterisk $\left(^{*}\right)$ denotes unspecific bands. (D) Quantification of Hps1 mRNA expression in CAD cells. Expression levels were normalized against Gapdh mRNA levels and expression of siControl sample was set to 1. (E) Quantification of the number of lysosomes per $10 \mu \mathrm{m}^{2}$ area in the indicated samples. (F) Boxplot representation of the distribution of the size of lysosomes in the various samples. (G) Density plot of the distribution of the lysosomal sizes in siControl, siPtbp1 and siPtbp 1/2 treated CAD cells. $(\mathrm{H})$ Density plot of the distribution of lysosomal sizes in siControl cells, with or without overexpression of Hps1.

$(n=3000)$ (Fig. 3.14F). Distributional analysis of these data showed a broader distribution of the lysosome sizes in siPtbp1 and siPtbp1/2 CAD cells, with a greater skew towards larger sized lysosomes (Fig. 3.14G). Finally, we also observed a pronounced clustering of the lysosomes close to the perinuclear region in siPtbp1 and siPtbp1/2 cells (Fig. 
3.14A). Taken together, our results suggest that the developmental knockdown of Ptbp1 may dramatically alter the lysosomal compartment.

To check whether the changes in the lysosome characteristics were at least in part due to Hps1 down-regulation, we overexpressed Hps1 in the siRNA-treated CAD cells and repeated the above analyses (Fig. 3.14B). RT-qPCR assay confirmed that the overall Hps1 mRNA expression increased by three-fold in the Hps1 overexpressing samples (Fig. 3.14D). Interestingly, we observed a reduction in the density and size of the lysosomes upon Hps1 overexpression (Fig. 3.14E,F). On average, the amount of lysosomes reduced to 3 particles $/ 10 \mu \mathrm{m}^{2}$ in these cells, and the median area of the lysosomes was $0.073 \mu \mathrm{m}^{2}$. More importantly, the distribution of the lysosome sizes was significantly narrower in Hps1-overexpressed cells (Fig. 3.14H). By comparing the size distribution of lysosomes between mock-treated and Hps1 overexpressed siControl cells, we observed a slightly higher amounts of lysosomes $\left(>0.1 \mu \mathrm{m}^{2}\right.$ in size) in mock-treated cells (Fig. 3.14H). Finally, we observed a less apparent clustering of lysosomes near the perinuclear region in Hps1-overexpressed cells (Fig. 3.14B). Taken together, these results indicated that down-regulation of the Hps1 levels as a result of diminished Ptbp1 expression may affect the morphology and possibly the function of the lysosomal compartment in developing neurons. 


\subsection{Ptbp1 regulates a number of other alternative 5'ss and 3'ss events}

So far, our data showed that Ptbp1 binding to cis-elements between two competing splice sites of dissimilar 'strengths' on Hps1 mRNA favor the usage of the u5'ss. To find out whether this type of regulation affected other transcripts, we searched for other examples of Ptbp1-dependent alternative 5'ss and 3'ss choice using a simple, Fisher's exact testbased bioinformatics pipeline (Fig. 3.15A-C). We began by testing functionality of this approach by comparing RNA-seq datasets from untreated CAD cells and L929 fibrosarcoma cells and validating the newly identified events using RT-PCR (Fig. 3.16A). Then, we repeated the analysis using RNA-seq datasets obtained for CAD cells transfected with control siRNA, Ptbp1-specific siRNAs or both Ptbp1- and Ptbp2specific siRNAs. The pipeline identified 41 alternative 5'ss events and 52 alternative 3'ss events significantly regulated in both siPtbp1 and

A

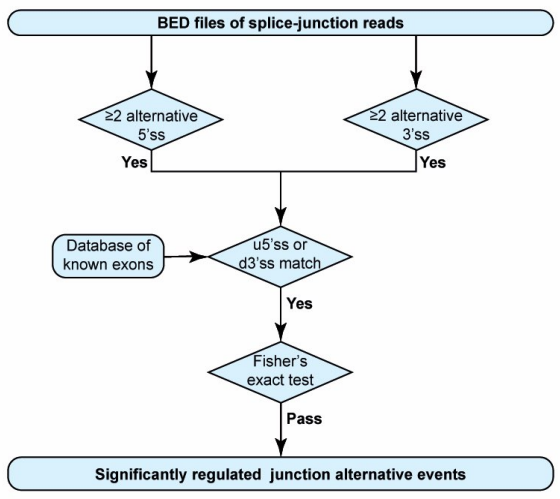

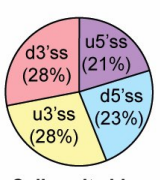

Splice site bias

C

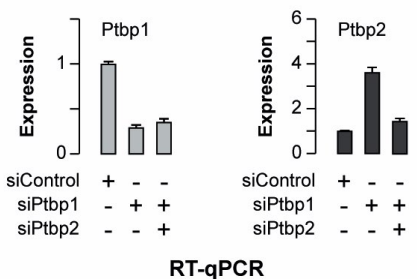

Figure 3.15 Ptbp1 regulates a class of 5'ss and 3'ss events (I). (A) Data analysis workflow used to identify regulated alternative 5'ss and 3'ss junctions. (B) Summary of newly identified events regulated by Ptbp1. The pie chart on the left classifies A5C and $A 3 C$ events based on whether Ptbp1 and Ptbp2 bias the AS choice towards upstream or downstream splice site alternative. The other two pie charts categorize $A 5 C$ and $A 3 C$ events according to their effect on mRNA function. (C) CAD cells were treated with Ptbp1-specific siRNA (siPtbp1), a mixture of siPtbp1 and Ptbp2-specific siRNA (siPtbp2) or control siRNA (siControl) and the expression levels of Ptbp1 and Ptbp2 mRNAs were analyzed by RT-qPCR. Data are averaged from 3 independent experiments \pm SD. 
siPtbp $1 / 2$ samples (Fisher's exact test $p<0.05$ and $5 \%$ difference in the percent spliced in statistic ( $\Psi)$; Fig. 3.15B, Appendix 3,4). Some of these events were confirmed using RT-PCR analysis (Fig. 3.16B). Of note, in $48 \%$ of the 5'ss events (including Hps1) Ptbp1 favored the usage of the u5'ss.

To test whether the newly uncovered alternative 5'ss events featured pyrimidine-rich sequences between a weak u5'ss and a strong d5'ss, we measured density of putative Ptbp1-binding tetramers (UCUC, UCUU, UUCU, CUCU) between u5'ss and d5'ss in three classes of alternative 5' events; (1) biased towards u5'ss in the presence of Ptbp1, (2) biased towards the d5'ss in the presence of Ptbp1 and (3) 100 randomly selected Ptbp1-independent events (Fig. 3.17A). Our analysis showed

A
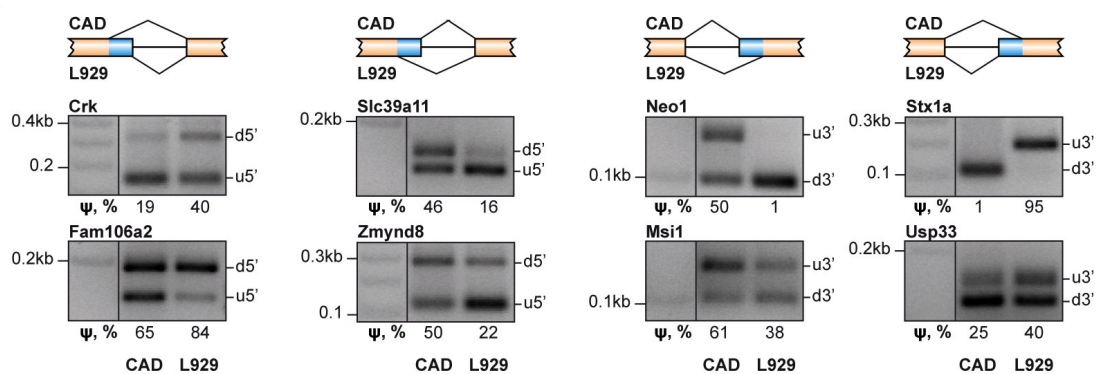

RT-PCR

B

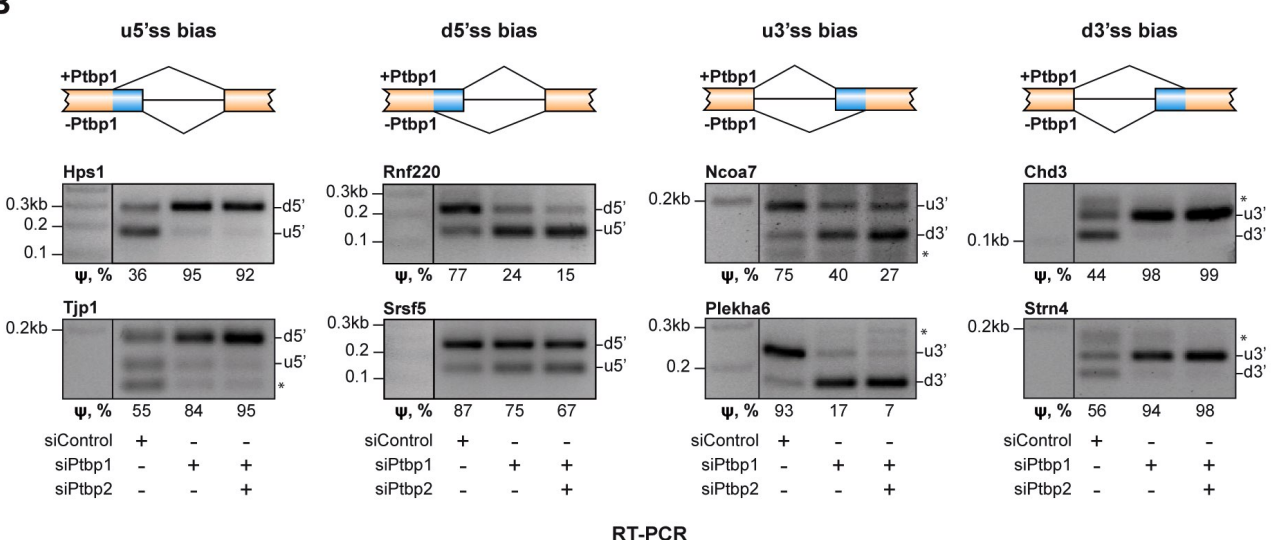

Figure 3.16 Ptbp1 regulates a class of 5'ss and 3'ss events (II). RT-PCR validation of examples of the four splicing topologies (Ptbp1-biased choice of u59ss, d59ss, u39ss or d39ss) in (A) training set of wild-type CAD and L929 samples or (B) CAD samples treated with siRNAs. $\Psi$ (percent spliced in) values shown at the bottom indicate the abundance of the longer splice product isoform as percentage of the total. Data are averaged from 3 independent analyses. 
that the incidence of Ptbp1 motifs was significantly higher in the class-1 events compared to the class-3 control (KS test, $p=0.0041$ ) whereas the class 2 events did not significantly differ from the control (KS test, $p$ $=0.25)$. In addition, when we calculated the differences between predicted 5'ss strengths for each class of events, the distribution of this difference $(\Delta S=S(d 5$ 'ss-du5'ss) $)$ showed a significant positive bias for the class-1 (Wilcoxon rank sum test, $p=0.044$ ) but not for the class-2 events (Wilcoxon rank sum test, $p=0.51$ ) (Fig. 3.17B). Therefore, we concluded that the molecular mechanism underlying Hps1 regulation might be common amongst alternative 5' splicing events with Ptbp1induced u5'ss bias.

A

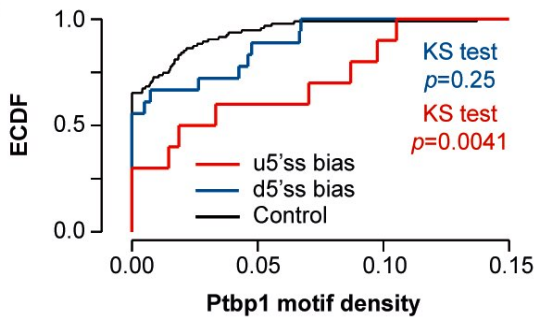

B

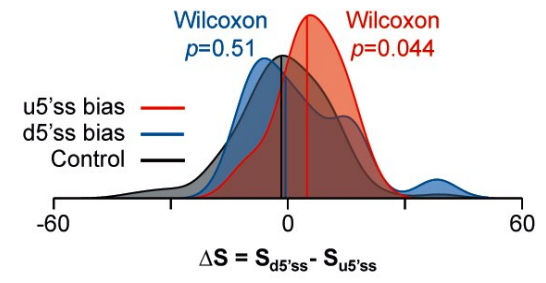

Figure 3.17 Hps1-like regulation of 5'ss usage may recur in other genes. (A) Empirical cumulative distribution function (ECDF) plot of Ptbp1 motif density within exon segments demarcated by the two 5'ss alternatives in A5C genes. (B) Density plot of the difference between d5'ss and u5'ss strengths. Median values are shown by vertical colored lines.

\subsection{Ptbp1 activates inclusion of a subset of cassette exons}

The above data are consistent with earlier observations suggesting that Ptbp1 can function as either repressor or activator of alternative splicing depending on the context. Molecular mechanisms underlying repressive functions of Ptbp1 have been understood relatively well. However, how Ptbp1 can promote utilization of alternative features remains unknown. 
To address this problem, we turned to a relatively simple model, genes containing Ptbp1-activated cassette exons. We argued that this would allow us to study Ptbp1 effects in the presence of a single 5'ss rather than two competing 5'ss's occurring in the Hps1 pre-mRNA. To identify Ptbp1-activated cassette exons systematically, we mined our RNA-seq datasets collected for CAD cells treated with siPtbp1, siPtbp1/2 or siControl. Exons that were consistently and significantly $(p<0.05)$ skipped in both siPtbp1 and siPtbp1/2 samples were tested for their predicted 5'ss 'strengths' as well as examined for the presence of putative polypyrimidine-rich tracts downstream of the exon. In total, we uncovered 13 genes that contain a Ptbp1-activated exon which is consistently down-regulated in siPtbp1 and siPtbp1/2 samples (Table. 2). Some of these exons (Ktn1, Snap25) have been previously investigated by other groups (Llorian et al., 2010). Amongst novel Ptbp1 targets, we focused on Deltex2 (Dtx2) an E3 ubiquitin ligase and a Table 2. List of genes containing Ptbp1-activated cassette exons

\begin{tabular}{clll}
\hline S/N & Gene Identifier & Ptbp1-regulated exon \# & $\begin{array}{l}\text { Chromosomal location } \\
\text { (July2007/mm9) }\end{array}$ \\
\hline 1 & App & Exon 8 & chr16:85,040,436-85,040,612 \\
\hline 2 & Atp6v1h & Exon 7 & chr1:5,091,150-5,091,205 \\
\hline 3 & Cadm1 & Exon 8 & chr9:47,625,817-47,626,900 \\
\hline 4 & Dtx2 & Exon 6 & chr5:136,502,340-136,502,478 \\
\hline 5 & Eml4 & Exon 4 & chr17:83,824,598-83,824,772 \\
\hline 6 & Flnc & Exon 31 & chr6:29,402,824-29,402,873 \\
\hline 7 & Ktn1 & Exon 38 & chr14:48,346,146-48,346,230 \\
8 & Nap1/1 & Exon 4 & chr10:110,923,700-110,923,803 \\
\hline 9 & Ndufv3 & Exon 3 & chr17:31,664,249-31,665,354 \\
\hline 10 & Pkm2 & Exon 9 & chr9:59,523,377-59,523,544 \\
\hline 11 & Snap25 & Exon 5 & chr2:136,595,479-136,595,598 \\
\hline 12 & Tpd52/2 & Exon 4 & chr2:48,346,146-48,346,230 \\
\hline 13 & Tpm1 & Exon 5 & chr9:66,880,273-66,880,349 \\
\hline & & &
\end{tabular}


regulatory component of the Notch signaling pathway (Kishi et al., 2001; Takeyama et al., 2003). Alternative splicing of its exon 6 (Dtxe6) was predicted to delete several proline-rich motifs, which are important for protein-protein interaction (Kishi et al., 2001).

\subsection{Inclusion of Dtx2e6 positively correlates with Ptbp1 expression}

To validate the nature of Dtx2e6 as a Ptbp1-regualted exon, we carried out RNAi knockdown experiment in CAD cells using control, Ptbp1- or both Ptbp1- and Ptbp2-specific siRNAs. RT-PCR analysis of Dtx2 splicing patterns using primers against constitutive exons flanking e6 showed that this alternative exon was efficiently included into the mRNA in control-treated samples $\left(\Psi_{\mathrm{e} 6}=89 \%\right)(\mathrm{Fig} .3 .18 \mathrm{~A})$. On the other hand, siRNA-mediated depletion of Ptbp1 and Ptbp1/2 led to a 2.6-fold and 3.1-fold reduction in the Dtx2e6 inclusion, respectively (ANOVA $p=$ $2.5 \times 10^{-4}$; Fig. $\left.3.18 \mathrm{~A}, \mathrm{~B}\right)$. No significant changes in the overall Dtx2 mRNA expression were detected using RT-qPCR (Fig. 3.18C). Therefore, this data suggests that Ptbp1 and possibly Ptbp2 promote Dtx2e6 inclusion and confirms that this alternative splicing event is not involved in regulation of mRNA steady-state levels, unlike the Hps1 example described above.

We then wondered whether Dtx2e6 splicing was regulated in a Ptbp1dependent manner in vivo. Our RT-qPCR analyses showed that Ptbp1 mRNA was expressed at relatively high levels in glial cells and low levels in neural stem cells (NSC) and neurons cultured ex vivo for 1, 3 or 
A

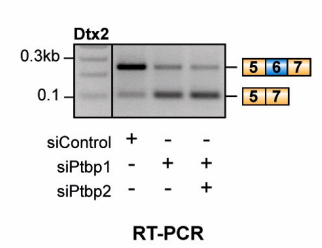

B

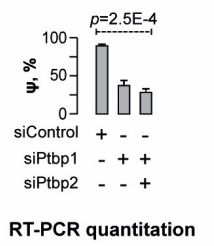

C

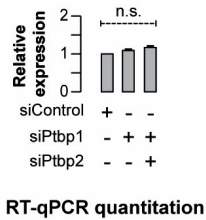

D

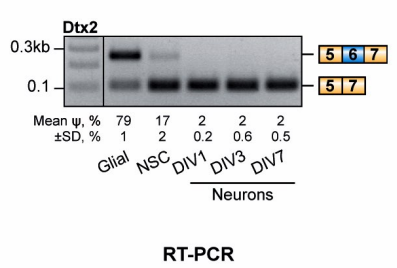

E

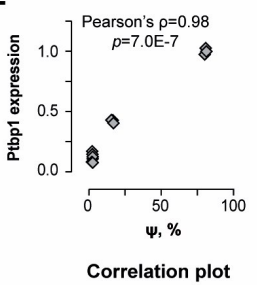

$\mathbf{F}$

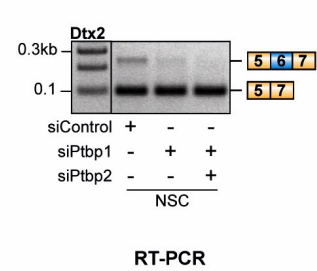

G

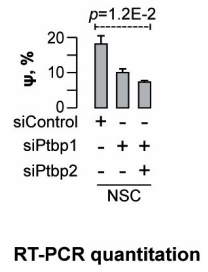

Figure 3.18 Ptbp1 activates splicing of Deltex2 exon 6 in cultured cells and in vivo (A) CAD cells were treated with siRNAs targeting Ptbp1, Ptbp1+2 or control and inclusion of Dtx2 exon 6 was validated using RT-PCR. (B) Quantitation of the amount of Dtx2-spliced transcript ( $\Psi$ (percent spliced in)) from results in (A). Data is represented as an average of three independent experiments, \pm SD. (C) RT-qPCR quantification of Dtx2 expression in samples in (A). Note the unchanged expression upon Ptbp1 or Ptbp1+2 knockdown. (D) Analysis of Dtx2 exon 6 inclusion in mouse tissue sample and cultured neurons. $\Psi$ and SD values are presented below each lane and represent average of 2 independent expeirments. (E) Positive correlation between Dtx2e6 inclusion and Ptbp1 expression levels in mouse cells. (F) Neuronal stem cells were treated with siPtbp1, siPtbp1+2 or siControl and Dtx2e6 splicing pattern was determined using RT-PCR. (G) Quantitation of the relative amounts of Dtx2e6-spliced transcripts from experiment in (F). Data is represented as an average of 2 independent experiments, \pm SD.

7 days (DIV1, DIV3, DIV7; Fig. 3.18D). Notably, we observed a predominant expression of the Dtx2e6 spliced-in transcripts in glial cells $\left(\Psi_{\mathrm{e} 6}=79 \%\right)$, whereas the skipped form was more abundant in the rest of the samples $\left(\Psi_{\mathrm{e} 6}=1 \%-20 \%\right.$; Fig. 3.18D). Overall, there was a strong positive correlation between Ptbp1 expression levels and the efficiency of Dtx2e6 inclusion (Pearson's correlation coefficient $\rho=0.98, p=$ 7.0 $\times 10^{-7}$; Fig. 3.18E). Furthermore, treating NSCs with siPtbp1 or siPtbp1/2 dampened the levels of the Dtx2e6 spliced-in form (ANOVA $p$ $=1.2 \times 10^{-2}$, Fig. $3.18 \mathrm{~F}, \mathrm{G}$ ). Overall, these results suggested that Ptbp1 stimulates inclusion of the Dtx2e6 exon in vivo. 


\subsection{Polypyrimidine sequences downstream of Dtx2e6 are necessary for its efficient inclusion}

To better understand the molecular mechanism of this Ptbp1-mediated splicing activation of Dtx2e6, we designed a minigene containing Dtx2e6 within its natural intronic context (300 bp of intronic sequences on each side) under the control of a doxycycline-inducible promoter (TRE-miniDtx2; Fig. 3.19A). CAD cells pre-treated with siControl, siPtbp1 or siPtbp $1 / 2$ were transfected with this construct and the minigene-specific splicing patterns were analyzed by RT-PCR (Fig. 3.19B,C). Our results showed that $20 \%$ of the minigene-derived transcripts included the

Dtx2e6 in the control sample and that this value was significantly reduced in the Ptbp1 and Ptbp1/2-knockdown samples $\left(\Psi_{\mathrm{e} 6}=3 \%\right.$ and $\Psi_{\mathrm{e} 6}=1 \%$, respectively). This indicated that splicing of TRE-mini-Dtx2derived transcripts was Ptbp1 protein-dependent and that the ciselements responsible for this regulation were located within the vicinity of the Dtx2e6.

Since the intron sequence downstream of Dtx2e6 contained pyrimidinerich stretches we decided to test functional significance of this part of the Dtx2 gene by preparing TRE-mini-Dtx2 mutants with progressive downstream deletions ( $\operatorname{Dtx} 2 \Delta 150, \operatorname{Dtx} 2 \Delta 210$ and $\operatorname{Dtx} 2 \Delta 250)$. These constructs were introduced into CAD cells pre-treated with siControl, siPtbp1 or siPtbp1/2 (Fig. 3.19D) and the Dtx2e6 inclusion was analyzed by RT-PCR with minigene-specific primers. We detected a significant decrease in the efficiency of Dtx2e6 inclusion in the Dtx2 $\Delta 210$ and the Dtx2 $\Delta 250$ transcripts but not in Dtx2 $\Delta 150$ (Fig. 3.19D,E). This indicated 
that a putative splicing enhancer required for optimal Dtx2e6 splicing

resided between 50 to $150 \mathrm{nt}$ downstream of this alternative exon.

Three pyrimidine-rich sequences (Py1, Py2 and Py3) containing Ptbp1

binding consensus occur 60 to 110 nt downstream of Dtx2e6 (Fig.

3.19A) and all three of them show a high degree of conservation across mammalian species. To elucidate possible contribution of these elements to Dtx2e6 activation, we mutated them individually in the TRE-

A

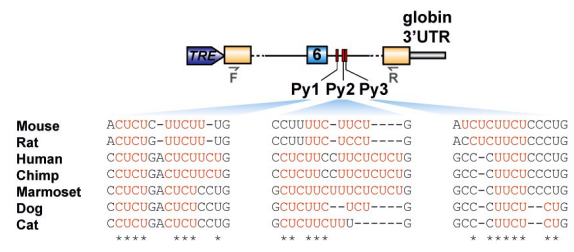

TRE-mini-Dtx2

D

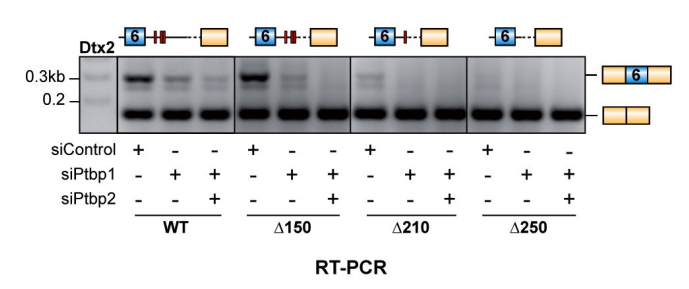

$\mathbf{F}$

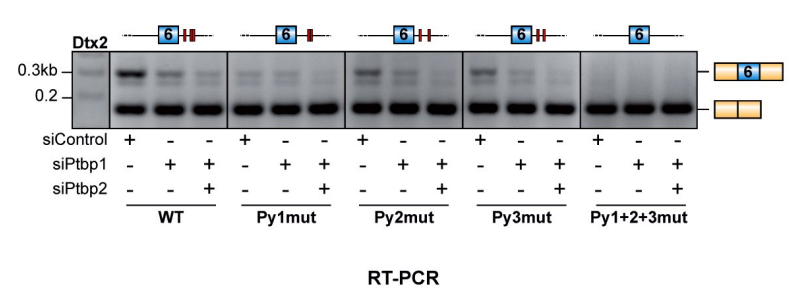

B

C
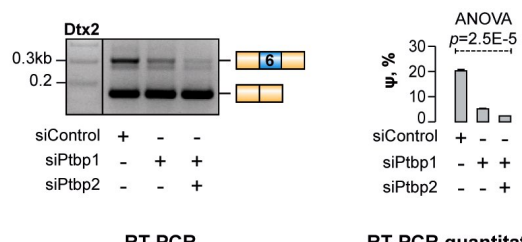

RT-PCR quantitation

E

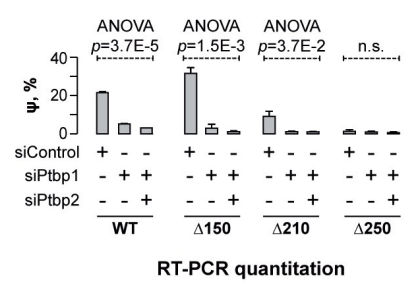

G

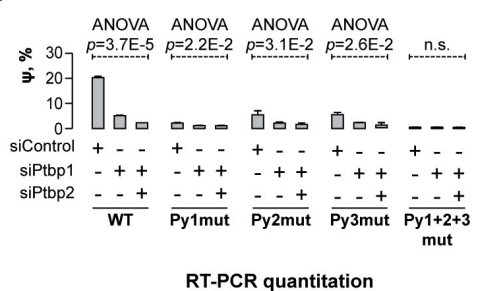

Figure 3.19 Polypyrimidine-rich stretches downstream of Dtx2e6 are necessary for its inclusion (A) Top, diagram of TRE-mini-Dtx2 minigene lasmid which was constructed by cloning Dtx2 exon 6 and 300bp flanking introns into the intron of pEM791. Below, sequence alignment of the three polypyrimidine-stretches in various mammalian species. (B) CAD cells pre-treated with siPtbp1, siPtbp1+2 or siControl were transfected with TRE-mini-Dtx2 and the mingene-specific splicing pattern was validated using RT-PCR. Note the decrease in Dtx2e6 inclusion upon Ptbp1 or Ptbp1+2 knockdown. (C) Quantitation of the amount of Dtx2e6-spliced minigene transcripts from experiment in (B). (D) Expression of downstream intron-truncated versions of TRE-mini-Dtx2 in siRNA-treated CAD cells and validation using RT-PCR. (E) Quantitation of results in (D). (F) Expression of TRE-mini-Dtx2 minigene with mutant Py1, Py2 or Py3 sequences in siRNA-treated CAD cells. (G) Quantitation of results in $(F)$. All quantitation data are represented as averages of 3 independent experiments, \pm SD. 
mini-Dtx2 context (Fig. 319F) and transfected the mutant constructs into siRNA-treated CAD cells. RT-PCR analyses of minigene-specific splicing pattern revealed reduced inclusion of Dtx2e6 in the siControl samples (Fig. 3.19F,G). Amongst the three mutants, TRE-mini-Dtx2Py1mut showed the greatest decrease in the Dtx2e6 utilization, arguing for possibly greater functional importance of this sequence. Notably, simultaneous genetic inactivation of all three Py elements resulted in quantitative skipping of Dtx2e6 (TRE-mini-Dtx2 Py1+Py2+Py3mut; Fig. 3.19F). Overall, these results point at the importance of the downstream Py elements for optimal Dtx2e6 inclusion.

\subsection{Interaction between Ptbp1 and U1 snRNA stem-loop 4 of is required for optimal Dtx2e6 inclusion}

We showed in our previous experiments that Ptbp1 regulated Hps1 splicing by stimulating a weak 5'ss. Since 5'ss interacts with U1 snRNP at the initial steps of splicing, we wondered whether Ptbp1 could activate 5'ss's in general and the Dtx2e6 5'ss in particular by promoting U1 snRNP recruitment. Prediction analysis on the strength of Dtx2e6 5'ss binding to U1 snRNA gave a MaxEnt score of 6.44 while the consensus 5'ss motif gave a score of 10.86 . This weak predicted binding affinity could be attributed to the three non-base pairing nucleotides at positions $-3,+5$ and +7 relative to the exon junction (Fig. 3.20A).

To address this possibility we decided to express a mutated U1 snRNA with improved complementarity to the relatively weak Dtx2e6 5'ss. We reasoned that such U1 suppressor system (Tan and Roca, 2016) could 
be used to study the influence of Ptbp1-U1 snRNA interaction on Dtx2e6 splicing. To this end, we prepared a U1 snRNA expression plasmid that contained a ' $C$ ' to ' $A$ ' mutation of its fourth 5 '-terminal nucleotide (U1A4) which was predicted to improve its base-paring with the Dtx2e6 5'ss (Fig. 3.20A). CAD cells pre-treated with siControl, siPtbp1 or siPtbp1/2 were transfected with a mixture of TRE-mini-Dtx2 and either a U1A4 suppressor plasmid or a mock plasmid. RT-PCR analysis of the minigene-specific splicing pattern clearly showed an increase in Dtx2e6 inclusion in the U1A4 overexpressing samples (Fig. 3.20B). This splicing enhancement was not simply a result of an overall increase in cellular U1 snRNA levels since this effect was not observed when we overexpressed the wild-type U1 snRNA (Fig. 3.20B,C). In addition, coexpression of either U1WT or U1A4 had no effect on splicing of transcripts derived from a control minigene encoding Tubg1 exon 4 . This indicated that the U1A4 suppressor snRNA specifically activates Dtx2e6.

Notably, Ptbp1 has been previously shown to inhibit splicing of an alternative exon in the $c$-src gene by directly interacting with stem-loop 4 (SL4) of U1 snRNA (Sharma et al., 2011). We therefore examined possible significance of this interaction in the context of Dtx2e6 activation. To this end, we prepared the U1A4-SL4-M10 mutant where several G-C base pairs of the SL4 stem were substituted to A-U in the U1A4 context. This mutation was previously shown to improve Ptbp1 binding to otherwise wild-type U1 (Sharma et al., 2014). We also prepared another mutant, U1A4-SL4-Dm, containing SL4 from Drosophila melanogaster, a modification known to reduce the efficiency of the interaction between U1 and Ptbp1 (Sharma et al., 2014). CAD 
cells pre-treated with siControl, siPtbp1 or siPtbp1/2 were co-transfected

with TRE-mini-Dtx2 and either U1A4, U1A4-SL4-M10 or U1A4-SL4-Dm

and the minigene-specific Dtx2e6 splicing was analyzed by RT-PCR

A

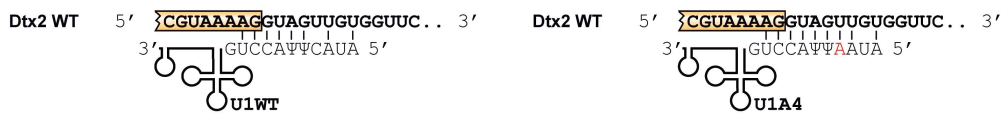

B
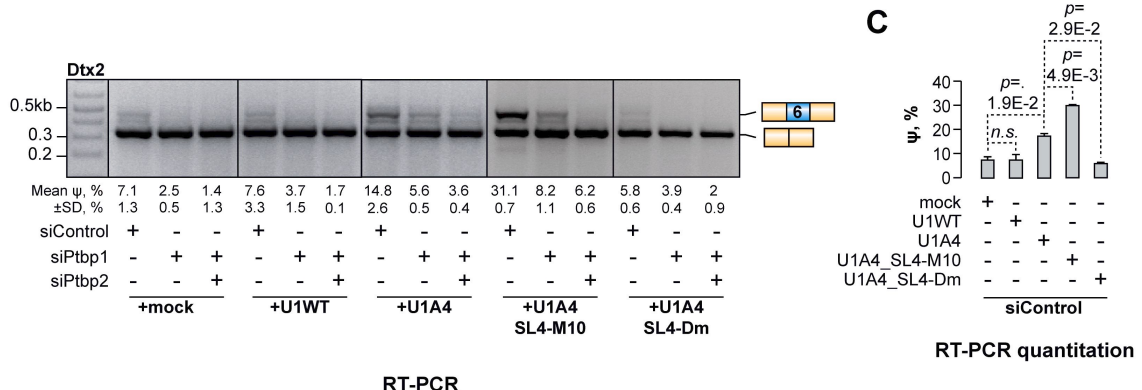

D

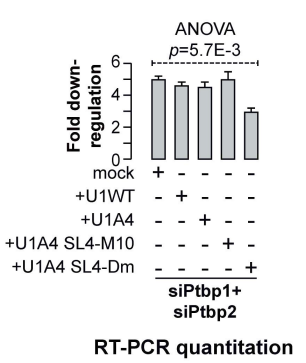

G

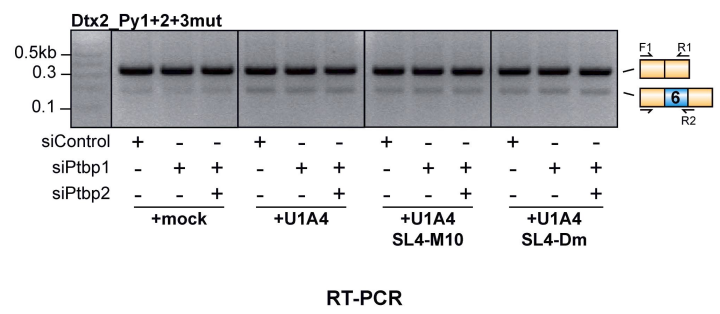

E

RT-PCR

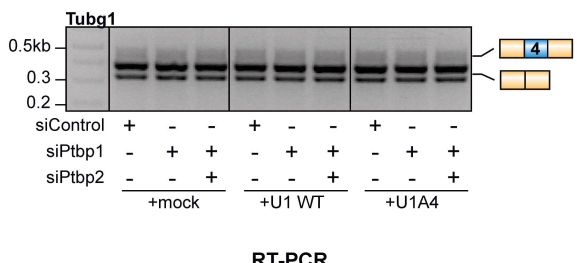

H

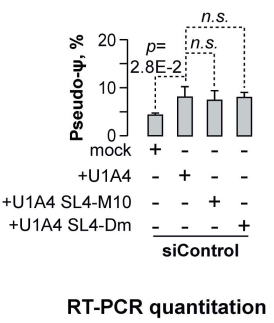

Figure 3.20 Ptbp1-U1 stem loop 4 (U1-SL4) interaction is crucial for Dtx2e6 splicing regulation $(A)$ Sequence of 3' end junction of Dtx2 exon 6 interacting with U1 wild-type (left) or U1 with an C->A mutation at the 4th base (right, mutation denoted in red). Yellow boxed segments represent exon 6 sequence. (B) siRNAtreated CAD cells were co-transfected with TRE-mini-Dtx2e6 and a variant of the U1 suppressor plasmid. Minigene-specific splicing pattern was analyzed by RT-PCR. Note the increase in Dtx2e6 splicing efficiency upon expression of U1A4 snRNA with an improved SL4 sequence for Ptbp1 interaction. The average amount of spliced in products $(\Psi$ (percent spliced in)) in each sample and its standard deviation is listed below each lane. (C) Comparison of the siControl $\Psi$-values from experiment in (B). (D) Quantitation of $\Psi$ fold down-regulation values between siControl and siPtbp1+2 samples from experiment in (B). (E) A repeat of experiment in (B) with the replacement of TRE-mini-Dtx2e6 with a Ptbp1 un-regulated Tubg1 exon. (F) Quantitation of the average $\Psi$-values in (E). Note the lack of change in the levels. (G) A repeat of experiment in $(B)$ with the replacement of TRE-mini-Dtx2e6 with a mutant lacking all three polypyrimidine-rich stretches. $(\mathrm{H})$ Quantitation of results in $(\mathrm{G})$. All data are represented as an average of three independent experiments, \pm SD. 
(Fig. 3.20B-D). We observed an increase in exon inclusion in siControltreated samples co-transfected with U1A4-SL4-M10 and a decrease in exon splicing in samples co-transfected with U1A4-SL4-Dm, as compared to the corresponding U1A4 samples. Importantly, the inhibitory effect of siPtbp1 and siPtbp $1 / 2$ on the Dtx2e6 inclusion was significantly lower in U1A4-SL4-Dm as compared to other samples suggesting that the U1A4-SL4-Dm mutant was the least sensitive to Ptbp1 regulation (Fig. 3.20D). To show that this effect is dependent on binding of Ptbp1 on the RNA, we co-transfected the various U1 suppressor constructs with Dtx2-Py1+2+3mut. To better detect Dtx2e6 splicing, we carried out a multiplex PCR reaction designed to enrich the spliced-isoform (Fig. 3.20G). Our analysis revealed that the sequence modifications on U1A4 stem loop 4 did not alter Dtx2e6 splicing, suggesting that binding of Ptbp1 to Dtx2 RNA is required for the regulation (Fig. 3.20G,H). These results supported the model that Ptbp1 activates Dtx2e6 splicing by interacting with the SL4 element of U1 snRNA.

\subsection{Ptbp1 promotes binding of U1 snRNP to Ptbp1-activated 5' splice sites}

The fact that U1 SL4 affected minigene splicing in a manner requiring Ptbp1 binding to the Py sites suggested that Ptbp1 might promote Dtx2e6 inclusion by stimulating U1 snRNP recruitment onto the Dtx2e6 5'ss. To test this prediction, we incubated a biotin-labelled Dtx2 RNA bait containing Dtx2e6 5'ss and downstream pyrimidine-rich sequences, with HeLa nuclear extract (NE; Fig. 3.21A). The RNA-protein complexes 
were purified using streptavidin beads and analyzed using immunoblot (protein) or RT-PCR/RT-qPCR (RNA). Our immunoblot results showed that both Ptbp1 and a component of the U1 snRNP, U1-70k, were readily bound to the WT Dtx2 bait (Fig. 3.21A). The binding of U1-70k to Dtx2 was specific to the 5'ss since we observed no interaction between U1-70k with a 5'ss mutant bait. Interestingly, incubation of HeLa NE with Dtx2 bait that contained no Ptbp1 binding sites (Py-mut) showed a significant reduction in the amounts of bound U1-70k (111-fold, $p=$ $2.0 \times 10^{-2}$; Fig. 3.21B,C). Our RT-qPCR quantification of the relative amounts of pulled-down U1 snRNA similarly showed a clear decrease in the amount of bound U1 snRNA in Dtx2-Py-mut sample (Fig. 3.21D). To further confirm that U1 snRNP binding to Dtx2 depended on Ptbp1, we repeated the experiment by incubating WT Dtx2 bait with a Ptbp1immunodepleted HeLa nuclear extract. This led to a significant decrease in the amounts of U1-70k and U1 snRNA recruited to the bait (Fig. 3.21E,F). Satisfyingly, the addition of recombinant Ptbp1 to the Ptbp1immunodepleted mixtures was sufficient to rescue $\mathrm{U} 1 \mathrm{snRNP}$ binding as evident from both immunoblot and RT-qPCR results (Fig. 3.21E-G). In conclusion, these results suggested that Ptbp1 promotes U1 snRNP binding to the 5'ss of Dtx2 exon 6 thus providing a mechanism by which Ptbp1 can activate Dtx2e6 splicing.

We showed previously that Ptbp1 regulates the choice between competing 5'ss's in exon 18 of the Hps1 gene by activating the u5'ss. In light of our Dtx2 results, we wondered whether Ptbp1 also stimulated recruitment of U1 snRNP to the Hps1 u5'ss. To address this possibility, we repeated the above U1 snRNP pull-down experiment using a 
A

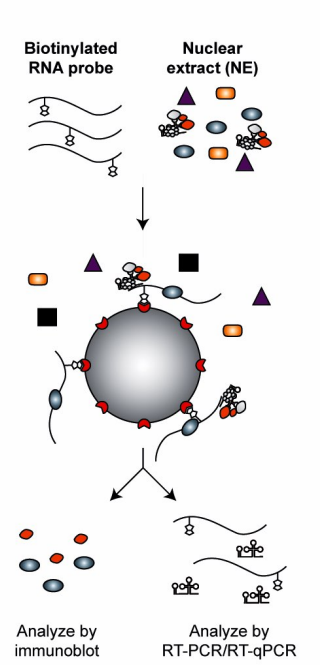

B

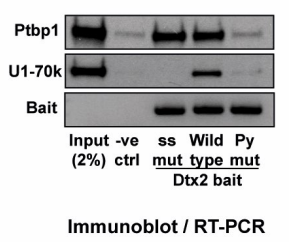

E

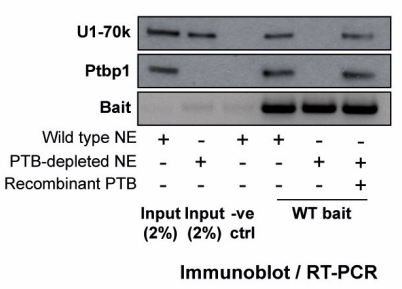

C

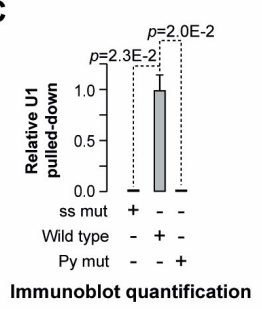

D

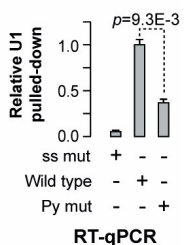

$\mathbf{F}$

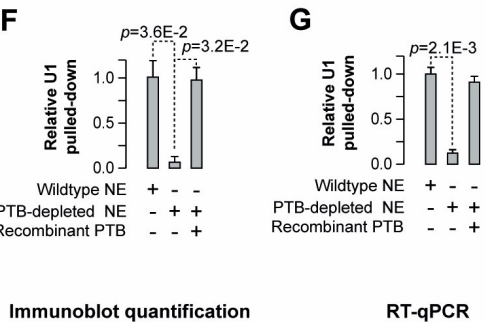

Figure 3.21 Ptbp1 promotes U1 snRNP binding to the weak 5'ss (I) (A) Schematic diagram of the pull-down strategy used in this experiment. HeLa nuclear extracts that contain Ptbp1 (shwon as gray ovals) and U1 snRNP (shown as a complex of orange ovals bound to a structured RNA) (B) Immunoblot (top two panels) and RT-PCR (bottom panel) analysis of the amount pulled-down Ptbp1 and U1-70k using the Dtx2 RNA bait. RNA bait without biotin label was used as negative control (-ve ctrl). (C) Quantitation of the relative amounts of U1-70k pulled-down in (B). (D) RT-qPCR quantification of the relative amounts of U1 snRNA pulled-down in (B). (E) A similar experiment as in (B) using wild-type or Ptbp1-depleted nuclear extracts (NE). (F) Quantitation of the relative amounts of U1-70k pulled-down in (E). (G) RT-qPCR quantification of the relative amounts of U1 snRNA pulled-down in experiment in (B). Data are represented as averages of two independent experiments, \pm SD.

biotinylated Hps1 RNA bait containing the u5'ss sequence together with the downstream Ptbp1 binding sequences (Py1 and Py2; Fig. 3.22). This probe efficiently recruited $\mathrm{U} 1$ snRNA as judged by the U1-70k immunoblot signal. Notably, the amount of bound U1-70k decreased 4fold when we used a mutant Hps1 bait lacking the most critical Ptbp1binding element (Py2mut) (Fig. 3.22A,B). Similar reduction in the amount of bound U1 snRNP complex was observed when we incubated WT Hps1 RNA bait with Ptbp1-immunodepleted HeLa nuclear extract (Fig. 3.22C,D). The addition of recombinant Ptbp1 to the Ptbp1immunodepelted reaction was sufficient to rescue U1 snRNP binding (Fig. 3.22C,D). Altogether, these results suggested that Ptbp1 promotes 
A

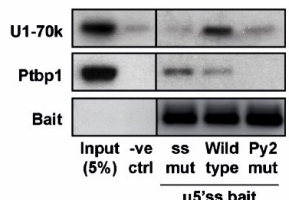

Immunoblot/RT-PCR
B

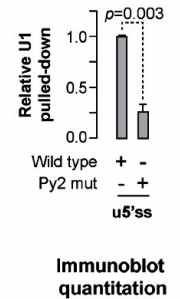

C

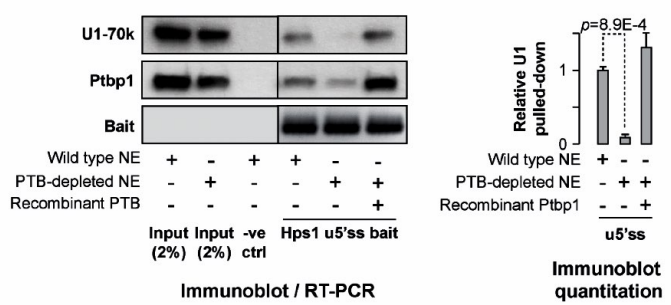

Figure 3.22 Ptbp1 promotes U1 snRNP binding to the weak 5'ss (II) (A) Immunoblot (top two panels) and RT-PCR (bottom panel) analysis of the amount pulled-down Ptbp1 and U1-70k using the Hps1 RNA baits containing u5'ss sequence. RNA bait without biotin label was used as negative control (-ve ctrl). (B) Quantitation of the relative amounts of U1-70k pulled-down in (A). (C) A similar experiment as in (A) using wild-type or Ptbp1-depleted nuclear extracts (NE). (D) Quantitation of the relative amounts of $\mathrm{U} 1-70 \mathrm{k}$ pulled-down in experiment in (C). Data are represented as averages of two independent experiments, $\pm S D$.

recruitment of U1 snRNP to the regulated 5'ss in both Dtx2 and Hps1 pre-mRNAs.

\subsection{Knockout of Dtx2 exon 6 affects the expression of a subset of genes involved in the Notch pathway}

Dtx2 has been identified as a component of the Notch signaling pathway, which controls neuronal differentiation in addition to its other functions (Artavanis-Tsakonas et al., 1999; Yamada et al., 2011). Activation of the Notch pathway is known to maintain 'stemness' of progenitor cells through a number of downstream targets including the Hes family transcription factors (Bray, 2006; Lutolf et al., 2002). Therefore, the Notch signaling has to be downregulated in cells undergoing neurogenesis. To study the biological effect of Dtx2e6 skipping in this pathway, we knocked out this alternative exon in Neuro-2a (N2a) cell lines using the CRISPR-Cas9 technology (Fig. 3.23A). This cell line has been previously shown to express high levels of Ptbp1 and large amounts of e6-included Dtx2 transcripts. Moreover, 
Table 3. List of positively-regulated Notch targets

\begin{tabular}{rll}
\hline S/N & Gene & References \\
\hline 1 & Hes1 & Fischer et al. (2007), Iso et al (2003) \\
2 & Hes5 & Fischer et al. (2007), Iso et al (2003) \\
3 & Hey1 & Iso et al (2001), Jarriault et al (1998) \\
4 & Hey2 & Iso et al (2001), Jarriault et al (1998) \\
5 & Nrarp & Izon et al (2002), Lamar (2001) \\
6 & Myc & Satoh et al. (2004), Palomero (2006) \\
7 & Nfkb1 & Vilimas et al (2007) \\
8 & Nfkb2 & Oswald et al (1992) \\
9 & Ccnd1 & Ronchini et al (2001) \\
10 & Cdkn1a & Ronchini et al (2001) \\
11 & Gata3 & Fang et al (2007), Amsen et al (2007) \\
12 & Erbb2 & Hirose et al (2010) \\
\hline
\end{tabular}

Ptbp1 knockdown in this context promotes Dtx2e6 skipping (Fig. 3.23B).

We therefore used RT-PCR to screen CRISPR-Cas9 mutagenized clones and identified two clones that showed complete skipping of Dtx2e6 in the presence of Ptbp1, unlike their WT counterparts (Fig. 3.23C). RT-qPCR quantification of Dtx2 mRNA revealed no difference in its steady-state levels between the mutants and the WT (Fig. 3.23D). This confirmed that neither the Dtx2e6 inclusion status nor the modifications introduced by CRISPR-Cas9 mutagenesis altered Dtx2 mRNA stability. Thus, we selected the two mutant clones for subsequent experiments.

Activation of the Notch pathway is expected to alter the expression of a number of genes (Borggrefe and Oswald, 2009), including examples listed in Table 3. To test whether developmental skipping of Dtx2e6 could affect at least a subset of these targets, we compared the expression of the corresponding genes between the Dtx2e6-deletion mutant and the wild-type cells using RT-qPCR. From the 12 targets 


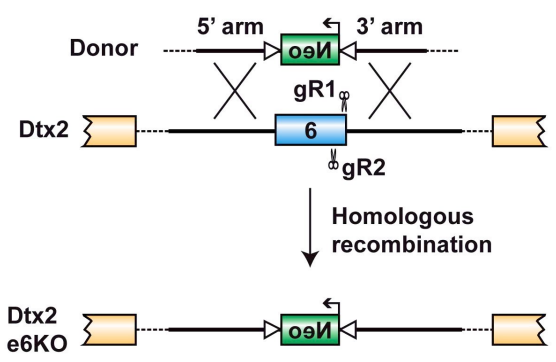

Crispr/Cas9-mediated knockout of Dtx2e6

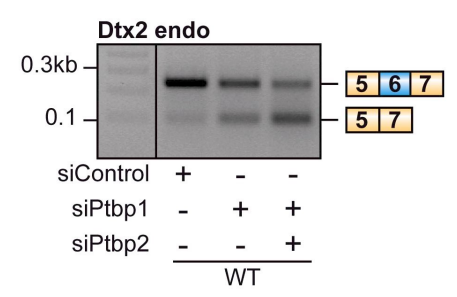

RT-PCR
C

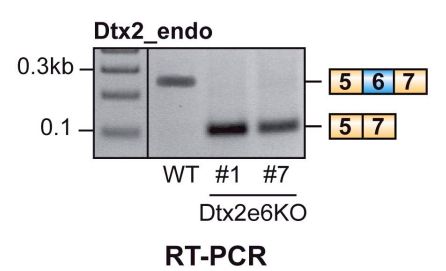

D

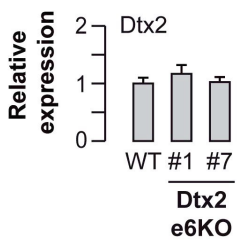

RT-qPCR quantification

D

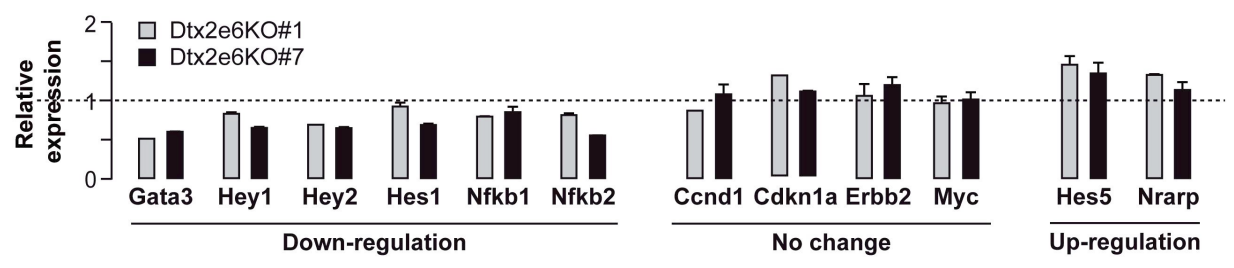

Figure 3.23 Knockout of Dtx2e6 affects expression of some Notch target genes (I) (A) Schematic representation of the CRISPR/Cas9 mediated knockout of Dtx2 exon 6 (Dtx2e6). Donor plasmid containing a neomycin-resistant gene flanked by sequences homologous to Dtx2e6 intronic sequences was transfected together with two single guide RNAs ( $\mathrm{gR}$ ) co-expressed with a nickase version of the Cas9 enzyme. Dtx2e6 is replaced with a Neomycin-resistant gene expressed on the opposite strand. (B) RT-PCR analysis on the alternative Dtx2 transcripts obtained post-mutagenesis. Note the complete absence of Dtxe6-spliced or cryptic 5'ssspliced isoforms in both mutant N2a strains. As control, N2a lines were transfected with a donor plasmid lacking homologous Dtx2 sequences (WT). (C) Quantification of the expression of Dtx2 transcripts from experiment in (B) showing unchanged expression levels. (D) Quantification of the expression of some Notch target genes in WT, and Dtx2e6KO strains. Expression levels were normalized to Gapdh and expression of genes in WT were set to 1 (dotted line). Data are presented as average of three independent experiments, \pm SD.

previously shown to be up-regulated by the Notch pathway, 6 were consistently down-regulated in Dtx2e6 knocked-out clones (Fig. 3.23D; Gata3, Hey1, Hey2, Hes1, Nfkb1 and Nfkb2) and 2 were up-regulated (Hes5 and Nrarp) while the remaining 4 genes showed no difference in the expression levels. 
Next, we transfected the N2a clones with a plasmid expressing miR-124, a microRNA that was previously reported to down-regulate Ptbp1 and thus was expected to promote Dtx2e6 skipping. Indeed, expression of miR-124 in these cells triggered down-regulation of Ptbp1 expression and a concomitant increase in Ptbp2 mRNA levels (Fig. 3.24B). More importantly, 3 of the 6 target genes down-regulated in the Dtx2e6-deleted clones were also down-regulated in miR-124-transfected samples (Fig. 3.24C; Gata3, Hes1 and Hey2). Similarly, both genes upregulated in the Dtx2e6-deleted clones were consistently up-regulated by miR-124 (Fig. 3.24C). These data indicated that alternative splicing of the Dtx2e6 exon might modulate activity of the Notch pathway.

A

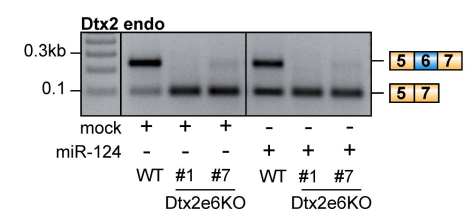

C

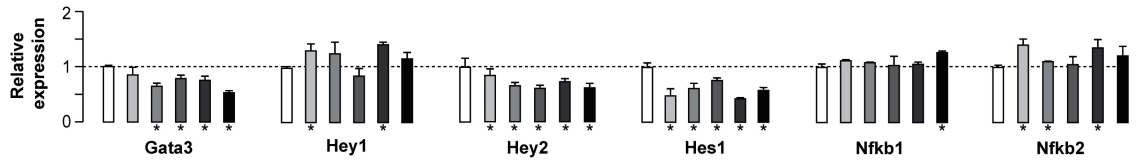

B

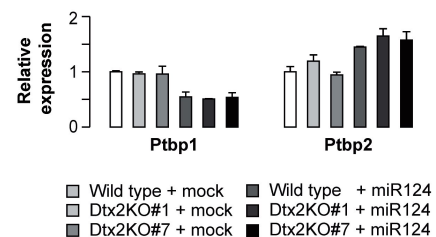

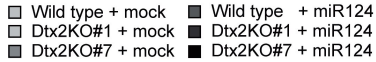
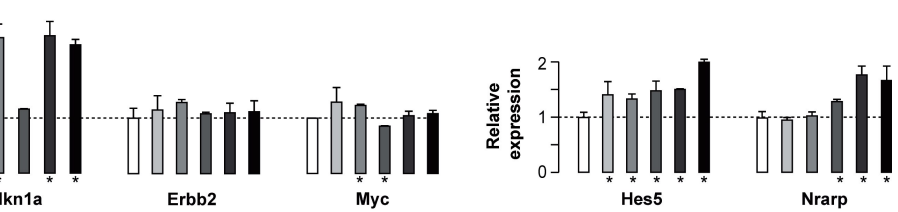

Figure 3.24 Knockout of Dtx2e6 affects expression of some Notch target genes (II) (A) N2a WT control cell lines and Dtx2e6KO strans were transfected with miR-124-expressing plasmid and the Dtx2 splicing pattern was analyzed by RT-PCR. Note the increase in Dtx2e6-skipped form upon miR-124 expression. (B). RT-qPCR quantification of Ptbp1 and Ptbp2 mRNA expression from experiment in (A). Expression levels are normalized to Gapdh internal control. (C) Quantification of Notch target gene expression in samples in experiment $(A)$. Bar colour scheme is similar to the graph in (B) and target genes are catagorized based on its expression pattern as in Fig. 3.23D. Data are presented as average of three independent experiments, \pm SD. 


\section{Discussion}

Here, we investigated molecular mechanisms underlying Ptbp1mediated splicing activation (Fig. 4.1). We show that, at least in the case of the Hps1 and Dtx2 genes, Ptbp1 facilitates splicing by directly promoting the recruitment of the early spliceosomal component, U1 snRNP, to a relatively weak donor splice site (5'ss). In both cases this regulation relies on Ptbp1 interaction with polypyrimidine-rich sequences found downstream of the regulated 5'ss. Our in vivo U1 suppressor experiments revealed that the stem-loop 4 element of U1 snRNA was required for splicing stimulation by Ptbp1. Importantly, both Hps1 and Dtx2 regulation occurs in developing neurons, where Ptbp1 levels naturally decline as a result of increased miR-124 expression. This, in turn, reduces the expression of Hps1 transcripts and promotes production of exon 6-skipped Dtx2 mRNAs. Our data suggest that both of these effects result in important functional consequences. In the case of Hps1, the shift towards the usage of d5'ss on Hps1 exon 18 produces
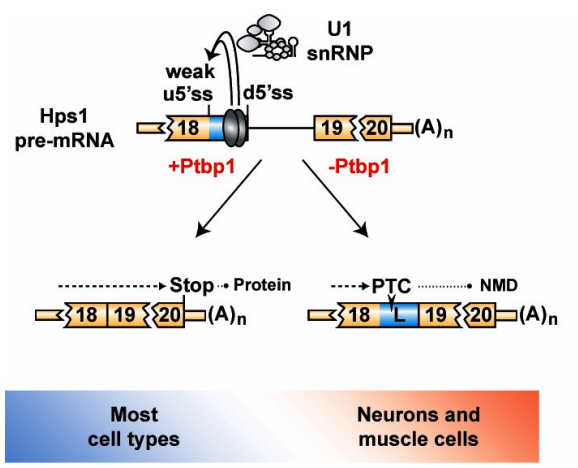

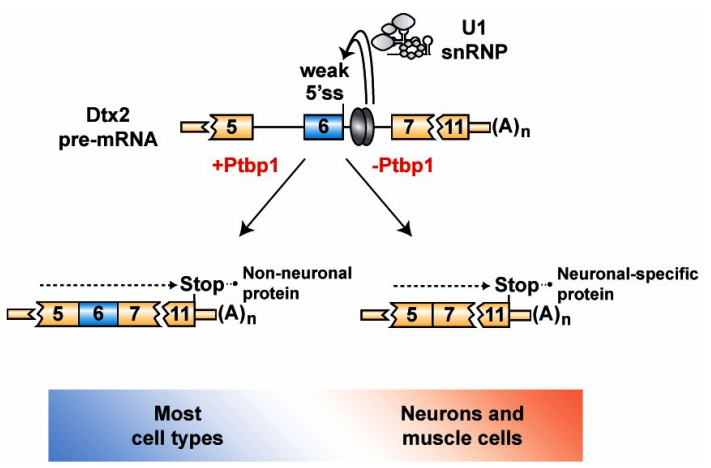

Figure 4.1 Recurring mechanism of Ptbp1-mediated splicing activation. Ptbp1 binds downstream of a weak 5'ss in the Hps1 (left) and Dtx2 (right) mRNAs to activate the usage of the 5'ss by promoting U1 snRNP recruitment. This splicing stimulation allows the production of full length Hps1 and Dtx2 transcripts in cells expressing steady levels of Ptbp1. Down-regulation of Ptbp1 levels in neurons and muscle cells induces the usage of the d5'ss on Hps1 to produce a PTC-containing mRNA isoform that is targeted for mRNA decay. This represent a Ptbp1-dependent system for fine-tuning of target gene expression. On the other hand, absence of Ptbp1 results in the skipping of Dtx2 exon 6 to produce a neuronal-specific protein isoform that may play a role in dampening the notch signalling pathway. 
an NMD-susceptible transcript, which dampens Hps1 expression in developing neurons and alters the morphology of the lysosomal compartment. On the other hand, the Dtx2 splicing switch appears to modulate the activity of the Notch pathway.

\subsection{Splicing activation by Ptbp1}

The recent findings that splicing regulators may function in a positionspecific manner has provided a fresh perspective on splicing regulation mechanisms and re-evaluated the earlier distinction between SR and hnRNP proteins as invariant activators and repressors of this process (Erkelenz et al., 2013; Martinez-Contreras et al., 2006). Historically, Ptbp1 has been identified as a splicing repressor interacting with exonicor/and intronic silencer elements (Amir-Ahmady et al., 2005). Amongst other mechanisms accounting for such repressive function, Ptbp1 has been proposed to occlude binding of constitutive splicing factors to their cognate cis-elements or interfere with exon- or intron definition complexes (Chou et al., 2000; Sharma et al., 2008; Spellman and Smith, 2006). On the other hand, Ptbp1 binding downstream of some alternative exons was proposed to promote splicing via a poorly understood mechanism (Erkelenz et al., 2013; Llorian et al., 2010). Here, we show that in the context of Dtx2 and Hps1 splicing, Ptbp1 promotes the recruitment of $U 1$ snRNP to an upstream 5'ss. The decision to study the effect of Ptbp1 on U1 snRNP binding was predicated on two recent findings. (1) Research done by the Black laboratory demonstrated that Ptbp1 could directly interact with the stem- 
loop 4 sequences of U1 snRNA via its RRM1 and RRM2 domains (Sharma et al., 2011). Although, in this context, Ptbp1 functions as a splicing repressor of the $\mathrm{N} 1$ exon of the $c$-src gene, we hypothesized that the same protein-RNA interaction may be used by Ptbp1 to activate splicing in some other contexts. (2) The splicing regulator, Tia-1, activates splicing by binding to intronic elements downstream of a weak 5'ss to recruit U1 snRNP (Forch et al., 2000; Forch et al., 2002). Seeing that Ptbp1 similarly binds downstream of weak 5'ss to induce splicing, it has been a logical starting point to check whether the activating mechanisms of Ptbp1 is similar to that of Tia-1.

Despite our new knowledge on the influence of Ptbp1 on U1 snRNP recruitment, we are still far from complete understanding of the mechanism underlying Ptbp1-mediated splicing activation. Although we established that Ptbp1 and U1 snRNA interact with each other, we cannot rule out the possibility that $U 1$ snRNP recruitment is achieved through some additional binding partners. Ptbp1 is known to interact with several RNA splicing factors, including hnRNPL, FUS and splicing factor proline/glutamine-rich (SFPQ) proteins (Hahm et al., 1998; Meissner et al., 2000). One piece of evidence from my project that might be consistent with this possibility is the modest rescue of Hps1 u5'ss utilization by recombinant Ptbp1 (Fig. 3.8C). It is plausible that Ptbp1 immunodepletion from the nuclear extract eliminates some yet-to-be identified Ptbp1-interacting partners required for the u5'ss activation.

It is also possible that, in addition to direct $U 1$ snRNP binding, Ptbp1 induces a local change in the target pre-mRNP structure that improves accessibility of the U1 snRNP to the regulated 5'ss. Computational 
analyses of the RNA regions near the 5'ss of Hps1 and Dtx2 revealed a relatively stable secondary structures that may interfere with U1 snRNP binding, at least theoretically (mfold Web Server [http:// unafold.rna.albany.edu/?q=mfold]; Fig. 4.2). We have recently set up an experiment where a terminal 5'-labelled Hps1 RNA were treated with site-specific endonucleases or RNA-cleaving compound to probe the local RNA structure. It would be interesting to follow up on this possibility in the future using corresponding biochemical assays such as RNase accessibility studies or SHAPE (Wilkinson et al., 2006). The knowledge gathered from such RNA structural determination assay would allow us to design "informational suppression" experiments. Essentially, this test introduces a mutation that possibly perturb the RNA structure and change the outcome of splicing. Compensatory mutations may then be generated to restore the internal base pairing and 'suppress' the splicing change (Glass et al., 1982). Using 2'-O-methyl modified antisense oligonucleotides against U1 snRNA 5'-terminus we should be able to modulate U1-5'ss interactions in these assays (Barabino et al., 1990; Seiwert and Steitz, 1993).

We also wonder how Ptbp1 is able to exert two distinct effects in the case of c-src (repression) and Dtx2 or Hps1 u5'ss (activation) despite seemingly common molecular interactions with U1 snRNP. Would it be possible to convert a Ptbp1-activating exon to a repressive nature by adding Ptbp1 binding motifs upstream of the exon? Do Ptbp1-repressive exons contain any additional elements licensing this regulation? An in vitro study by the Nilsen lab have demonstrated that the presence of certain silencer elements within the vicinity of a regulated 5'ss may 
A

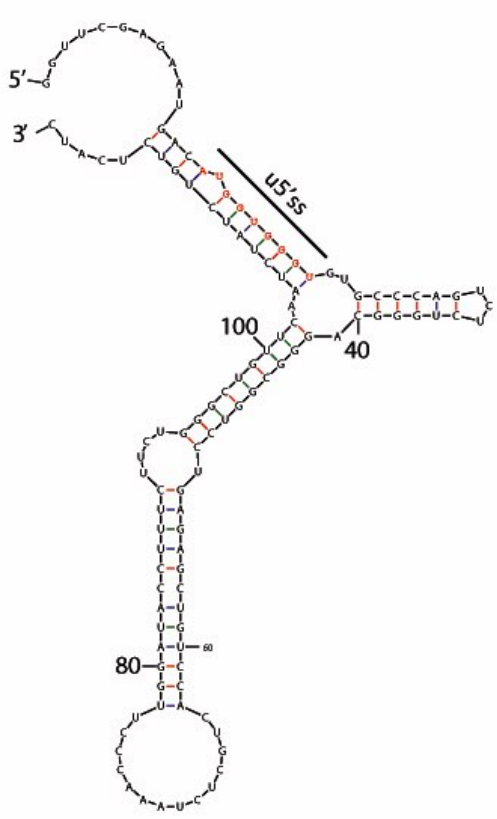

Hps1

$d G=-41.60$
B

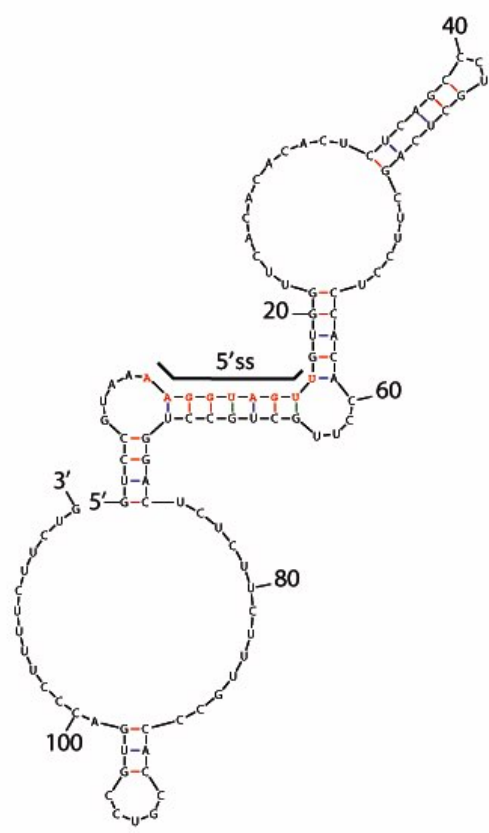

\section{Dtx2}

$d G=-19.00$

Figure 4.2 Secondary RNA structure of Ptbp1-regulated 5'ss. Sequences spanning -15 to +120 relative to the regulated 5 'ss of Hps1 (A) and Dtx2 (B) were used to predict its secondary structure fold using mfold web server. 5' and ' 3 ' end of the sequences, as well as the position of the nucleotides have been denoted. Location of Hps1 u5'ss and Dtx2 5'ss are indicated and labelled. Note the near-toperfect base pairing of these 5'ss sequences.

affect the structure of the U1snRNP/5'ss complex (Yu et al., 2008). This structural change may in turn distort the direct interaction between $\mathrm{U} 1$ snRNP and the downstream-binding U2 snRNP, thus explaining for the functional effect of silencer elements. Therefore, it may be possible that Ptbp1-activated and Ptbp1-repressed exons differ by their local U1/5'ss structure. Also, understanding the effect of Ptbp1 on the assembly of other spliceosomal complexes may shed some light on its splicing activating function. These and other questions pertaining dual functions of Ptbp1 and other splicing regulators can be answered through systematic mutagenesis of the corresponding minigene constructs.

\subsection{Regulation of alternative splice site usage by Ptbp1}


An important aspect of our study is that it provides a transcriptome-wide perspective on Ptbp1 regulation of alternative splice site usage. Although utilization of alternative 5'ss's and 3'ss's has been less studied as compared to other splicing topologies, these forms of AS constitute a major part of tissue-specific splicing programs (Wang et al., 2008; Yeo et al., 2004). Interestingly, our analyses showed a roughly equal role played by Ptbp1 in biasing the choice towards the four types of splice sites, u5'ss, d5'ss, u3'ss, and d3'ss (Fig. 3.15B). This hints at diverse molecular mechanisms underlying AS regulation for each individual gene. Similarly, the functional consequences of this regulation are also rather variable. Most of the Ptbp1-regulated 5'ss's and 3'ss's alter corresponding ORF sequences, whereas two examples are predicted to be regulated by AS-NMD. These newly identified Ptbp1 targets belong to diverse functional categories, including transcriptional regulators (e.g., Chd3, Ezh2, Hmga1, Mef2a, Msx1, Ncoa7 and Prmt1) and RNA metabolism (e.g., Hnrnpc, Hnrnph3, Larp4, Serbp1, Son, Srsf5 and Ythdc1). Additional work will obviously be required to understand the role of alternative splicing in biological activity of these genes.

It is interesting to note that the selection between alternative 5'ss's in the case of Hps1 and possibly other regulated genes in the "u5'ss bias" category, relies on a finely tuned balance between the u5'ss and the d5'ss strengths. All tested mutations that disrupt this intrinsic balance result in the constitutive usage of the u5'ss. In addition, recombinant Hps1 transcripts containing two equally strong or equally weak 5'ss fail to undergo alternative splicing and select only one alternative in a virtually constitutive manner. Notably, this group contains the highest 
density of Ptbp1 binding sites between the two 5'ss. This recurring mode of regulation led us to speculate that Ptbp1 may also functions as an activator of the u5'ss in other genes belonging to this category. We hope to address this interesting prediction in our future studies.

\subsection{Pervasive post-transcriptional regulation of gene expression level by Ptbp1}

From our initial microarray screen, we identified 18 poison exoncontaining genes up-regulated by Ptbp1 at the level of mRNA abundance. These genes represent Ptbp1 targets whose expression should be stabilized in most non-neuronal cell types but dampened in neurons. Hps1 encodes a protein involved in biogenesis of lysosomerelated organelles mediating the formation of early melanosomes in keratinocytes and HeLa cells (Dell'Angelica et al., 2000). In line with this function, we show that down-regulation of this Ptbp1 target profoundly affects the morphology and distribution of lysosomes in mouse neuroblastoma cell lines (Fig. 3.14). However, it remains unclear how this change in lysosomal phenotype may contribute to neurogenesis in vivo. One intriguing possibility would be that these changes are required for facilitating neuronal autophagy. Autophagy is a regulated catabolic process involved in turning over cellular organelles and macrocomplexes and believed to be of particular importance in post-mitotic cells such as neurons. Underscoring its contribution to normal neuronal physiology, defects in autophagy have been linked to neurodegenerative conditions such as Alzheimer's and Parkinson's disease (Lynch-Day et al., 2012; Zare-Shahabadi et al., 2015). It is conceivable that changes in 
the lysosomal characteristics might improve the efficiency of autophagy in neurons. This might be an interesting hypothesis to address in the future.

Interestingly, $33 \%$ of the newly identified poison exon-containing targets participate in cytoskeletal reorganization (Ctnnal1, lqgap1, Fhod1, Lima1, Fmn/3, Daam2, Myo19). Earlier studies on the cytoskeletal dynamics involved in axon initiation showed that depolymerization of actin filaments close to a single neurite of an unpolarized hippocampal neuron is sufficient to confer axonal identity (Bradke and Dotti, 1999). Therefore, it would be tempting to hypothesize that down-regulation of Ptbp1-dependent actin regulators may promote neuronal polarity and axon formation in developing brain. Changes in actin organization also promote cell migration and reaction to extracellular cues (Mattila and Lappalainen, 2008). Glioblastoma cells commonly express exceedingly high levels of Ptbp1 and are capable of migration within the cerebrospinal fluid (Ferrarese et al., 2014; McCutcheon et al., 2004). It is therefore plausible that stabilization of Ptbp1 AS-NMD targets in this form of cancer underlies its invasive properties. These data, along with findings from other labs, point to a central role played by Ptbp1 in the neuronal development in general and regulation of mRNA steady-state expression levels in particular.

High-throughput RNA-sequencing (RNA-seq) has recently become an increasingly affordable option and current bioinformatics pipelines provide a rapid and user-friendly way to analyze the RNA-seq data. Although gene expression microarrays were sufficient for our initial studies and led to discovery of several important AS-NMS targets, we 
plan to re-analyze our samples using RNA-seq in the nearest future. Using publicly available pipelines such as RAINMAN and SpliceR, the discovery of PTC-containing transcripts can be automated while enjoying relatively low false positive rates. We expect that such additional analyses will substantially expand our knowledge about the genes regulated by Ptbp1 at the AS-NMD level.

\subsection{Functional significance of Dtx2 splicing regulation}

Dtx2 is predicted to function as a ubiquitin ligase that can modulate the Notch signalling pathway in a positive or negative manner. Apart from the finding that Dtx2 controls avian Bmp4 expression during neural crest formation, there is limited information on its role in mammalian neuronal system (Endo et al., 2003). While the expression of the Dtx2e6-skipped isoform has been documented in earlier studies, its biological significance still remains to be characterized (Kishi et al., 2001). Translation of this exon 6-skipped transcript is predicted to produce a protein isoform lacking two out of four proline-rich motifs (Kishi et al., 2001). This motif has been proposed to interact with the Notch intracellular domain (NICD); however, no experimental evidence confirming that Deltex bind Notch directly has been reported thus far. If indeed this interaction exists, we predict that the exon 6-skipped Dtx2 protein may bind NICD weaker than its exon 6-included isoform thus leading to downstream biological effects. Given that Dtx2 exon 6 splicing is regulated in development this AS circuitry may participate in downregulation of the Notch signalling pathway during neurogenesis. 
In line with this model, our analysis of Notch target genes in Dtx2e6-KO cell lines revealed several interesting results. At least three Notchregulated transcription factors were consistently down-regulated in mutant neuroblastoma cells exclusively expressing the Dtx2e6-skipped isoform and in wild-type neuroblastoma cells pre-treated with miR-124, a miRNA promoting Dtx2e6 skipping. Expression of two of these targets, Hes1 and Hey2, is known to maintain 'stemness' of neuronal precursor cells by repressing transcription of neuron-specific genes (Borggrefe and Oswald, 2009; Ohtsuka et al., 1999). Four other genes previously documented to be positively regulated by Notch showed no change in their expression levels in our neuroblastoma samples (Ccnd1, Cdk1a, Erbb2, Myc). It is plausible that these genes are activated by a Dtx2independent branch of the Notch pathway. Finally, our data showed that Hes5 is consistently up-regulated in Dtx2e6KO cells and miR-124treated cells. Since Hes5 is known to be positively-regulated by the Notch pathway, further studies will be required to understand contribution of Deltex2 isoforms in this context.

In conclusion, this project has unveiled novel mechanisms underlying Ptbp1-regulated alternative splicing and provided insights into functional significance of corresponding splicing changes during neuronal development. Data gathered from this project contribute to the rapidly expanding knowledge of the molecular functions of splicing regulators and their role in normal developmental and physiological processes. Given the importance of Ptbp1 in neural lineage, our work may also illuminate critical mechanisms involved in the emergence of neuroectodermal cancers and neurodegenerative diseases. 


\section{References}

Ahmad, S., Bhatia, K., Kannan, A., and Gangwani, L. (2016). Molecular Mechanisms of Neurodegeneration in Spinal Muscular Atrophy. J Exp Neurosci 10, 39-49.

Amir-Ahmady, B., Boutz, P.L., Markovtsov, V., Phillips, M.L., and Black, D.L. (2005). Exon repression by polypyrimidine tract binding protein. RNA 11, 699-716.

Amsen, D., Antov, A., Jankovic, D., Sher, A., Radtke, F., Souabni, A., Busslinger, M., McCright, B., Gridley, T., and Flavell, R.A. (2007). Direct regulation of Gata3 expression determines the $T$ helper differentiation potential of Notch. Immunity 27, 89-99.

Anthony, K., and Gallo, J.M. (2010). Aberrant RNA processing events in neurological disorders. Brain Res 1338, 67-77.

Applequist, S.E., Selg, M., Raman, C., and Jack, H.M. (1997). Cloning and characterization of HUPF1, a human homolog of the Saccharomyces cerevisiae nonsense mRNA-reducing UPF1 protein. Nucleic Acids Res 25, 814-821.

Artavanis-Tsakonas, S., Rand, M.D., and Lake, R.J. (1999). Notch signaling: cell fate control and signal integration in development. Science 284, 770-776.

Barabino, S.M., Blencowe, B.J., Ryder, U., Sproat, B.S., and Lamond, A.I. (1990). Targeted snRNP depletion reveals an additional role for mammalian U1 snRNP in spliceosome assembly. Cell 63, 293-302.

Black, D.L. (2003). Mechanisms of alternative pre-messenger RNA splicing. Annual review of biochemistry 72, 291-336.

Bodea, L.G., Eckert, A., Ittner, L.M., Piguet, O., and Gotz, J. (2016). Tau physiology and pathomechanisms in frontotemporal lobar degeneration. Journal of neurochemistry 138 Suppl 1, 71-94.

Borggrefe, T., and Oswald, F. (2009). The Notch signaling pathway: transcriptional regulation at Notch target genes. Cell Mol Life Sci 66, 1631-1646.

Boutz, P.L., Stoilov, P., Li, Q., Lin, C.H., Chawla, G., Ostrow, K., Shiue, L., Ares, M., Jr., and Black, D.L. (2007). A post-transcriptional regulatory switch in polypyrimidine tract-binding proteins reprograms alternative splicing in developing neurons. Genes Dev 21, 1636-1652. 
Bradke, F., and Dotti, C.G. (1999). The role of local actin instability in axon formation. Science 283, 1931-1934.

Bray, S.J. (2006). Notch signalling: a simple pathway becomes complex. Nat Rev Mol Cell Biol 7, 678-689.

Buckanovich, R.J., Posner, J.B., and Darnell, R.B. (1993). Nova, the paraneoplastic Ri antigen, is homologous to an RNA-binding protein and is specifically expressed in the developing motor system. Neuron 11, 657-672.

Burrell, J.R., Halliday, G.M., Kril, J.J., Ittner, L.M., Gotz, J., Kiernan, M.C., and Hodges, J.R. (2016). The frontotemporal dementia-motor neuron disease continuum. Lancet 388, 919-931.

Busch, A., and Hertel, K.J. (2012). Evolution of SR protein and hnRNP splicing regulatory factors. Wiley interdisciplinary reviews RNA 3, 1-12.

Calarco, J.A., Superina, S., O'Hanlon, D., Gabut, M., Raj, B., Pan, Q., Skalska, U., Clarke, L., Gelinas, D., van der Kooy, D., et al. (2009). Regulation of vertebrate nervous system alternative splicing and development by an SR-related protein. Cell 138, 898-910.

Castelo-Branco, P., Furger, A., Wollerton, M., Smith, C., Moreira, A., and Proudfoot, N. (2004). Polypyrimidine tract binding protein modulates efficiency of polyadenylation. Molecular and cellular biology 24, 4174-4183.

Chan, R.C., and Black, D.L. (1997). The polypyrimidine tract binding protein binds upstream of neural cell-specific c-src exon $\mathrm{N} 1$ to repress the splicing of the intron downstream. Mol Cell Biol 17, 4667-4676.

Chang, Y.F., Imam, J.S., and Wilkinson, M.F. (2007). The nonsensemediated decay RNA surveillance pathway. Annual review of biochemistry $76,51-74$.

Chen, M., and Manley, J.L. (2009). Mechanisms of alternative splicing regulation: insights from molecular and genomics approaches. Nat Rev Mol Cell Biol 10, 741-754.

Chou, M.Y., Underwood, J.G., Nikolic, J., Luu, M.H., and Black, D.L. (2000). Multisite RNA binding and release of polypyrimidine tract binding protein during the regulation of c-src neural-specific splicing. Mol Cell 5, 949-957.

Coelho, M.B., and Smith, C.W. (2014). Regulation of alternative premRNA splicing. Methods Mol Biol 1126, 55-82. 
Colak, D., Ji, S.J., Porse, B.T., and Jaffrey, S.R. (2013). Regulation of axon guidance by compartmentalized nonsense-mediated mRNA decay. Cell 153, 1252-1265.

De Conti, L., Baralle, M., and Buratti, E. (2013). Exon and intron definition in pre-mRNA splicing. Wiley Interdiscip Rev RNA 4, 49-60.

Dell'Angelica, E.C., Aguilar, R.C., Wolins, N., Hazelwood, S., Gahl, W.A., and Bonifacino, J.S. (2000). Molecular characterization of the protein encoded by the Hermansky-Pudlak syndrome type 1 gene. J Biol Chem $275,1300-1306$.

Endo, Y., Osumi, N., and Wakamatsu, Y. (2003). Deltex/Dtx mediates $\mathrm{NOTCH}$ signaling in regulation of Bmp4 expression in cranial neural crest formation during avian development. Dev Growth Differ 45, 241-248.

Eom, T., Zhang, C., Wang, H., Lay, K., Fak, J., Noebels, J.L., and Darnell, R.B. (2013). NOVA-dependent regulation of cryptic NMD exons controls synaptic protein levels after seizure. Elife 2, e00178.

Erkelenz, S., Mueller, W.F., Evans, M.S., Busch, A., Schoneweis, K., Hertel, K.J., and Schaal, H. (2013). Position-dependent splicing activation and repression by SR and hnRNP proteins rely on common mechanisms. Rna 19, 96-102.

Fang, T.C., Yashiro-Ohtani, Y., Del Bianco, C., Knoblock, D.M., Blacklow, S.C., and Pear, W.S. (2007). Notch directly regulates Gata3 expression during T helper 2 cell differentiation. Immunity 27, 100-110.

Faustino, N.A., and Cooper, T.A. (2003). Pre-mRNA splicing and human disease. Genes \& development 17, 419-437.

Ferrarese, R., Harsh, G.R.t., Yadav, A.K., Bug, E., Maticzka, D., Reichardt, W., Dombrowski, S.M., Miller, T.E., Masilamani, A.P., Dai, F., et al. (2014). Lineage-specific splicing of a brain-enriched alternative exon promotes glioblastoma progression. J Clin Invest 124, 2861-2876.

Fischer, A., and Gessler, M. (2007). Delta-Notch--and then? Protein interactions and proposed modes of repression by Hes and Hey bHLH factors. Nucleic Acids Res 35, 4583-4596.

Forch, P., Puig, O., Kedersha, N., Martinez, C., Granneman, S., Seraphin, B., Anderson, P., and Valcarcel, J. (2000). The apoptosispromoting factor TIA-1 is a regulator of alternative pre-mRNA splicing. Mol Cell 6, 1089-1098. 
Forch, P., Puig, O., Martinez, C., Seraphin, B., and Valcarcel, J. (2002). The splicing regulator TIA-1 interacts with U1-C to promote U1 snRNP recruitment to 5' splice sites. EMBO J 21, 6882-6892.

Forch, P., and Valcarcel, J. (2001). Molecular mechanisms of gene expression regulation by the apoptosis-promoting protein TIA-1. Apoptosis 6, 463-468.

Fourmann, J.B., Schmitzova, J., Christian, H., Urlaub, H., Ficner, R., Boon, K.L., Fabrizio, P., and Luhrmann, R. (2013). Dissection of the factor requirements for spliceosome disassembly and the elucidation of its dissociation products using a purified splicing system. Genes \& development 27, 413-428.

Galej, W.P., Wilkinson, M.E., Fica, S.M., Oubridge, C., Newman, A.J., and Nagai, K. (2016). Cryo-EM structure of the spliceosome immediately after branching. Nature 537, 197-201.

Gao, K., Masuda, A., Matsuura, T., and Ohno, K. (2008). Human branch point consensus sequence is yUnAy. Nucleic Acids Res 36, 2257-2267.

Geuens, T., Bouhy, D., and Timmerman, V. (2016). The hnRNP family: insights into their role in health and disease. Hum Genet 135, 851-867.

Glass, R.E., Nene, V., and Hunter, M.G. (1982). Informational suppression as a tool for the investigation of gene structure and function. Biochem J 203, 1-13.

Gromak, N., Rideau, A., Southby, J., Scadden, A.D., Gooding, C., Huttelmaier, S., Singer, R.H., and Smith, C.W. (2003). The PTB interacting protein raver1 regulates alpha-tropomyosin alternative splicing. The EMBO journal 22, 6356-6364.

Guerrero, E.N., Wang, H., Mitra, J., Hegde, P.M., Stowell, S.E., Liachko, N.F., Kraemer, B.C., Garruto, R.M., Rao, K.S., and Hegde, M.L. (2016). TDP-43/FUS in motor neuron disease: Complexity and challenges. Prog Neurobiol 145-146, 78-97.

Hahm, B., Cho, O.H., Kim, J.E., Kim, Y.K., Kim, J.H., Oh, Y.L., and Jang, S.K. (1998). Polypyrimidine tract-binding protein interacts with HnRNP L. FEBS Lett 425, 401-406.

Hamid, F.M., and Makeyev, E.V. (2014). Emerging functions of alternative splicing coupled with nonsense-mediated decay. Biochemical Society transactions $42,1168-1173$. 
Hertel, K.J. (2008). Combinatorial control of exon recognition. J Biol Chem 283, 1211-1215.

Hirose, H., Ishii, H., Mimori, K., Ohta, D., Ohkuma, M., Tsujii, H., Saito, T., Sekimoto, M., Doki, Y., and Mori, M. (2010). Notch pathway as candidate therapeutic target in Her2/Neu/ErbB2 receptor-negative breast tumors. Oncol Rep 23, 35-43.

Huang, C.S., Shi, S.H., Ule, J., Ruggiu, M., Barker, L.A., Darnell, R.B., Jan, Y.N., and Jan, L.Y. (2005). Common molecular pathways mediate long-term potentiation of synaptic excitation and slow synaptic inhibition. Cell 123, 105-118.

Hutton, M., Lendon, C.L., Rizzu, P., Baker, M., Froelich, S., Houlden, H., Pickering-Brown, S., Chakraverty, S., Isaacs, A., Grover, A., et al. (1998). Association of missense and 5'-splice-site mutations in tau with the inherited dementia FTDP-17. Nature 393, 702-705.

Irimia, M., Rukov, J.L., and Roy, S.W. (2009). Evolution of alternative splicing regulation: changes in predicted exonic splicing regulators are not associated with changes in alternative splicing levels in primates. PloS one 4, e5800.

Irimia, M., Weatheritt, R.J., Ellis, J.D., Parikshak, N.N., GonatopoulosPournatzis, T., Babor, M., Quesnel-Vallieres, M., Tapial, J., Raj, B., O'Hanlon, D., et al. (2014). A highly conserved program of neuronal microexons is misregulated in autistic brains. Cell 159, 1511-1523.

Ishigaki, S., Masuda, A., Fujioka, Y., Iguchi, Y., Katsuno, M., Shibata, A., Urano, F., Sobue, G., and Ohno, K. (2012). Position-dependent FUSRNA interactions regulate alternative splicing events and transcriptions. Scientific reports 2, 529 .

Ishigaki, Y., Li, X., Serin, G., and Maquat, L.E. (2001). Evidence for a pioneer round of $m R N A$ translation: mRNAs subject to nonsensemediated decay in mammalian cells are bound by CBP80 and CBP20. Cell 106, 607-617.

Iso, T., Kedes, L., and Hamamori, Y. (2003). HES and HERP families: multiple effectors of the Notch signaling pathway. J Cell Physiol 194, 237-255.

Iso, T., Sartorelli, V., Chung, G., Shichinohe, T., Kedes, L., and Hamamori, Y. (2001). HERP, a new primary target of Notch regulated by ligand binding. Mol Cell Biol 21, 6071-6079. 
Izon, D.J., Aster, J.C., He, Y., Weng, A., Karnell, F.G., Patriub, V., Xu, L., Bakkour, S., Rodriguez, C., Allman, D., et al. (2002). Deltex1 redirects lymphoid progenitors to the B cell lineage by antagonizing Notch1. Immunity 16, 231-243.

Jarriault, S., Le Bail, O., Hirsinger, E., Pourquie, O., Logeat, F., Strong, C.F., Brou, C., Seidah, N.G., and Isra I, A. (1998). Delta-1 activation of notch-1 signaling results in HES-1 transactivation. Mol Cell Biol 18, 7423-7431.

Jean-Philippe, J., Paz, S., and Caputi, M. (2013). hnRNP A1: the Swiss army knife of gene expression. Int J Mol Sci 14, 18999-19024.

Jensen, K.B., Dredge, B.K., Stefani, G., Zhong, R., Buckanovich, R.J., Okano, H.J., Yang, Y.Y., and Darnell, R.B. (2000). Nova-1 regulates neuron-specific alternative splicing and is essential for neuronal viability. Neuron 25, 359-371.

Kafasla, P., Lin, H., Curry, S., and Jackson, R.J. (2011). Activation of picornaviral IRESs by PTB shows differential dependence on each PTB RNA-binding domain. Rna 17, 1120-1131.

Kent, O.A., and MacMillan, A.M. (2002). Early organization of pre-mRNA during spliceosome assembly. Nat Struct Biol 9, 576-581.

Keppetipola, N., Sharma, S., Li, Q., and Black, D.L. (2012). Neuronal regulation of pre-mRNA splicing by polypyrimidine tract binding proteins, PTBP1 and PTBP2. Crit Rev Biochem Mol Biol 47, 360-378.

Kishi, N., Tang, Z., Maeda, Y., Hirai, A., Mo, R., Ito, M., Suzuki, S., Nakao, K., Kinoshita, T., Kadesch, T., et al. (2001). Murine homologs of deltex define a novel gene family involved in vertebrate Notch signaling and neurogenesis. Int J Dev Neurosci 19, 21-35.

Kurosaki, T., and Maquat, L.E. (2016). Nonsense-mediated mRNA decay in humans at a glance. J Cell Sci 129, 461-467.

La Porta, J., Matus-Nicodemos, R., Valentin-Acevedo, A., and Covey, L.R. (2016). The RNA-Binding Protein, Polypyrimidine Tract-Binding Protein 1 (PTBP1) Is a Key Regulator of CD4 T Cell Activation. PloS one 11, e0158708.

Lamar, E., Deblandre, G., Wettstein, D., Gawantka, V., Pollet, N., Niehrs, C., and Kintner, C. (2001). Nrarp is a novel intracellular component of the Notch signaling pathway. Genes Dev 15, 1885-1899. 
Lareau, L.F., Brooks, A.N., Soergel, D.A., Meng, Q., and Brenner, S.E. (2007a). The coupling of alternative splicing and nonsense-mediated mRNA decay. Adv Exp Med Biol 623, 190-211.

Lareau, L.F., Green, R.E., Bhatnagar, R.S., and Brenner, S.E. (2004). The evolving roles of alternative splicing. Current opinion in structural biology 14, 273-282.

Lareau, L.F., Inada, M., Green, R.E., Wengrod, J.C., and Brenner, S.E. (2007b). Unproductive splicing of SR genes associated with highly conserved and ultraconserved DNA elements. Nature 446, 926-929.

Lee, Y., and Rio, D.C. (2015). Mechanisms and Regulation of Alternative Pre-mRNA Splicing. Annu Rev Biochem 84, 291-323.

Li, Q., Lee, J.A., and Black, D.L. (2007). Neuronal regulation of alternative pre-mRNA splicing. Nature reviews Neuroscience 8 , 819-831.

Li, Q., Zheng, S., Han, A., Lin, C.H., Stoilov, P., Fu, X.D., and Black, D.L. (2014). The splicing regulator PTBP2 controls a program of embryonic splicing required for neuronal maturation. Elife 3, e01201.

Licatalosi, D.D., Mele, A., Fak, J.J., Ule, J., Kayikci, M., Chi, S.W., Clark, T.A., Schweitzer, A.C., Blume, J.E., Wang, X., et al. (2008). HITS-CLIP yields genome-wide insights into brain alternative RNA processing. Nature 456, 464-469.

Licatalosi, D.D., Yano, M., Fak, J.J., Mele, A., Grabinski, S.E., Zhang, C., and Darnell, R.B. (2012). Ptbp2 represses adult-specific splicing to regulate the generation of neuronal precursors in the embryonic brain. Genes Dev 26, 1626-1642.

Llorian, M., Schwartz, S., Clark, T.A., Hollander, D., Tan, L.Y., Spellman, R., Gordon, A., Schweitzer, A.C., de la Grange, P., Ast, G., et al. (2010). Position-dependent alternative splicing activity revealed by global profiling of alternative splicing events regulated by PTB. Nature structural \& molecular biology $17,1114-1123$.

Lutolf, S., Radtke, F., Aguet, M., Suter, U., and Taylor, V. (2002). Notch1 is required for neuronal and glial differentiation in the cerebellum. Development 129, 373-385.

Lynch-Day, M.A., Mao, K., Wang, K., Zhao, M., and Klionsky, D.J. (2012). The role of autophagy in Parkinson's disease. Cold Spring Harb Perspect Med 2, a009357. 
Mackenzie, I.R., and Neumann, M. (2016). Molecular neuropathology of frontotemporal dementia: insights into disease mechanisms from postmortem studies. Journal of neurochemistry 138 Suppl 1, 54-70.

Makeyev, E.V., Zhang, J., Carrasco, M.A., and Maniatis, T. (2007). The MicroRNA miR-124 promotes neuronal differentiation by triggering brainspecific alternative pre-mRNA splicing. Molecular cell 27, 435-448.

Maquat, L.E. (2004). Nonsense-mediated mRNA decay: splicing, translation and mRNP dynamics. Nat Rev Mol Cell Biol 5, 89-99.

Martina, J.A., Moriyama, K., and Bonifacino, J.S. (2003). BLOC-3, a protein complex containing the Hermansky-Pudlak syndrome gene products HPS1 and HPS4. J Biol Chem 278, 29376-29384.

Martinez-Contreras, R., Cloutier, P., Shkreta, L., Fisette, J.F., Revil, T., and Chabot, B. (2007). hnRNP proteins and splicing control. Adv Exp Med Biol 623, 123-147.

Martinez-Contreras, R., Fisette, J.F., Nasim, F.U., Madden, R., Cordeau, M., and Chabot, B. (2006). Intronic binding sites for hnRNP A/B and hnRNP F/H proteins stimulate pre-mRNA splicing. PLoS Biol 4, e21.

Matera, A.G., and Wang, Z. (2014). A day in the life of the spliceosome. Nat Rev Mol Cell Biol 15, 108-121.

Matlin, A.J., Clark, F., and Smith, C.W. (2005). Understanding alternative splicing: towards a cellular code. Nat Rev Mol Cell Biol 6, 386-398.

Mattila, P.K., and Lappalainen, P. (2008). Filopodia: molecular architecture and cellular functions. Nat Rev Mol Cell Biol 9, 446-454.

McCutcheon, I.E., Hentschel, S.J., Fuller, G.N., Jin, W., and Cote, G.J. (2004). Expression of the splicing regulator polypyrimidine tract-binding protein in normal and neoplastic brain. Neuro Oncol 6, 9-14.

McGlincy, N.J., and Smith, C.W. (2008). Alternative splicing resulting in nonsense-mediated mRNA decay: what is the meaning of nonsense? Trends in biochemical sciences 33, 385-393.

Meissner, M., Dechat, T., Gerner, C., Grimm, R., Foisner, R., and Sauermann, G. (2000). Differential nuclear localization and nuclear matrix association of the splicing factors PSF and PTB. J Cell Biochem 76, 559-566. 
Millevoi, S., Decorsiere, A., Loulergue, C., lacovoni, J., Bernat, S., Antoniou, M., and Vagner, S. (2009). A physical and functional link between splicing factors promotes pre-mRNA 3' end processing. Nucleic acids research $37,4672-4683$.

Mills, J.D., and Janitz, M. (2012). Alternative splicing of mRNA in the molecular pathology of neurodegenerative diseases. Neurobiol Aging 33, 1012 e1011-1024.

Morgan, S., and Orrell, R.W. (2016). Pathogenesis of amyotrophic lateral sclerosis. Br Med Bull 119, 87-98.

Motta-Mena, L.B., Heyd, F., and Lynch, K.W. (2010). Context-dependent regulatory mechanism of the splicing factor hnRNP L. Mol Cell 37, 223-234.

Muhlemann, O. (2008). Recognition of nonsense mRNA: towards a unified model. Biochem Soc Trans 36, 497-501.

Muhlemann, O., Eberle, A.B., Stalder, L., and Zamudio Orozco, R. (2008). Recognition and elimination of nonsense mRNA. Biochim Biophys Acta 1779, 538-549.

Nakano, Y., Jahan, I., Bonde, G., Sun, X., Hildebrand, M.S., Engelhardt, J.F., Smith, R.J., Cornell, R.A., Fritzsch, B., and Banfi, B. (2012). A mutation in the Srrm4 gene causes alternative splicing defects and deafness in the Bronx waltzer mouse. PLoS genetics 8, e1002966.

Nakaya, T., Alexiou, P., Maragkakis, M., Chang, A., and Mourelatos, Z. (2013). FUS regulates genes coding for RNA-binding proteins in neurons by binding to their highly conserved introns. Rna 19, 498-509.

Nazarian, R., Falcon-Perez, J.M., and Dell'Angelica, E.C. (2003). Biogenesis of lysosome-related organelles complex 3 (BLOC-3): a complex containing the Hermansky-Pudlak syndrome (HPS) proteins HPS1 and HPS4. Proc Natl Acad Sci U S A 100, 8770-8775.

Neu-Yilik, G., and Kulozik, A.E. (2008). NMD: multitasking between mRNA surveillance and modulation of gene expression. Advances in genetics 62, 185-243.

Nguyen, T.H., Galej, W.P., Bai, X.C., Oubridge, C., Newman, A.J., Scheres, S.H., and Nagai, K. (2016). Cryo-EM structure of the yeast U4/ U6.U5 tri-snRNP at 3.7 A resolution. Nature 530, 298-302.

Ni, J.Z., Grate, L., Donohue, J.P., Preston, C., Nobida, N., O'Brien, G., Shiue, L., Clark, T.A., Blume, J.E., and Ares, M., Jr. (2007). 
Ultraconserved elements are associated with homeostatic control of splicing regulators by alternative splicing and nonsense-mediated decay. Genes Dev 21, 708-718.

Oberstrass, F.C., Auweter, S.D., Erat, M., Hargous, Y., Henning, A., Wenter, P., Reymond, L., Amir-Ahmady, B., Pitsch, S., Black, D.L., et al. (2005). Structure of PTB bound to RNA: specific binding and implications for splicing regulation. Science 309, 2054-2057.

Oh, H., Lee, E., Jang, H.N., Lee, J., Moon, H., Sheng, Z., Jun, Y., Loh, T.J., Cho, S., Zhou, J., et al. (2013). hnRNP A1 contacts exon 5 to promote exon 6 inclusion of apoptotic Fas gene. Apoptosis 18, 825-835.

Oh, J., Liu, Z.X., Feng, G.H., Raposo, G., and Spritz, R.A. (2000). The Hermansky-Pudlak syndrome (HPS) protein is part of a high molecular weight complex involved in biogenesis of early melanosomes. Hum Mol Genet 9, 375-385.

Ohtsuka, T., Ishibashi, M., Gradwohl, G., Nakanishi, S., Guillemot, F., and Kageyama, R. (1999). Hes1 and Hes5 as notch effectors in mammalian neuronal differentiation. EMBO J 18, 2196-2207.

Orozco, D., and Edbauer, D. (2013). FUS-mediated alternative splicing in the nervous system: consequences for ALS and FTLD. J Mol Med (Berl) 91, 1343-1354.

Oswald, F., Liptay, S., Adler, G., and Schmid, R.M. (1998). NF-kappaB2 is a putative target gene of activated Notch-1 via RBP-Jkappa. Mol Cell Biol 18, 2077-2088.

Palacios, I.M. (2002). RNA processing: splicing and the cytoplasmic localisation of mRNA. Curr Biol 12, R50-52.

Palomero, T., Lim, W.K., Odom, D.T., Sulis, M.L., Real, P.J., Margolin, A., Barnes, K.C., O'Neil, J., Neuberg, D., Weng, A.P., et al. (2006). NOTCH1 directly regulates c-MYC and activates a feed-forward-loop transcriptional network promoting leukemic cell growth. Proc Natl Acad Sci U S A 103, 18261-18266.

Pan, Q., Shai, O., Lee, L.J., Frey, B.J., and Blencowe, B.J. (2008). Deep surveying of alternative splicing complexity in the human transcriptome by high-throughput sequencing. Nature genetics $40,1413-1415$.

Polymenidou, M., Lagier-Tourenne, C., Hutt, K.R., Huelga, S.C., Moran, J., Liang, T.Y., Ling, S.C., Sun, E., Wancewicz, E., Mazur, C., et al. (2011). Long pre-mRNA depletion and RNA missplicing contribute to neuronal vulnerability from loss of TDP-43. Nat Neurosci 14, 459-468. 
Quesnel-Vallieres, M., Irimia, M., Cordes, S.P., and Blencowe, B.J. (2015). Essential roles for the splicing regulator nSR100/SRRM4 during nervous system development. Genes \& development 29, 746-759.

Ratti, A., and Buratti, E. (2016). Physiological functions and pathobiology of TDP-43 and FUS/TLS proteins. Journal of neurochemistry 138 Suppl 1, 95-111.

Roca, X., Krainer, A.R., and Eperon, I.C. (2013). Pick one, but be quick: 5 ' splice sites and the problems of too many choices. Genes Dev 27, 129-144.

Ronchini, C., and Capobianco, A.J. (2001). Induction of cyclin D1 transcription and CDK2 activity by Notch(ic): implication for cell cycle disruption in transformation by Notch(ic). Mol Cell Biol 21, 5925-5934.

Rossbach, O., Hung, L.H., Khrameeva, E., Schreiner, S., Konig, J., Curk, T., Zupan, B., Ule, J., Gelfand, M.S., and Bindereif, A. (2014). Crosslinking-immunoprecipitation (iCLIP) analysis reveals global regulatory roles of hnRNP L. RNA Biol 11, 146-155.

Ruggiu, M., Herbst, R., Kim, N., Jevsek, M., Fak, J.J., Mann, M.A., Fischbach, G., Burden, S.J., and Darnell, R.B. (2009). Rescuing Z+ agrin splicing in Nova null mice restores synapse formation and unmasks a physiologic defect in motor neuron firing. Proceedings of the National Academy of Sciences of the United States of America 106, 3513-3518.

Sahebi, M., Hanafi, M.M., van Wijnen, A.J., Azizi, P., Abiri, R., Ashkani, S., and Taheri, S. (2016). Towards understanding pre-mRNA splicing mechanisms and the role of SR proteins. Gene 587, 107-119.

Satoh, Y., Matsumura, I., Tanaka, H., Ezoe, S., Sugahara, H., Mizuki, M., Shibayama, H., Ishiko, E., Ishiko, J., Nakajima, K., et al. (2004). Roles for c-Myc in self-renewal of hematopoietic stem cells. J Biol Chem 279, 24986-24993.

Seiwert, S.D., and Steitz, J.A. (1993). Uncoupling two functions of the U1 small nuclear ribonucleoprotein particle during in vitro splicing. Molecular and cellular biology 13, 3135-3145.

Sharma, S., Kohlstaedt, L.A., Damianov, A., Rio, D.C., and Black, D.L. (2008). Polypyrimidine tract binding protein controls the transition from exon definition to an intron defined spliceosome. Nat Struct Mol Biol 15, 183-191. 
Sharma, S., Maris, C., Allain, F.H., and Black, D.L. (2011). U1 snRNA directly interacts with polypyrimidine tract-binding protein during splicing repression. Mol Cell 41, 579-588.

Sharma, S., Wongpalee, S.P., Vashisht, A., Wohlschlegel, J.A., and Black, D.L. (2014). Stem-loop 4 of U1 snRNA is essential for splicing and interacts with the U2 snRNP-specific SF3A1 protein during spliceosome assembly. Genes Dev 28, 2518-2531.

Spellman, R., and Smith, C.W. (2006). Novel modes of splicing repression by PTB. Trends Biochem Sci 31, 73-76.

Takeyama, K., Aguiar, R.C., Gu, L., He, C., Freeman, G.J., Kutok, J.L., Aster, J.C., and Shipp, M.A. (2003). The BAL-binding protein BBAP and related Deltex family members exhibit ubiquitin-protein isopeptide ligase activity. J Biol Chem 278, 21930-21937.

Tan, J., and Roca, X. (2016). Informational Suppression to Probe RNA:RNA Interactions in the Context of Ribonucleoproteins: U1 and 5' Splice-Site Base-Pairing. Methods Mol Biol 1421, 243-268.

Trapnell, C., Pachter, L., and Salzberg, S.L. (2009). TopHat: discovering splice junctions with RNA-Seq. Bioinformatics 25, 1105-1111.

Ule, J., Jensen, K.B., Ruggiu, M., Mele, A., Ule, A., and Darnell, R.B. (2003). CLIP identifies Nova-regulated RNA networks in the brain. Science 302, 1212-1215.

Ule, J., Stefani, G., Mele, A., Ruggiu, M., Wang, X., Taneri, B., Gaasterland, T., Blencowe, B.J., and Darnell, R.B. (2006). An RNA map predicting Nova-dependent splicing regulation. Nature 444, 580-586.

Ule, J., Ule, A., Spencer, J., Williams, A., Hu, J.S., Cline, M., Wang, H., Clark, T., Fraser, C., Ruggiu, M., et al. (2005). Nova regulates brainspecific splicing to shape the synapse. Nature genetics $37,844-852$.

Vilimas, T., Mascarenhas, J., Palomero, T., Mandal, M., Buonamici, S., Meng, F., Thompson, B., Spaulding, C., Macaroun, S., Alegre, M.L., et al. (2007). Targeting the NF-kappaB signaling pathway in Notch1induced T-cell leukemia. Nat Med 13, 70-77.

Vuong, C.K., Black, D.L., and Zheng, S. (2016). The neurogenetics of alternative splicing. Nature reviews Neuroscience 17, 265-281.

Wagner, S.D., and Berglund, J.A. (2014). Alternative pre-mRNA splicing. Methods Mol Biol 1126, 45-54. 
Wan, R., Yan, C., Bai, R., Huang, G., and Shi, Y. (2016). Structure of a yeast catalytic step I spliceosome at 3.4 A resolution. Science 353, 895-904.

Wang, E.T., Sandberg, R., Luo, S., Khrebtukova, I., Zhang, L., Mayr, C., Kingsmore, S.F., Schroth, G.P., and Burge, C.B. (2008). Alternative isoform regulation in human tissue transcriptomes. Nature 456, 470-476.

Wang, J., Gao, Q.S., Wang, Y., Lafyatis, R., Stamm, S., and Andreadis, A. (2004). Tau exon 10, whose missplicing causes frontotemporal dementia, is regulated by an intricate interplay of cis elements and trans factors. Journal of neurochemistry 88, 1078-1090.

Wilkinson, K.A., Merino, E.J., and Weeks, K.M. (2006). Selective 2'hydroxyl acylation analyzed by primer extension (SHAPE): quantitative RNA structure analysis at single nucleotide resolution. Nat Protoc 1, 1610-1616.

Wollerton, M.C., Gooding, C., Wagner, E.J., Garcia-Blanco, M.A., and Smith, C.W. (2004). Autoregulation of polypyrimidine tract binding protein by alternative splicing leading to nonsense-mediated decay. Molecular cell 13, 91-100.

Wong, J.J., Ritchie, W., Ebner, O.A., Selbach, M., Wong, J.W., Huang, Y., Gao, D., Pinello, N., Gonzalez, M., Baidya, K., et al. (2013).

Orchestrated intron retention regulates normal granulocyte differentiation. Cell 154, 583-595.

Xue, Y., Zhou, Y., Wu, T., Zhu, T., Ji, X., Kwon, Y.S., Zhang, C., Yeo, G., Black, D.L., Sun, H., et al. (2009). Genome-wide analysis of PTB-RNA interactions reveals a strategy used by the general splicing repressor to modulate exon inclusion or skipping. Molecular cell 36, 996-1006.

Yamada, K., Fuwa, T.J., Ayukawa, T., Tanaka, T., Nakamura, A., Wilkin, M.B., Baron, M., and Matsuno, K. (2011). Roles of Drosophila deltex in Notch receptor endocytic trafficking and activation. Genes Cells 16, 261-272.

Yamashita, A. (2013). Role of SMG-1-mediated Upf1 phosphorylation in mammalian nonsense-mediated mRNA decay. Genes Cells 18, 161-175.

Yan, C., Hang, J., Wan, R., Huang, M., Wong, C.C., and Shi, Y. (2015). Structure of a yeast spliceosome at 3.6-angstrom resolution. Science $349,1182-1191$. 
Yan, C., Wan, R., Bai, R., Huang, G., and Shi, Y. (2016). Structure of a yeast activated spliceosome at $3.5 \mathrm{~A}$ resolution. Science 353, 904-911.

Yang, Y.Y., Yin, G.L., and Darnell, R.B. (1998). The neuronal RNAbinding protein Nova-2 is implicated as the autoantigen targeted in POMA patients with dementia. Proceedings of the National Academy of Sciences of the United States of America 95, 13254-13259.

Yap, K., Lim, Z.Q., Khandelia, P., Friedman, B., and Makeyev, E.V. (2012). Coordinated regulation of neuronal mRNA steady-state levels through developmentally controlled intron retention. Genes \& development 26, 1209-1223.

Yap, K., and Makeyev, E.V. (2013). Regulation of gene expression in mammalian nervous system through alternative pre-mRNA splicing coupled with RNA quality control mechanisms. Mol Cell Neurosci 56, 420-428.

Yeo, G., Holste, D., Kreiman, G., and Burge, C.B. (2004). Variation in alternative splicing across human tissues. Genome Biol 5, R74.

Yeo, G.W., Coufal, N.G., Liang, T.Y., Peng, G.E., Fu, X.D., and Gage, F.H. (2009). An RNA code for the FOX2 splicing regulator revealed by mapping RNA-protein interactions in stem cells. Nat Struct Mol Biol 16, 130-137.

Yoshimoto, R., Kataoka, N., Okawa, K., and Ohno, M. (2009). Isolation and characterization of post-splicing lariat-intron complexes. Nucleic acids research 37, 891-902.

Yu, Y., Maroney, P.A., Denker, J.A., Zhang, X.H., Dybkov, O., Luhrmann, R., Jankowsky, E., Chasin, L.A., and Nilsen, T.W. (2008). Dynamic regulation of alternative splicing by silencers that modulate 5 ' splice site competition. Cell 135, 1224-1236.

Zare-Shahabadi, A., Masliah, E., Johnson, G.V., and Rezaei, N. (2015). Autophagy in Alzheimer's disease. Rev Neurosci 26, 385-395.

Zhang, X., Chen, M.H., Wu, X., Kodani, A., Fan, J., Doan, R., Ozawa, M., Ma, J., Yoshida, N., Reiter, J.F., et al. (2016). Cell-Type-Specific Alternative Splicing Governs Cell Fate in the Developing Cerebral Cortex. Cell 166, 1147-1162 e1115.

Zhang, X.H., Leslie, C.S., and Chasin, L.A. (2005). Computational searches for splicing signals. Methods 37, 292-305. 
Zheng, S. (2016). Alternative splicing and nonsense-mediated mRNA decay enforce neural specific gene expression. Int J Dev Neurosci.

Zheng, S., Gray, E.E., Chawla, G., Porse, B.T., O'Dell, T.J., and Black, D.L. (2012). PSD-95 is post-transcriptionally repressed during early neural development by PTBP1 and PTBP2. Nat Neurosci 15, 381-388, S381.

Zhou, Z., and Fu, X.D. (2013). Regulation of splicing by SR proteins and SR protein-specific kinases. Chromosoma 122, 191-207. 


\section{Author's publications}

Fursham M. Hamid and Eugene V. Makeyev (2016) (In preparation).

Fursham M. Hamid and Eugene V. Makeyev (2016) Exaptive origins of regulated mRNA decay in eukaryotes Bioessays 38 (Epub ahead of print).

Xinlei Qian, Fursham M. Hamid, Abbas El Sahili, Dina Amallia Darwis, Yee Hwa Wong, Shashi Bhushan, Eugene V. Makeyev and Julien Lescar (2016) Functional Evolution in Orthologous Cellencoded RNA-dependent RNA Polymerases. J Biol Chem 291(17): 9295-9309

Fursham M. Hamid and Eugene V. Makeyev (2014) Regulation of mRNA Abundance by Polypyrimidine Tract-Binding ProteinControlled Alternate 5' Splice Site Choice. PLoS Genet 10(11): e1004771.

Fursham M. Hamid and Eugene V. Makeyev (2014) Emerging functions of alternative splicing coupled with nonsensemediated decay. Biochemical Society Transactions, 42:1168-1173 


\section{Posters, awards, invited talks}

Poster 1 Regulation of mRNA Abundance By Developmentally Regulated Switch in Utilization of Alternate 5' Splice Sites

- 2013 Eukaryotic mRNA processing @ Cold Spring Harbor Laboratory

- 2013 6th Science Conclave @ Indian Institute of Information Technology (IIIT) Allahabad

Poster 2 A Mechanism Linking Expression Levels of Hps1 Gene with Abundance of Polypyrimidine Tract-Binding Protein

- 2014 The complex life of mRNA @ European Molecular Biology Laboratory 


\section{Regulation of mRNA Abundance By Developmentally Regulated Switch in Utilization of Alternate 5' Splice Sites}

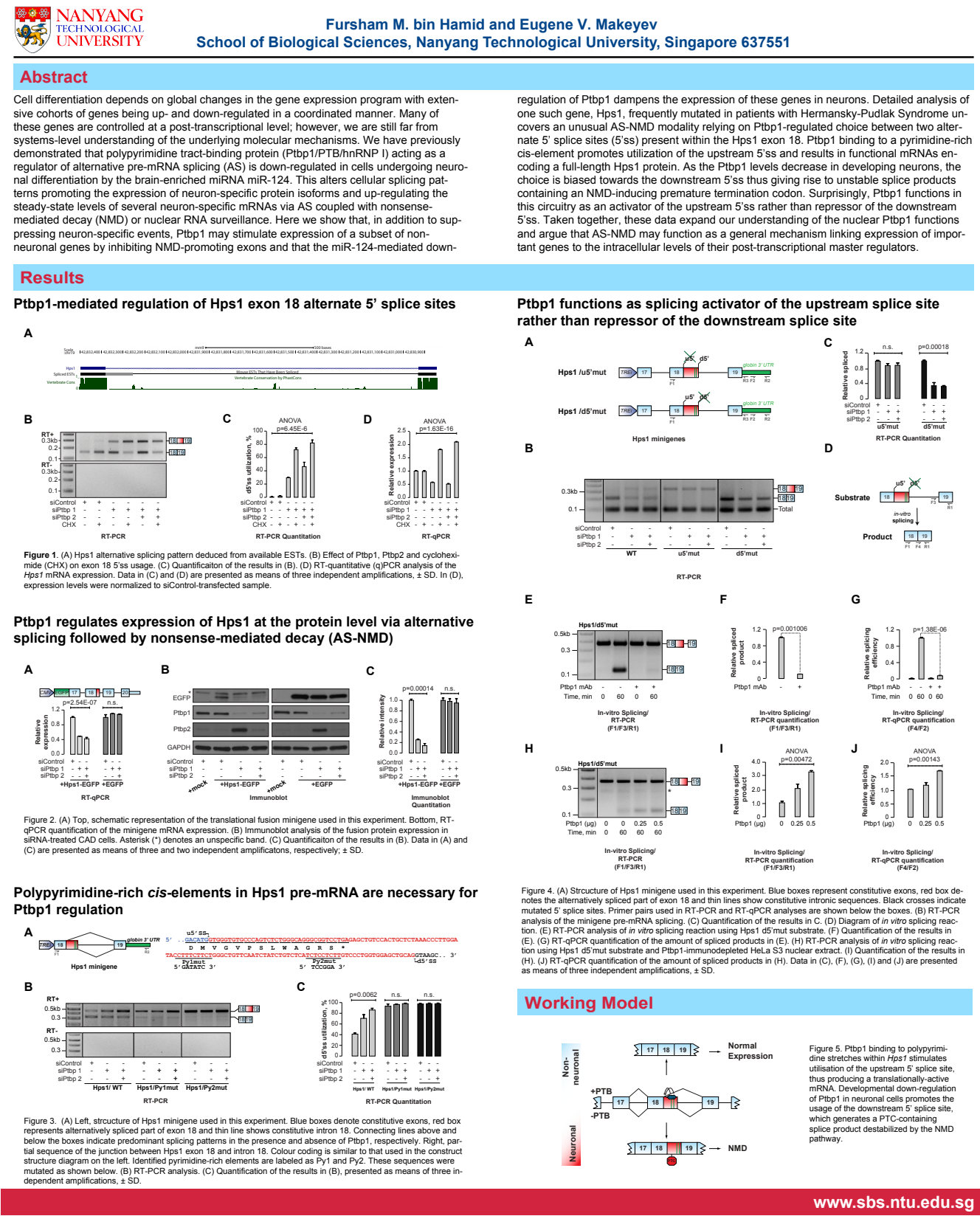




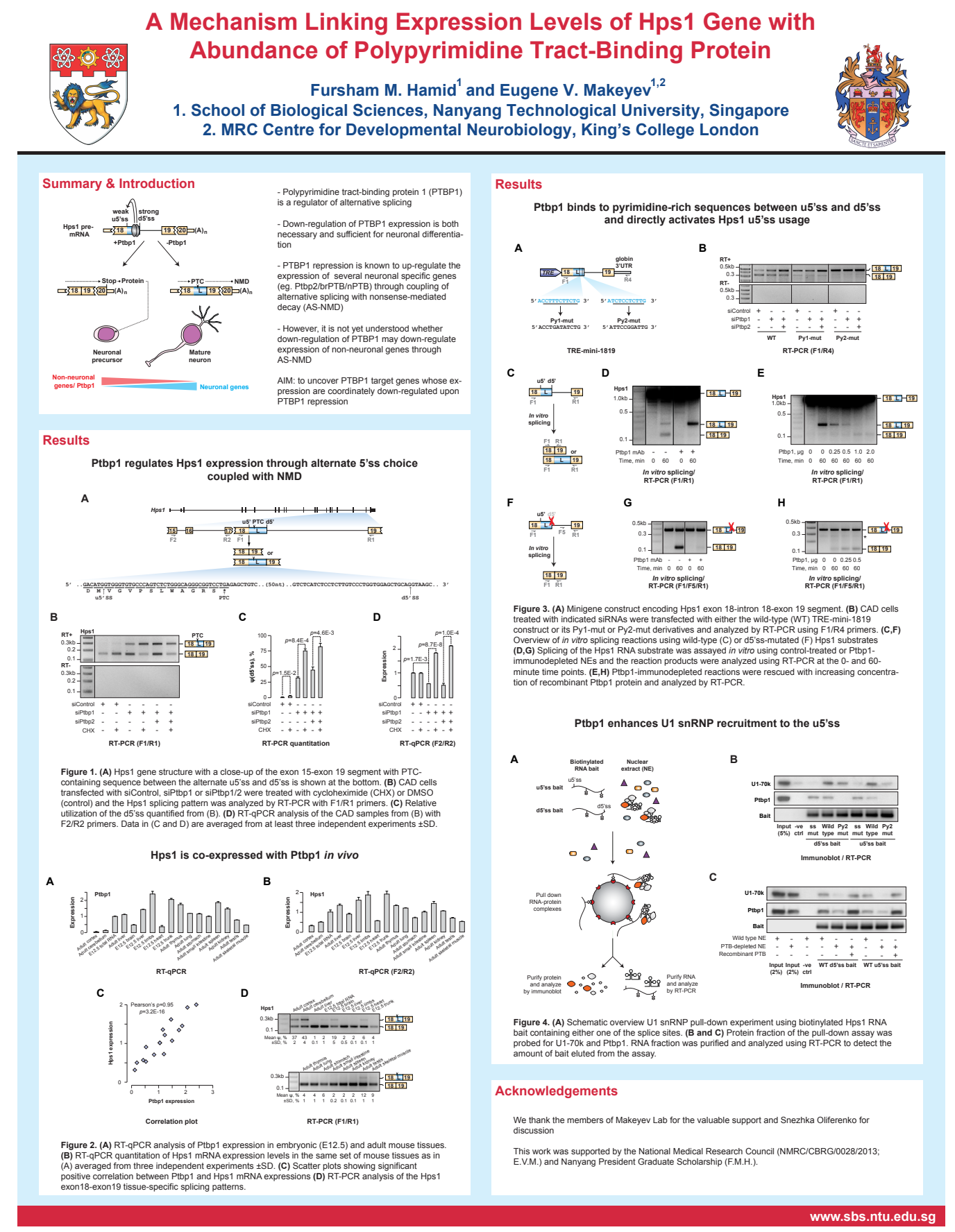




\section{Appendix}

Appendix 1 Primer sequences used in this project

Appendix 2 List of plasmids used in this project

Appendix 3 Ptbp1 alternate 5'ss events

Appendix 4 Ptbp1 alternate 3'ss events 


\section{Appendix 1. List of DNA oligonucleotides used in this study}

Hps1-related primers

$\begin{array}{lll}\text { ID } & \text { Given name } & \left.\text { Seq (5' -> } \mathbf{3}^{\prime}\right) \\ \text { EMO2655 } & \text { mHps1_F1 } & \text { CTGGGCTCTGGTCCGACT } \\ \text { EMO2656 } & \text { mHps1_R1 } & \text { GAGAGGACAGGCACCTCAAT } \\ \text { EM02937 } & \text { mHps1_qPCR_F1 } & \text { GACCGAGCCCAGAAACTCAT } \\ \text { EM02938 } & \text { mHps1_qPCR_R1 } & \text { CCTGGGAAATCCTCCAGGTA } \\ \text { EM051 } & \text { EGFP_seq1 } & \text { GCAGAACACCCCCATCG } \\ \text { EMO690 } & \text { eGFP_R1 } & \text { CTCCAGCAGGACCATGTGAT } \\ \text { EM03688 } & \text { rbHbb_3'UTR_F3 } & \text { CAATGCCCTGGCTCACAA } \\ \text { EM0790 } & \text { rbHbb_3UTR_r1 } & \text { AGCCAGAAGTCAGATGCTCA } \\ \text { EM03580 } & \text { mHps1_IR_F1 } & \text { TGTTTCTCAAGACACACACACA } \\ \text { EM03687 } & \text { rbHbb_3UTR_R2 } & \text { GCCACCACCTTCTGATAGGC } \\ \text { EM03252 } & \text { mHps1_qPCR_R3 } & \text { CTGCAGTTTGTATCCCTGCAG }\end{array}$

Dtx2-related primers

$\begin{array}{lll}\text { EMO4594 } & \text { Dtx2_F1 } & \text { AGATGCCAAAGGCCAGCA } \\ \text { EMO4595 } & \text { Dtx2_R1 } & \text { CACTTTCAGCTCCTCGGTGT } \\ \text { EMO4719 } & \text { Dtx2_exspec_R1 } & \text { GGACATTTCCTCAGCCTCTT } \\ \text { EMO4892 } & \text { Dtx2_qPCR_F1 } & \text { CTCAGCTCCTGCCCTCAG } \\ \text { EMO4893 } & \text { Dtx2_qPCR_R1 } & \text { GGCCTTTGGCATCTGCAC } \\ \text { EMO4883 } & \text { Dtx2_exJunc_R1 } & \text { CCGCGGTACCGACACCTTTAC }\end{array}$

Primers used for cloning and site-directed mutagenesis 
ID

EMO3589

EMO3590

EMO2802

EMO2803

EMO3509

EMO3510

EMO2901

EMO2902

EMO2903

EMO2904

EMO3068

EMO3069

EMO3070

EMO3071

EMO3558

EMO3559

EMO3513

EMO3514

EMO3305

EMO3306

EMO3307

EMO3308

EMO4327

EMO4328

EMO4329
Given name

mHps1_Sal1_F3

mHps1_BamH1_R3

mHps1_Agel_F1

mHps1_Acc65I_R1

mHps1_Agel_F2

mHps1_BsmBI_R2

mHps1_mut1_F1

mHps1_mut1_R1

mHps1_mut2_F1

mHps1_mut_R1

mHps1_bioprobe_F1

mHps1_bioprobe_R1

mHps1 ivs F1

mHps1_ivs_R1

mHps1_USmut_F3

mHps1_USmut_R3

mHps1_DSmut_F2

mHps1_DSmut_R2

mHps1_US mut1_F1

mHps1_US_mut1_R1

mHps1_DS_mut1_F1

mHps1_DS_mut1_R1

Hps1_u5'_strong_F1

Hps1_u5'_strong_R1

Hps1_u5'_strong_F2
Seq $\left(5^{\prime}->3^{\prime}\right)$

gccgtcgacTACCTGGAGGATTTCCCAG

gaaggatccTGCAAGCAAGACGGCCTA

GTAACCGGTAGAAGGGCTGCACCACACT

GAAGGTACCCTGTAGTAGTCACCTCCCAGCA

GTAACCGGTAGCCCCAACGAAAAGATGTC

GAACGTCTCGGTACGAGTCATCCGAGAGGACAGG

CTGCTCTAAACCCTTGGATACCTGATATCTGGGCTGTTCAATCTATCTGTC

GACAGATAGATTGAACAGCCCAGATATCAGGTATCCAAGGGTTTAGAGCAG

GCTGTTCAATCTATCTGTCTCATTCCGGATTGTCCCTGGTGGAGCTGCAGGTAAGC

GCTTACCTGCAGCTCCACCAGGGACAATCCGGAATGAGACAGATAGATTGAACAGC

GAAGGTACCGTCCACTGCTCTAAACCCTTG

GTAGGATCCTACCTGCAGCTCCACCAG

GAAGGTACCAGAAGGGCTGCACCACACT

GTAGGATCCCTGTAGTAGTCACCTCCCAGCA

GTTCGAGAATGACATGAAGGGTGTGCCCAGTC

GACTGGGCACACCCTTCATGTCATTCTCGAAC

GTGGAGCTGCAGCCAAGCACGTGAC

GTCACGTGCTTGGCTGCAGCTCCAC

CTACTTCCTGTGGTTCGAGAATGACCAGGTAAGCATGCCCAGTCTCTGGGCAGGGCGGTC

GACCGCCCTGCCCAGAGACTGGGCATGCTTACCTGGTCATTCTCGAACCACAGGAAGTAG

CCTCTTGTCCCTGGTGGAGCTGATGGTGGGTGCGTGACTGGGGTGTAAGACTGC

GCAGTCTTACACCCCAGTCACGCACCCACCATCAGCTCCACCAGGGACAAGAGG

CTACTTCCTGTGGTTCGAGAATGACTAGGTAAGTATGCCCAGTCTCTGGGCAGGGCGGTC

GACCGCCCTGCCCAGAGACTGGGCATACTTACCTAGTCATTCTCGAACCACAGGAAGTAG

CTTCCTGTGGTTCGAGAATGACCAGGTAAGTATGCCCAGTCTCTGGGCAGGGCGG 
Appendix 2. Plasmids generated in this study.

\begin{tabular}{|c|c|c|c|c|c|}
\hline Given name & ID & Purpose & Promoter & Vector & Insert or Treatment \\
\hline EGFP-Hps1 & pEM1258 & $\begin{array}{l}\text { Expression of EGFP- } \\
\text { tagged mini Hps1 } \\
\text { protein }\end{array}$ & CMV & $\begin{array}{l}\text { pEGFP-C1 cut with } \\
\text { Sall-BamHI }\end{array}$ & $\begin{array}{l}\text { 4.2kb size fragment spanning } \\
\text { exon } 17 \text { to the 3'UTR of mouse } \\
\text { Hps1 }\end{array}$ \\
\hline $\begin{array}{l}\text { TRE-mini-1819- } \\
\text { WT }\end{array}$ & pEM1136 & $\begin{array}{l}\text { Expression of Hps } 1 \\
\text { minigene }\end{array}$ & TRE & $\begin{array}{l}\text { pEM777 cut with } \\
\text { Agel and } A c c 65 \mathrm{I}\end{array}$ & $\begin{array}{l}\sim 1.5 \mathrm{~kb} \text { fragment spanning exon } \\
18 \text { to exon } 19 \text { of mouse Hps } 1\end{array}$ \\
\hline $\begin{array}{l}\text { TRE-mini-1819- } \\
\text { Py1mut }\end{array}$ & $\begin{array}{l}\text { pEM1136- } \\
\text { Py1mut }\end{array}$ & $\begin{array}{l}\text { Expression of Py1- } \\
\text { mutated Hps1 } \\
\text { minigene }\end{array}$ & TRE & pEM1136 & $\begin{array}{l}\text { Mutagenized using EMO2901 } \\
\text { and EMO2902 primers }\end{array}$ \\
\hline $\begin{array}{l}\text { TRE-mini-1819- } \\
\text { Py2mut }\end{array}$ & $\begin{array}{l}\text { pEM1136- } \\
\text { Py2mut }\end{array}$ & $\begin{array}{l}\text { Expression of Py2- } \\
\text { mutated Hps1 } \\
\text { minigene }\end{array}$ & TRE & pEM1136 & $\begin{array}{l}\text { Mutagenized using EMO2903 } \\
\text { and EMO2904 primers }\end{array}$ \\
\hline $\begin{array}{l}\text { TRE-mini-1819- } \\
\text { d5'ss/d5'ss }\end{array}$ & $\begin{array}{l}\text { pEM1136- } \\
\text { d5'ss/d5'ss }\end{array}$ & $\begin{array}{l}\text { Expression of Hps } 1 \\
\text { minigene with altered } \\
\text { u5'ss splice sites }\end{array}$ & TRE & pEM1136 & $\begin{array}{l}\text { Mutagenized using EMO3305 } \\
\text { and EMO3306 primers }\end{array}$ \\
\hline $\begin{array}{l}\text { TRE-mini-1819- } \\
\text { u5'ss/u5'ss }\end{array}$ & $\begin{array}{l}\text { pEM1136- } \\
\text { u5'ss/u5'ss }\end{array}$ & $\begin{array}{l}\text { Expression of Hps } 1 \\
\text { minigene with altered } \\
\text { d5'ss splice sites }\end{array}$ & TRE & pEM1136 & $\begin{array}{l}\text { Mutagenized using EMO3307 } \\
\text { and EMO3308 primers }\end{array}$ \\
\hline $\begin{array}{l}\text { TRE-mini-1819- } \\
\text { d5'ss/u5'ss }\end{array}$ & $\begin{array}{l}\text { pEM1136- } \\
\text { d5'ss/u5'ss }\end{array}$ & $\begin{array}{l}\text { Expression of Hps } 1 \\
\text { minigene with } \\
\text { swapped splice sites }\end{array}$ & TRE & pEM1136-u5'ss/u5'ss & $\begin{array}{l}\text { Mutagenized using EMO3305 } \\
\text { and EMO3306 primers }\end{array}$ \\
\hline T7-mini-18L-WT & pEM1191 & $\begin{array}{l}\text { In vitro transcription of } \\
\text { Hps1 probe }\end{array}$ & T7 & $\begin{array}{l}\text { pGEM3zf(+) cut with } \\
\text { Acc65I and BamHI }\end{array}$ & $\begin{array}{l}\text { 100bp fragment consisting of } \\
\text { polypyrimidine sequences }\end{array}$ \\
\hline $\begin{array}{l}\text { T7-mini-18L- } \\
\text { Py1mut }\end{array}$ & pEM1192 & $\begin{array}{l}\text { In vitro transcription of } \\
\text { Py1-mutated Hps } 1 \\
\text { probe }\end{array}$ & T7 & $\begin{array}{l}\text { pGEM3zf(+) cut with } \\
\text { Acc65I and BamHI }\end{array}$ & $\begin{array}{l}\text { 100bp fragment consisting of } \\
\text { mutated polypyrimidine } \\
\text { sequences }\end{array}$ \\
\hline $\begin{array}{l}\text { T7-mini-18L- } \\
\text { Py2mut }\end{array}$ & pEM1193 & $\begin{array}{l}\text { In vitro transcription of } \\
\text { Py2-mutated Hps1 } \\
\text { probe }\end{array}$ & T7 & $\begin{array}{l}\text { pGEM3zf(+) cut with } \\
\text { Acc65I and BamHI }\end{array}$ & $\begin{array}{l}\text { 100bp fragment consisting of } \\
\text { mutated polypyrimidine } \\
\text { sequences }\end{array}$ \\
\hline $\begin{array}{l}\text { T7-mini-1819- } \\
\text { WT }\end{array}$ & pEM1198 & $\begin{array}{l}\text { In vitro transcription of } \\
\text { Hps1 splicing } \\
\text { substrate }\end{array}$ & T7 & $\begin{array}{l}\text { pGEM3zf(+) cut with } \\
\text { Acc65I and BamHI }\end{array}$ & $\begin{array}{l}\sim 1.5 \mathrm{~kb} \text { fragment spanning exon } \\
18 \text { to exon } 19 \text { of mouse Hps } 1\end{array}$ \\
\hline $\begin{array}{l}\text { T7-mini-1819- } \\
\text { d5'mut }\end{array}$ & $\begin{array}{l}\text { pEM1198- } \\
\text { d5'mut }\end{array}$ & $\begin{array}{l}\text { In vitro transcription of } \\
\text { mutated Hps1 splicing } \\
\text { substrate }\end{array}$ & T7 & pEM1198 & $\begin{array}{l}\text { Mutagenized using EMO3513 } \\
\text { and EMO3514 primers }\end{array}$ \\
\hline $\begin{array}{l}\text { TRE-mini-1719- } \\
\text { WT }\end{array}$ & pEM1246 & $\begin{array}{l}\text { Expression of } \mathrm{Hps} 1 \\
\text { minigene }\end{array}$ & TRE & $\begin{array}{l}\text { pEM777 cut with } \\
\text { Agel and Acc65I }\end{array}$ & $\begin{array}{l}\sim 3.5 \mathrm{~kb} \text { fragment spanning exon } \\
17 \text { to exon } 19 \text { of mouse Hps } 1\end{array}$ \\
\hline $\begin{array}{l}\text { TRE-mini-1719- } \\
\text { u5'mut }\end{array}$ & $\begin{array}{l}\text { pEM1246- } \\
\text { u5'mut }\end{array}$ & $\begin{array}{l}\text { Expression of u5'ss- } \\
\text { mutated Hps } 1 \\
\text { minigene }\end{array}$ & TRE & pEM1246 & $\begin{array}{l}\text { Mutagenized using EMO3558 } \\
\text { and EMO3559 primers }\end{array}$ \\
\hline $\begin{array}{l}\text { TRE-mini-1719- } \\
\text { d5'mut }\end{array}$ & $\begin{array}{l}\text { pEM1246- } \\
\text { d5'mut }\end{array}$ & $\begin{array}{l}\text { Expression of d5'ss- } \\
\text { mutated Hps } 1 \\
\text { minigene }\end{array}$ & TRE & pEM1246 & $\begin{array}{l}\text { Mutagenized using EMO3513 } \\
\text { and EMO3514 primers }\end{array}$ \\
\hline $\begin{array}{l}\text { TRE-mini- } \\
\text { Dtx2e6-WT }\end{array}$ & pEM1482 & $\begin{array}{l}\text { Expression of Dtx2 } \\
\text { minigene }\end{array}$ & TRE & $\begin{array}{l}\text { pEM791 cut with } \\
\text { BsmBI }\end{array}$ & $\begin{array}{l}\text { 900b fragment spanning exon } 6 \\
\text { and } 300 \mathrm{~b} \text { upstream and } \\
\text { downstream intron of mouse } \\
\text { Dtx2 }\end{array}$ \\
\hline $\begin{array}{l}\text { TRE-mini- } \\
\text { Dtx2e6- } \Delta 150\end{array}$ & $\begin{array}{l}\text { pEM1482- } \\
\Delta 150\end{array}$ & $\begin{array}{l}\text { Expression of intron- } \\
\text { deleted Dtx2 minigene }\end{array}$ & TRE & $\begin{array}{l}\text { pEM791 cut with } \\
\text { BsmBI }\end{array}$ & $\begin{array}{l}\text { 750b fragment spanning exon } 6 \\
\text { and upstream and downstream } \\
\text { intron of mouse Dtx2 }\end{array}$ \\
\hline $\begin{array}{l}\text { TRE-mini- } \\
\text { Dtx2e6- } \Delta 210\end{array}$ & $\begin{array}{l}\text { pEM1482- } \\
\Delta 210\end{array}$ & $\begin{array}{l}\text { Expression of intron- } \\
\text { deleted Dtx2 minigene }\end{array}$ & TRE & $\begin{array}{l}\text { pEM791 cut with } \\
\text { BsmBI }\end{array}$ & $\begin{array}{l}\sim 690 \mathrm{~b} \text { fragment spanning exon } 6 \\
\text { and upstream and downstream } \\
\text { intron of mouse Dtx2 }\end{array}$ \\
\hline
\end{tabular}


Appendix 2. Plasmids generated in this study.

\begin{tabular}{|c|c|c|c|c|c|}
\hline Given name & ID & Purpose & Promoter & Vector & Insert or Treatment \\
\hline $\begin{array}{l}\text { TRE-mini- } \\
\text { Dtx2e6- } \Delta 250\end{array}$ & $\begin{array}{l}\text { pEM1482- } \\
\Delta 250\end{array}$ & $\begin{array}{l}\text { Expression of intron- } \\
\text { deleted Dtx2 minigene }\end{array}$ & TRE & $\begin{array}{l}\text { pEM791 cut with } \\
\text { BsmBI }\end{array}$ & $\begin{array}{l}\sim 650 \mathrm{~b} \text { fragment spanning exon } 6 \\
\text { and upstream and downstream } \\
\text { intron of mouse Dtx2 }\end{array}$ \\
\hline $\begin{array}{l}\text { TRE-mini- } \\
\text { Dtx2e6- Py1mut }\end{array}$ & $\begin{array}{l}\text { pEM1482- } \\
\text { Py1mut }\end{array}$ & $\begin{array}{l}\text { Expression of Py1mut } \\
\text { Dtx2 minigene }\end{array}$ & TRE & pEM1482 & $\begin{array}{l}\text { Mutagenized using EMO4576 } \\
\text { and EMO4577 primers }\end{array}$ \\
\hline $\begin{array}{l}\text { TRE-mini- } \\
\text { Dtx2e6- Py2mut }\end{array}$ & $\begin{array}{l}\text { pEM1482- } \\
\text { Py2mut }\end{array}$ & $\begin{array}{l}\text { Expression of Py2mut } \\
\text { Dtx2 minigene }\end{array}$ & TRE & pEM1482 & $\begin{array}{l}\text { Mutagenized using EMO4578 } \\
\text { and EMO4579 primers }\end{array}$ \\
\hline $\begin{array}{l}\text { TRE-mini- } \\
\text { Dtx2e6- Py3mut }\end{array}$ & $\begin{array}{l}\text { pEM1482- } \\
\text { Py3mut }\end{array}$ & $\begin{array}{l}\text { Expression of Py3mut } \\
\text { Dtx2 minigene }\end{array}$ & TRE & pEM1482 & $\begin{array}{l}\text { Mutagenized using EMO4581 } \\
\text { and EMO4581 primers }\end{array}$ \\
\hline $\begin{array}{l}\text { TRE-mini-1819- } \\
\text { d5'ss/d5'ss }\end{array}$ & $\begin{array}{l}\text { pEM1136- } \\
\text { d5'ss/d5'ss }\end{array}$ & $\begin{array}{l}\text { Expression of Hps1 } \\
\text { minigene with altered } \\
\text { u5'ss splice sites }\end{array}$ & TRE & pEM1136 & $\begin{array}{l}\text { Mutagenized using EMO3305 } \\
\text { and EMO3306 primers }\end{array}$ \\
\hline U1-snRNA-A4 & pNS6-U1-A4 & $\begin{array}{l}\text { Expression of } \\
\text { exogenous U1 with } \\
\text { altered sequence }\end{array}$ & CMV & pNS6-U1 & $\begin{array}{l}\text { Mutagenized using EMO4826and } \\
\text { EMO4827 primers }\end{array}$ \\
\hline $\begin{array}{l}\text { U1-snRNA-A4- } \\
\text { SL4Dm }\end{array}$ & $\begin{array}{l}\text { pNS6-U1-A4- } \\
\text { SL4Dm }\end{array}$ & $\begin{array}{l}\text { Expression of } \\
\text { exogenous U1 with } \\
\text { altered sequence }\end{array}$ & CMV & pNS6-U1 & $\begin{array}{l}\text { Mutagenized using EMO4873and } \\
\text { EMO4874 primers }\end{array}$ \\
\hline $\begin{array}{l}\text { U1-snRNA-A4- } \\
\text { SL4M10 }\end{array}$ & $\begin{array}{l}\text { pNS6-U1-A4- } \\
\text { SL4M10 }\end{array}$ & $\begin{array}{l}\text { Expression of } \\
\text { exogenous U1 with } \\
\text { altered sequence }\end{array}$ & CMV & pNS6-U1 & $\begin{array}{l}\text { Mutagenized using EMO4875and } \\
\text { EMO4876 primers }\end{array}$ \\
\hline TRE-mini-Tubg1 & pEM1485 & $\begin{array}{l}\text { Expression of Tubg } 1 \\
\text { minigene }\end{array}$ & TRE & $\begin{array}{l}\text { pEM791 cut with } \\
\text { BsmBI }\end{array}$ & $\begin{array}{l}\text { 900b fragment spanning exon } 4 \\
\text { and } 300 \mathrm{~b} \text { upstream and } \\
\text { downstream intron of mouse } \\
\text { Tubg1 }\end{array}$ \\
\hline $\begin{array}{l}\text { pNeo-loxp- } \\
\text { Dtx2_arms }\end{array}$ & pEM1486 & $\begin{array}{l}\text { Donor plasmid for } \\
\text { crispr/cas9 } \\
\text { modification of } \\
\text { Dtx2e76 }\end{array}$ & & pNeo-loxp & $\begin{array}{l}\text { 1 kb each homology arms } \\
\text { upstream and downstream of } \\
\text { Dtx2e6 }\end{array}$ \\
\hline Dtx2-gRNA1 & pEM1487 & $\begin{array}{l}\text { Guide RNA sequence } \\
\text { for nickase targeting of } \\
\text { Dtx2e6 }\end{array}$ & & px335 & $\begin{array}{l}\text { 20b guide RNA targeting } \\
\text { Dtx2e6 }\end{array}$ \\
\hline Dtx2-gRNA2 & pEM1488 & $\begin{array}{l}\text { Guide RNA sequence } \\
\text { for nickase targeting of } \\
\text { Dtx2e6 }\end{array}$ & & px335 & $\begin{array}{l}\text { 20b guide RNA targeting } \\
\text { Dtx2e6 }\end{array}$ \\
\hline
\end{tabular}


siPtbp1 - siControl

\begin{tabular}{|c|c|c|c|c|c|}
\hline GenelD & $P$ value & $\Delta \psi$ & $P$ value & $\Delta \psi$ & Candidate? \\
\hline Prmt1 & $2.75 \mathrm{E}-03$ & $100.0 \%$ & 7.38E-03 & $44.8 \%$ & Yes \\
\hline Hps1 & $2.50 \mathrm{E}-02$ & $92.9 \%$ & 2.50E-02 & $92.9 \%$ & Yes \\
\hline Sgpl1 & 3.59E-02 & $50.0 \%$ & $1.81 \mathrm{E}-02$ & $54.5 \%$ & Yes \\
\hline Scap & 2.90E-02 & $43.4 \%$ & 2.53E-02 & $45.6 \%$ & Yes \\
\hline Usp5 & $2.55 \mathrm{E}-10$ & $39.2 \%$ & $1.28 \mathrm{E}-20$ & $68.6 \%$ & Yes \\
\hline Tjp1 & $1.05 \mathrm{E}-02$ & $38.9 \%$ & 8.04E-03 & $38.9 \%$ & Yes \\
\hline Mzt1 & $2.58 \mathrm{E}-04$ & $27.3 \%$ & 3.38E-05 & $27.3 \%$ & Yes \\
\hline Ezh2 & $1.88 \mathrm{E}-02$ & $23.1 \%$ & $3.52 \mathrm{E}-03$ & $31.5 \%$ & Yes \\
\hline Vdac3 & 4.65E-06 & $22.2 \%$ & 3.07E-05 & $21.1 \%$ & Yes \\
\hline Zfp821 & $2.56 \mathrm{E}-02$ & $21.5 \%$ & 2.87E-03 & $28.0 \%$ & Yes \\
\hline Rnf126 & 1.59E-04 & $15.5 \%$ & 7.73E-04 & $15.5 \%$ & Yes \\
\hline Hmga1 & 4.01E-02 & $13.8 \%$ & $6.83 \mathrm{E}-03$ & $20.2 \%$ & Yes \\
\hline Ndufa7 & $3.45 \mathrm{E}-05$ & $12.1 \%$ & $3.71 \mathrm{E}-04$ & $10.1 \%$ & Yes \\
\hline 1700017B05। & $1.08 \mathrm{E}-02$ & $11.1 \%$ & 2.83E-02 & $11.1 \%$ & Yes \\
\hline Atp5g1 & 5.63E-04 & $10.5 \%$ & $1.48 \mathrm{E}-04$ & $12.1 \%$ & Yes \\
\hline Mrpl42 & 5.88E-07 & $10.2 \%$ & 5.64E-08 & $12.2 \%$ & Yes \\
\hline Elp3 & $2.74 \mathrm{E}-02$ & $-10.2 \%$ & $2.89 \mathrm{E}-02$ & $-10.2 \%$ & Yes \\
\hline Jagn1 & $3.41 E-02$ & $-13.3 \%$ & 3.82E-02 & $-13.3 \%$ & Yes \\
\hline Srsf5 & $1.13 \mathrm{E}-02$ & $-13.4 \%$ & 3.33E-07 & $-29.4 \%$ & Yes \\
\hline Srsf5 & 1.99E-03 & $-15.6 \%$ & 3.67E-05 & $-23.9 \%$ & Yes \\
\hline Ssna1 & 4.01E-02 & $-16.7 \%$ & $1.72 \mathrm{E}-02$ & $-20.6 \%$ & Yes \\
\hline Tmem214 & $1.81 \mathrm{E}-02$ & $-18.6 \%$ & 7.19E-03 & $-18.6 \%$ & Yes \\
\hline mKIAA1902 & 3.69E-04 & $-18.9 \%$ & 4.31E-03 & $-15.4 \%$ & Yes \\
\hline Tmem14c & $1.49 \mathrm{E}-04$ & $-19.3 \%$ & $1.13 \mathrm{E}-02$ & $-13.3 \%$ & Yes \\
\hline Wwc1 & $1.76 \mathrm{E}-02$ & $-20.0 \%$ & 1.16E-02 & $-20.4 \%$ & Yes \\
\hline Prrc2c & 2.96E-03 & $-21.7 \%$ & 6.77E-03 & $-20.5 \%$ & Yes \\
\hline Asap1 & 4.55E-02 & $-27.8 \%$ & 4.55E-02 & $-23.5 \%$ & Yes \\
\hline Tmem134 & 3.91E-03 & $-29.1 \%$ & 6.53E-03 & $-31.3 \%$ & Yes \\
\hline Cdk11b & $2.85 \mathrm{E}-03$ & $-33.9 \%$ & 7.09E-03 & $-28.4 \%$ & Yes \\
\hline Rnf220 & 5.61E-04 & $-40.9 \%$ & 4.72E-02 & $-27.9 \%$ & Yes \\
\hline Hnrnph3 & $4.53 \mathrm{E}-04$ & $-41.7 \%$ & $6.40 \mathrm{E}-04$ & $-42.4 \%$ & Yes \\
\hline Hccs & $6.02 \mathrm{E}-04$ & $-41.7 \%$ & 5.49E-04 & $-50.5 \%$ & Yes \\
\hline Keap1 & 3.07E-02 & $-42.9 \%$ & 4.41E-02 & $-50.0 \%$ & Yes \\
\hline Adcy6 & 1.46E-02 & $-44.0 \%$ & 1.50E-02 & $-44.0 \%$ & Yes \\
\hline Mef2a & $2.20 \mathrm{E}-02$ & $-47.7 \%$ & 6.19E-03 & $-75.0 \%$ & Yes \\
\hline Bcs1l & 4.98E-02 & $-54.8 \%$ & 4.98E-02 & $-56.1 \%$ & Yes \\
\hline Chst11 & $3.50 \mathrm{E}-02$ & $-60.0 \%$ & $2.56 \mathrm{E}-02$ & $-57.1 \%$ & Yes \\
\hline
\end{tabular}




\begin{tabular}{|c|c|c|c|c|c|}
\hline \multirow[b]{2}{*}{ GenelD } & \multicolumn{2}{|c|}{ siPtbp1 - siControl } & \multicolumn{2}{|c|}{ siPtbp1/2 - siControl } & \multirow[b]{2}{*}{ Candidate? } \\
\hline & $P$ value & $\Delta \psi$ & $P$ value & $\Delta \psi$ & \\
\hline Larp4 & $3.14 \mathrm{E}-05$ & $-100.0 \%$ & 3.03E-03 & $-100.0 \%$ & Yes \\
\hline Plekha6 & $5.83 \mathrm{E}-04$ & $-100.0 \%$ & $3.33 \mathrm{E}-02$ & $-75.0 \%$ & Yes \\
\hline Mbtd1 & $1.82 \mathrm{E}-02$ & $-100.0 \%$ & $1.82 \mathrm{E}-02$ & $-100.0 \%$ & Yes \\
\hline Bod1l & $2.86 \mathrm{E}-02$ & $-100.0 \%$ & $2.86 \mathrm{E}-02$ & $-100.0 \%$ & Yes \\
\hline Rap1gap & $2.13 \mathrm{E}-03$ & $-62.5 \%$ & $3.10 \mathrm{E}-02$ & $-62.5 \%$ & Yes \\
\hline Ncoa7 & $3.19 \mathrm{E}-03$ & $-54.2 \%$ & $2.19 \mathrm{E}-03$ & $-65.3 \%$ & Yes \\
\hline Wapal & $1.53 \mathrm{E}-03$ & $-45.2 \%$ & $1.14 \mathrm{E}-02$ & $-38.1 \%$ & Yes \\
\hline Cacnb3 & $4.18 \mathrm{E}-11$ & $-45.1 \%$ & $2.42 \mathrm{E}-08$ & $-37.6 \%$ & Yes \\
\hline Rsrc2 & $1.34 \mathrm{E}-02$ & $-45.0 \%$ & $1.03 \mathrm{E}-03$ & $-72.7 \%$ & Yes \\
\hline Atg2b & $9.96 \mathrm{E}-03$ & $-44.4 \%$ & $9.96 \mathrm{E}-03$ & $-44.4 \%$ & Yes \\
\hline Sbno1 & $8.14 \mathrm{E}-03$ & $-41.9 \%$ & $8.14 \mathrm{E}-03$ & $-46.7 \%$ & Yes \\
\hline Dtx2 & $1.25 \mathrm{E}-03$ & $-41.1 \%$ & 4.47E-03 & $-38.9 \%$ & Yes \\
\hline Phrf1 & $1.06 \mathrm{E}-03$ & $-37.4 \%$ & $5.94 \mathrm{E}-05$ & $-47.9 \%$ & Yes \\
\hline St6galnac6 & 4.57E-03 & $-36.4 \%$ & $1.47 \mathrm{E}-03$ & $-47.4 \%$ & Yes \\
\hline Armcx2 & 7.70E-04 & $-35.7 \%$ & $3.55 \mathrm{E}-02$ & $-18.4 \%$ & Yes \\
\hline Ralgps2 & 3.57E-02 & $-34.6 \%$ & $6.02 \mathrm{E}-03$ & $-47.6 \%$ & Yes \\
\hline Slc35b1 & $2.35 \mathrm{E}-02$ & $-29.4 \%$ & 1.19E-02 & $-34.2 \%$ & Yes \\
\hline Spr & 8.05E-03 & $-26.8 \%$ & $1.99 \mathrm{E}-02$ & $-24.3 \%$ & Yes \\
\hline Son & $4.41 \mathrm{E}-06$ & $-26.4 \%$ & $1.72 \mathrm{E}-06$ & $-26.6 \%$ & Yes \\
\hline Nsfl1c & $2.36 \mathrm{E}-03$ & $-24.4 \%$ & $1.24 \mathrm{E}-02$ & $-24.4 \%$ & Yes \\
\hline Hnrnpc & $6.29 \mathrm{E}-04$ & $-15.5 \%$ & 3.70E-04 & $-17.1 \%$ & Yes \\
\hline Stx1a & $1.63 \mathrm{E}-02$ & $-15.2 \%$ & 4.40E-02 & $-15.2 \%$ & Yes \\
\hline Vegfb & $1.25 \mathrm{E}-02$ & $-13.5 \%$ & 8.27E-03 & $-15.8 \%$ & Yes \\
\hline Hyou1 & $1.80 \mathrm{E}-03$ & $-11.5 \%$ & 5.34E-03 & $-10.5 \%$ & Yes \\
\hline H2afz & $2.12 \mathrm{E}-11$ & $11.7 \%$ & $5.41 \mathrm{E}-13$ & $11.7 \%$ & Yes \\
\hline Ndufa11 & 6.79E-03 & $13.0 \%$ & 7.12E-03 & $14.3 \%$ & Yes \\
\hline Serbp1 & $2.90 \mathrm{E}-05$ & $13.0 \%$ & $6.84 \mathrm{E}-05$ & $12.5 \%$ & Yes \\
\hline $\mathrm{B} 230208 \mathrm{H}]$ & $9.67 \mathrm{E}-04$ & $15.0 \%$ & 7.21E-04 & $15.0 \%$ & Yes \\
\hline Slc7a6os & $2.67 \mathrm{E}-02$ & $16.9 \%$ & $1.75 \mathrm{E}-03$ & $23.9 \%$ & Yes \\
\hline Nup88 & $1.32 \mathrm{E}-05$ & $20.6 \%$ & 4.00E-05 & $20.6 \%$ & Yes \\
\hline Msx1 & $2.65 \mathrm{E}-02$ & $21.4 \%$ & 4.96E-02 & $20.8 \%$ & Yes \\
\hline Sun1 & $1.98 \mathrm{E}-02$ & $21.8 \%$ & 4.91E-03 & $31.6 \%$ & Yes \\
\hline mKIAA415؛ & $4.42 \mathrm{E}-02$ & $22.7 \%$ & $2.58 \mathrm{E}-04$ & $42.3 \%$ & Yes \\
\hline Msl3 & 7.92E-03 & $25.0 \%$ & $3.87 \mathrm{E}-02$ & $25.0 \%$ & Yes \\
\hline Mapk8ip3 & $3.79 \mathrm{E}-02$ & $29.8 \%$ & $5.95 \mathrm{E}-03$ & $37.5 \%$ & Yes \\
\hline Strn4 & $1.16 \mathrm{E}-02$ & $30.3 \%$ & $4.84 \mathrm{E}-04$ & $32.4 \%$ & Yes \\
\hline Ythdc1 & 3.57E-03 & $30.4 \%$ & $2.24 \mathrm{E}-02$ & $23.3 \%$ & Yes \\
\hline Galnt7 & $4.51 \mathrm{E}-02$ & $41.7 \%$ & $1.41 \mathrm{E}-02$ & $54.5 \%$ & Yes \\
\hline Ift122 & $3.63 \mathrm{E}-03$ & $42.3 \%$ & $2.20 \mathrm{E}-03$ & $47.8 \%$ & Yes \\
\hline Golgb1 & $4.05 \mathrm{E}-03$ & $44.8 \%$ & $3.18 \mathrm{E}-02$ & $41.3 \%$ & Yes \\
\hline Mon2 & $1.29 \mathrm{E}-04$ & $49.4 \%$ & $2.76 \mathrm{E}-04$ & $51.7 \%$ & Yes \\
\hline Chd3 & $3.81 \mathrm{E}-10$ & $51.7 \%$ & 7.38E-06 & $43.8 \%$ & Yes \\
\hline Src & $1.09 \mathrm{E}-03$ & $52.0 \%$ & $3.60 \mathrm{E}-03$ & $50.0 \%$ & Yes \\
\hline Src & $1.09 \mathrm{E}-03$ & $52.0 \%$ & $3.60 \mathrm{E}-03$ & $50.0 \%$ & Yes \\
\hline Enah & $7.05 \mathrm{E}-11$ & $56.8 \%$ & $6.18 \mathrm{E}-09$ & $60.8 \%$ & Yes \\
\hline Ubqln1 & 4.06E-20 & $65.0 \%$ & 8.99E-18 & $65.0 \%$ & Yes \\
\hline Tpm2 & $4.52 \mathrm{E}-10$ & $75.0 \%$ & $1.07 \mathrm{E}-05$ & $63.9 \%$ & Yes \\
\hline
\end{tabular}

